Florida International University FIU Digital Commons

\title{
Priming for Honesty: A Novel Technique for Encouraging Children's True Disclosures of Adult Wrongdoing
}

Allison P. Mugno

Florida International University, amugn001@fiu.edu

DOI: $10.25148 /$ etd.FIDC001973

Follow this and additional works at: https:// digitalcommons.fiu.edu/etd

Part of the Child Psychology Commons, Experimental Analysis of Behavior Commons, Other $\underline{\text { Psychology Commons, and the Social Psychology Commons }}$

\section{Recommended Citation}

Mugno, Allison P., "Priming for Honesty: A Novel Technique for Encouraging Children's True Disclosures of Adult Wrongdoing" (2017). FIU Electronic Theses and Dissertations. 3360.

https://digitalcommons.fiu.edu/etd/3360 


\section{FLORIDA INTERNATIONAL UNIVERSITY}

Miami, Florida

\section{PRIMING FOR HONESTY: A NOVEL TECHNIQUE FOR ENCOURAGING CHILDREN'S TRUE DISCLOSURES OF ADULT WRONGDOING}

A dissertation submitted in partial fulfillment of the requirements for the degree of DOCTOR OF PHILOSOPHY

in

PSYCHOLOGY

by

Allison Mugno

2017 
To: Dean Michael R. Heithaus

College of Arts, Sciences and Education

This dissertation, written by Allison Mugno, and entitled Priming for Honesty: A Novel Technique for Encouraging Children's True Disclosures of Adult Wrongdoing, having been approved in respect to style and intellectual content, is referred to you for judgment.

We have read this dissertation and recommend it be approved.

$\begin{array}{r}\text { Asia Eaton } \\ \hline \text { Maureen Kenny } \\ \hline \text { Nadja Schreiber Compo } \\ \hline \text { Lindsay Malloy, Major Professor }\end{array}$

Date of Defense: June 29, 2017

The dissertation of Allison Mugno is approved.

Dean Michael R. Heithaus
College of Arts, Sciences and Education

Florida International University, 2017 
CC Copyright 2017 by Allison Mugno

All rights reserved. 


\section{DEDICATION}

This dissertation is dedicated to my family and friends for their unwavering support throughout this process. 


\section{ACKNOWLEDGMENTS}

I wish to thank my major professor, Lindsay Malloy, for her tremendous mentorship on this dissertation and throughout my graduate career. I admire your dedication, commitment, and passion to both your career and family, and feel truly fortunate to have had the opportunity to work with such an exceptionally supportive, knowledgeable, and kind mentor, teacher, and role model. I also wish to thank each of my committee members, Asia Eaton, Maureen Kenny, and Nadja Schreiber Compo. Your unique perspectives and expertise have greatly enhanced the quality of this dissertation, and I am extremely appreciative of your support of this project and, more broadly, of my professional development in the field. Many thanks also to the National Science Foundation Doctoral Dissertation Improvement Grant who funded this project.

I am grateful for the most amazing team of research assistants who worked with me on this project: Laura Acosta, Sandra Arango, Sophia Birriel-Sanchez, Sofia Castellon, Solace Mills, Andrea Primelles, Amanda Raude, Stephanie Sardinas, Claire Scott-Bacon, and Robert Wood. I appreciate your hard work, enthusiasm, humor, and friendship, and without all of you, this study would not have been possible.

Thank you to all of my friends who have also gone through/are going through this process, especially Ali, Amelia, Andrea, Diane, Keith, and Kristi. Laughing, talking, and spending time with each of you always made the day better. Finally, thank you to my family, particularly my mom, dad, Matt, Beth, Amy, Carolyn, Bob, Jeff, and Rylee, for your love, encouragement, patience, wisdom, wit, and for always been there for me. I hope you all know just how much you mean to me. 


\title{
ABSTRACT OF THE DISSERTATION \\ PRIMING FOR HONESTY: A NOVEL TECHNIQUE FOR ENCOURAGING \\ CHILDREN'S TRUE DISCLOSURES OF ADULT WRONGDOING
}

\author{
by
}

Allison Mugno

Florida International University, 2017

Miami, Florida

\section{Professor Lindsay Malloy, Major Professor}

Children are often involved in the legal system as victims of maltreatment, and their disclosure of adult wrongdoing is necessary to initiate effective legal responses and protect them from continued abuse. However, external pressures and children's perceptions of the consequences of truth-telling (e.g., punishment, removal from the home) may result in the delay of disclosure or failure to disclose altogether. Research examining techniques for promoting children's truth-telling has almost exclusively relied on explicit requests to tell the truth (e.g., a promise, reassurance, assessments of conceptual knowledge and moral discussions), and the success of these techniques has varied. The present study examined the benefit of priming honesty (i.e., indirectly or non-consciously activating the goal of honesty) on children's disclosure of an adult's transgression. One-hundred fifteen 6- to 9-year-olds ( $M$ age $=7.47$ years) participated in a first aid/safety event during which an adult (mother or stranger) engaged the child in play with a box of forbidden puppets, broke a puppet that was designed to break, and requested that the child keep it a secret. Before responding to questions about the puppets, children were either (1) primed for the goal of honesty (prime condition), (2) 
asked to promise to tell the truth (oath condition), or (3) not provided with any further instructions or information (control condition). Then, children were asked open-ended, direct, and suggestive questions about whether they or the adult touched, played with, or broke any puppets. Regression analyses revealed that children's truthful disclosures to direct questions increased when children witnessed a stranger transgressing rather than their mother. However, children's truthful disclosures across the question types did not differ by age or when a prime relative to a promise to tell the truth was used. Results advance our understanding of how children disclose negative events and the effectiveness of different techniques (including a novel technique) in encouraging children's true disclosures of a parent or stranger's transgression. 


\section{TABLE OF CONTENTS}

CHAPTER

PAGE

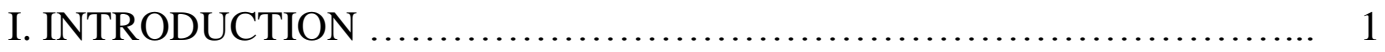

Study Aims ........................................................... 2

II. LITERATURE REVIEW .............................................. 3

Children's Disclosure Patterns ........................................ 3

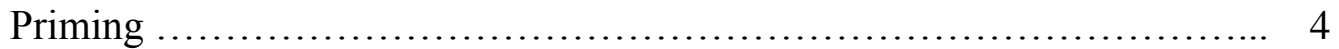

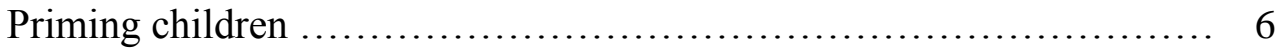

Honesty-Promotion Techniques ....................................... 7

Promise to tell the truth ............................................. 8

Truth-lie discussion............................................. 10

Reassurance ..................................................... 12

Newer techniques ................................................ 14

Putative confession ............................................ 14

Appealing to children's standards ................................ 15

Limitations of Prior Research .................................... 16

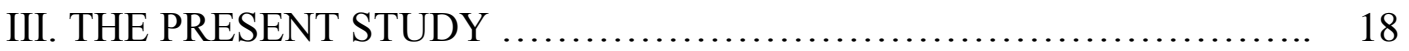

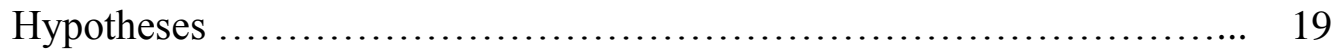

IV. METHOD ...................................................... 20

Participants ........................................................ 20

Design and Procedural Overview .................................... 22

Procedure ............................................................ 23

Transgression ................................................ 23

Honesty-promotion techniques .................................... 25

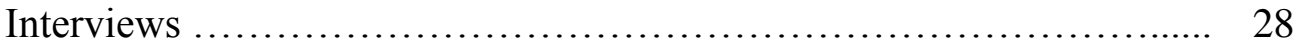

Manipulation checks …......................................... 30

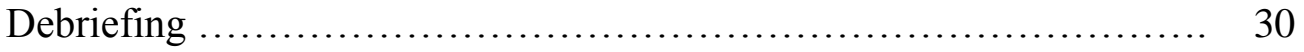

Child questionnaires ............................................ 31

Early Childhood Generalized Trust Belief Scale (ECGTBS) .......... 31

Attachment Security Scale ...................................... 32

Parent questionnaires ........................................... 33

Child-Parent Relationship Scale (CPRS) ........................ 34

Parenting Styles and Dimensions Questionnaire (PSDQ) ............ 35

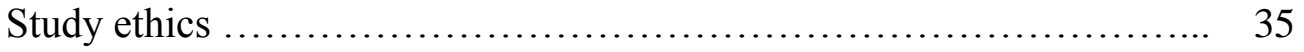

Coding and Data Reduction ........................................ 36

Data Analysis Plan ..................................................... 39

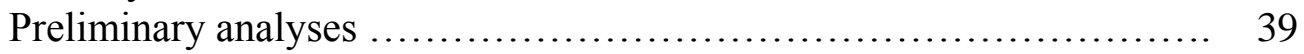

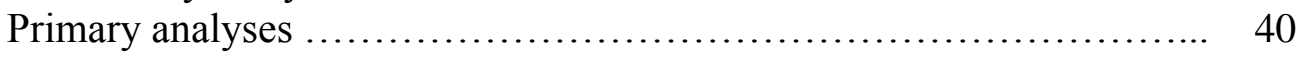


V. RESULTS ....................................................... 41

Preliminary Analyses ............................................ 41

Equivalence of study conditions in demographic characteristics ......... 41

Equivalence of study conditions in children's responses to manipulation

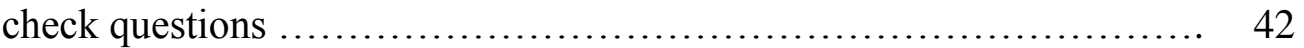

Effects of demographic characteristics on primary dependent variables .. 43

Effects of questionnaire counterbalancing on questionnaire scores and primary dependent variables .................................................. 43

Effects of incorrect responses to the oath on primary dependent variables

Effects of early disclosure on primary dependent variables ............... 44

Primary Analyses ..................................................... 44

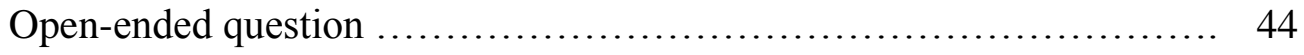

Direct question about something bad happening ...................... 45

Direct questions about the child's behavior ........................ 47

Direct questions about the transgressor's behavior ..................... 48

Suggestive questions about the child's behavior ..................... 49

Suggestive questions about the transgressor's behavior ................ 49

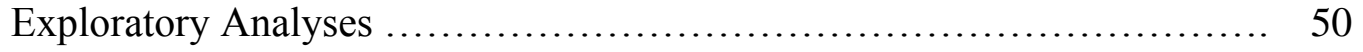

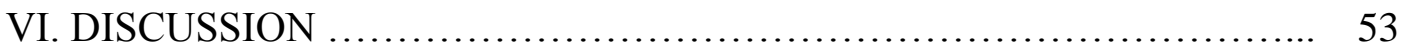

Honesty-Promotion Techniques …................................ 55

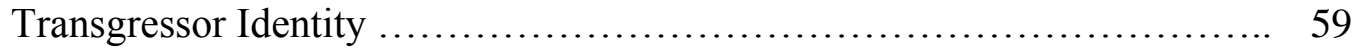

Age ................................................................. 62

Mother-Child Relationship Quality, Parenting Style, and Children's Trust .. 63

Limitations and Future Directions ........................................ 64

Conclusions and Practical Applications .............................. 65

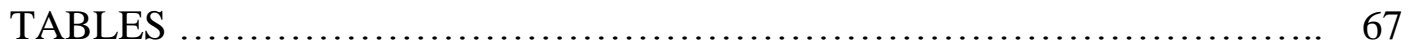

FIGURES ........................................................... 107

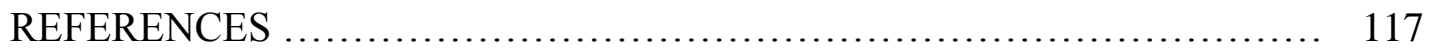

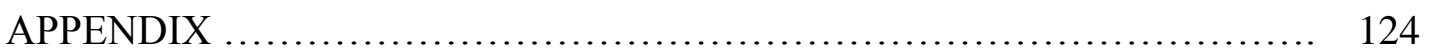

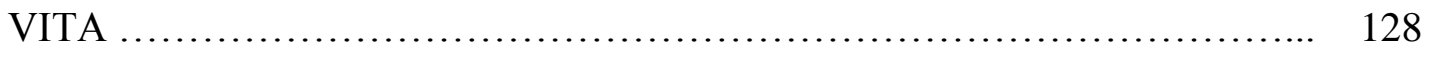




\section{LIST OF TABLES}

TABLE

1. Sample Breakdown of Parent 1's (Mother's) Highest Education

2. Sample Breakdown of Parent 2's Highest Education

3. Sample Breakdown of Total Annual Family Income

4. Kappa and Percent Agreement Scores for Coding of Primary Dependent Variables and Manipulation Check Questions

5. Primary Dependent Variables

6. Kappa and Percent Agreement Scores for Coding of Exploratory

Debriefing Questions

7. Sample Breakdown of Child Demographic Characteristics Across HonestyPromotion Technique $\mathrm{x}$ Transgressor Identity Conditions ....

8. Means and Standard Deviations of Manipulation Check Sum Scores Across Honesty-Promotion Technique and Transgressor Identity Conditions

9. Chi-Square Analyses for Effect of Child Sex on Dichotomous Primary

Dependent Variables

10. ANOVA Analyses for Effect of Child Sex on Primary Dependent Sum Score Variables

11. Chi-Square Analyses for Effect of Child Ethnicity on Dichotomous Primary Dependent Variables

12. ANOVA Analyses for Effect of Child Ethnicity on Primary Dependent Sum Score Variables

13. Chi-Square Analyses for Effect of Child Race on Dichotomous Primary Dependent Variables

14. ANOVA Analyses for Effect of Child Race on Primary Dependent Sum Score Variables

15. Chi-Square Analyses for Effect of Highest Parental Education on Dichotomous Primary Dependent Variables 
16. ANOVA Analyses for Effect of Highest Parental Education on Primary Dependent Sum Score Variables

17. Chi-Square Analyses for Effect of Total Annual Family Income on Dichotomous Primary Dependent Variables

18. ANOVA Analyses for Effect of Total Annual Family Income on Primary Dependent Sum Score Variables

19. Open-Ended Question: Binary Logistic Regression Analyses Examining Effects of Predictor Variables on Children's Disclosure of Adult Transgression

20. Open-Ended Question: Percent of Children Disclosing Adult Transgression Across Honesty-Promotion Technique, Transgressor Identity, and Age Conditions

21. Did Something Bad Happen: Binary Logistic Regression Analyses Examining Effects of Predictor Variables on Children's Admissions (Yes or No) that Something Bad Happened ........................................

22. Did Something Bad Happen: Percent of Children Admitting (Yes or No) that Something Bad Happened Across Honesty-Promotion Technique, Transgressor Identity, and Age Conditions

23. Did Something Bad Happen: Binary Logistic Regression Analyses Examining Effects of Predictor Variables on Children's Disclosure of Adult Transgression

24. Did Something Bad Happen: Percent of Children Disclosing Adult Transgression Across Honesty-Promotion Technique, Transgressor Identity, and Age Conditions

25. Ordinal Logistic Regression Analyses Examining Effects of Predictor Variables on Child Direct Sum Scores

26. Means and Standard Deviations for Child Direct Sum Scores Across Honesty-Promotion Technique, Transgressor Identity, and Age Conditions ...

27. Ordinal Logistic Regression Analyses Examining Effects of Predictor Variables on Transgressor Direct Sum Scores 
28. Means and Standard Deviations for Transgressor Direct Sum Scores Across Honesty-Promotion Technique, Transgressor Identity, and Age Conditions

29. Ordinal Logistic Regression Analyses Examining Effects of Predictor Variables on Child Suggestive Sum Scores ....

30. Means and Standard Deviations for Child Suggestive Sum Scores Across Honesty-Promotion Technique, Transgressor Identity, and Age Conditions .... 96

31. Ordinal Logistic Regression Analyses Examining Effects of Predictor Variables on Transgressor Suggestive Sum Scores

32. Means and Standard Deviations for Transgressor Suggestive Sum Scores Across Honesty-Promotion Technique, Transgressor Identity, and Age Conditions

33. Binary Logistic Regression Analyses for Effect of Children's Attachment to their Mother on Dichotomous Primary Dependent Variables

34. Ordinal Logistic Regression Analyses for Effect of Children's Attachment to their Mother on Primary Dependent Sum Score Variables

35. Binary Logistic Regression Analyses for Effect of Mother-Child Relationship Quality on Dichotomous Primary Dependent Variables

36. Ordinal Logistic Regression Analyses for Effect of Mother-Child Relationship Quality on Primary Dependent Sum Score Variables

37. Binary Logistic Regression Analyses for Effects of Parenting Styles on Dichotomous Primary Dependent Variables

38. Ordinal Logistic Regression Analyses for Effects of Parenting Styles on Primary Dependent Sum Score Variables

39. Binary Logistic Regression Analyses for Effects of Children's Average Total Trust in Mothers and Fathers on Dichotomous Primary Dependent Variables

40. Ordinal Logistic Regression Analyses for Effects of Children's Average Total Trust in Mothers and Fathers on Primary Dependent Sum Score Variables 


\section{LIST OF FIGURES}

FIGURE

PAGE

1. Flow Chart for Child Study Protocol ….............................. 107

2. Percent of children disclosing adult transgression to open-ended question ... 110

3. Percent of children admitting something bad happened to direct question ... 111

4. Percent of children disclosing adult transgression when directly asked if something bad happened ................................................ 112

5. Children's average sum scores to direct questions about child ............. 113

6. Children's average sum scores to direct questions about transgressor .......... 114

7. Children's average sum scores to suggestive questions about child ......... 115

8. Children's average sum scores to suggestive questions about transgressor .. 116 


\section{CHAPTER I}

\section{INTRODUCTION}

Children are often involved in the legal system and may testify in a variety of cases including domestic violence and child custody disputes. Most commonly, they enter the legal system as victims of maltreatment (e.g., physical, sexual abuse). In fact, approximately 4 million allegations of child maltreatment are made each year in the U.S. (U.S. Department of Health and Human Services, 2017). The number of allegations is a daunting and tragic statistic, yet may be a vast understatement of the true number of child maltreatment victims as a consequence of the underreporting of these allegations.

Because children are often the only witnesses to maltreatment, their abuse disclosures are imperative to initiate effective legal responses. However, decades of research reveal that children, especially those who are abused by a parent figure, commonly delay disclosures of maltreatment or fail to disclose as children altogether (see London, Bruck, Ceci, \& Shuman, 2005; London, Bruck, Wright, \& Ceci, 2008, for reviews). As children age, they also become more cognizant of the negative consequences of disclosure (Malloy, Brubacher, \& Lamb, 2011; Malloy, Quas, Lyon, \& Ahern, 2014). Thus, maltreatment is rarely brought to the attention of authorities, and when it is, investigations may close prematurely without credible disclosures from children (Mullen, Martin, Anderson, Romans, \& Herbison, 1993; Smith et al., 2000). The consequences of non-disclosure or delayed disclosure are dire, as they may result in ongoing abuse for the child victim and potentially other children. How, then, can we promote honesty in children and encourage their true disclosures of maltreatment? Although researchers have examined the development of lie-telling among children and their early understanding of truths and lies 
for over a century (see Talwar \& Crossman, 2012, for review), only relatively recently have they examined techniques for promoting honesty among children.

\section{Study Aims}

The present study examined a novel technique for promoting honesty in children. Specifically, we were interested in the benefits of priming honesty for eliciting children's true disclosures of an adult's act of wrongdoing because children are typically questioned about adults' transgressions in maltreatment cases. In such cases, children may feel involved in, or responsible for, the act of wrongdoing (Anderson, Martin, Mullen, Romans, \& Herbison, 1993; Quas, Goodman, \& Jones, 2003) and told or threatened to keep the transgression a secret, often by someone close to them (e.g., a parent figure; Malloy et al., 2011; Malloy, Lyon, \& Quas, 2007). The use of a prime, or non-conscious technique for promoting honesty, may be resistant to the influence of these factors on disclosing, whereas an explicit technique may not. That is, children who are primed may be non-consciously motivated to tell the truth, and this motivation may reduce their conscious reasoning about telling the truth. Also, the present study compared different techniques for promoting children's true disclosures of an adult's (in some cases, a parent's) act of wrongdoing. Specifically, we addressed five research questions: (1) Will priming honesty elicit more truthful disclosures from children regarding an adult's act of wrongdoing in comparison to requesting that children promise to tell the truth and a control condition?, (2) Will children be more honest about a stranger's than parent's act of wrongdoing?, (3) Will younger children be more honest about an adult's act of wrongdoing in comparison to older children?, (4) Will priming honesty elicit more truthful disclosures for a parent's rather than a stranger's act of wrongdoing?, and (5) 
Will priming honesty elicit more truthful disclosures from older children rather than younger children? The present study enhances our knowledge of the effectiveness of different honesty-promotion techniques in encouraging children's true disclosures of adult wrongdoing and more generally expands our knowledge of the benefit of priming when used with children. Furthermore, the results advance our theoretical understanding of the factors influencing children's willingness to disclose (e.g., conscious awareness of external pressures or consequences of disclosure, relationship with the perpetrator).

\section{CHAPTER II}

\section{LITERATURE REVIEW}

\section{Children's Disclosure Patterns}

Past research has shown that children are more or less forthcoming about an adult's transgression depending upon the type of question they are asked. For example, Malloy and Mugno (2016) found that 20.5\% of children first disclosed an adult's act of wrongdoing in response to an open-ended question, $38.4 \%$ in response to more direct questions, and $31.5 \%$ in response to suggestive questions. Other studies have found similar patterns of disclosure to these question types (Ahern, Stolzenberg, McWilliams, \& Lyon, 2016; Lyon, Malloy, Quas, \& Talwar, 2008; Pipe \& Wilson, 1994). However, although children tend to increasingly make truthful disclosures to more direct and suggestive questions, using these types of questions with children also increases the risk of children making false allegations. Therefore, it is important to examine other techniques for encouraging children's true disclosures to these different question types, which the present study aimed to do. 


\section{Priming}

Much human behavior is guided by non-conscious processing (Bargh, Schwader, Hailey, Dyer, \& Boothby, 2012). Psychologists have often been able to examine the effect of this non-conscious processing or storage of implicit memories through priming, or unknowing activation of mental representations by mere exposure to a stimulus. Over several decades, researchers have used a variety of priming techniques, such as flashing subliminal pictures (i.e., pictures flashed below participants' conscious awareness), as well as word search puzzles and scrambled sentence tests that incorporate words similar in meaning to the response that is being primed (e.g., words like bother or bold when priming for rudeness) to study the effects of non-conscious processing. In a series of experiments, Bargh, Chen, and Burrows (1996) demonstrated how trait concepts or stereotypes activated through priming could affect behavior. For example, priming rudeness and politeness influenced how quickly participants interrupted a conversation; priming a stereotype of the elderly influenced the speed with which participants walked to an elevator; and priming the stereotypes of Caucasians and African Americans influenced the hostility with which participants reacted to a supposed data-saving error on a computer task. Early priming studies focused on the effect of non-conscious processing on behaviors and perceptions, and researchers have continued to explore the effects of priming across a variety of psychological domains, such as judgment, decision-making, and goal pursuit (Bargh et al., 2012).

Bargh, Gollwitzer, Lee-Chai, Barndollar, and Trotschel (2001) showed that goals can be activated non-consciously: Priming the goal of high performance increased the number of words participants found in word-search puzzles and their persistence on a 
word generation task. Similarly, priming the goal of cooperation influenced how cooperatively participants behaved on a resource-dilemma task. Of particular interest to the present study, Rasinski, Visser, Zagatsky, and Rickett (2005) primed the goal of honesty in adults prior to having them complete a questionnaire inquiring about undesirable behaviors. Six different target words were presented, each with three corresponding words, and participants had to choose a corresponding word that seemed most similar to the target word. In the experimental condition, four of the target words were associated with honesty (in order to prime for this goal); however, in the control condition, all of the target words were neutral. Participants who completed the honesty priming task reported engaging in more unhealthy alcohol-related behaviors (i.e., binge drinking, black outs) than participants in the control condition, despite the fact that both groups received the same explicit instructions to respond honestly. The researchers concluded that priming the goal of honesty may encourage more accurate and honest responding on self-report questionnaires.

Using the same task as Rasinski et al. (2005), Vinski and Watter (2012) further explored the effectiveness of priming honesty. Their results suggested that adults primed for the goal of honesty may be more truthful about how much their mind wanders during an attention task. Randolph-Seng and Nielson (2007) primed for honesty in a different manner. These researchers had participants complete sentence-scramble tasks that either included religious, sports-related, or neutral words, prior to completion of a task (i.e., a circle task) where they were motivated to cheat (e.g., to earn extra credit). The researchers found that those in the religious prime condition were more honest (i.e., cheated significantly less) than both other conditions on the subsequent task. 
Furthermore, these results were replicated using a subliminal prime task where participants completed a computer task during which either religious or neutral words flashed before them below their conscious awareness. Interestingly, the results were found regardless of the participants' religious orientations, suggesting that the prime activated a stereotype of how religious people may be inclined to behave.

Although priming effects have been found across many psychological domains (Bargh et al., 2012), some researchers have failed to replicate priming effects and thus question the validity of the study findings. For example, through a series of experiments, Pashler, Rohrer, and Harris (2013) were not able to replicate the honesty priming effects found by Rasinski et al. (2005). They suggested that Rasinski et al.'s (2005) significant findings and those found in similar goal priming studies were likely a result of Type 1 error, and goal priming studies with null research findings, as they had found, have gone unpublished. However, the reason for these disparate findings may be because priming is mediated and moderated by certain factors that are more or less present in different studies. Bargh et al. (2012) delineated several of these factors. For example, a prime may only be effective when it is congruent with one's natural dispositions, behaviors, or goals. Also, a prime may be more effective when paired with positive affect (e.g., positively-valenced stimuli, relatable context) because positive feelings may serve as a motivation toward the nonconscious goal.

Priming children. Researchers have found that priming children as young as 18months-old affects their subsequent behavior (Over \& Carpenter, 2009). Although priming for honesty has not been examined in children, research has examined the priming of other goals in children. For example, Kesek, Cunningham, Packer, and 
Zelazo (2011) primed 4-year-olds either for the goal of obtaining many rewards or for the goal of obtaining immediate rewards. Children either listened to a story laden with words reflecting a many connotation or words reflecting an immediate connotation, prior to completing a delay of gratification task during which they had to choose between smaller, more immediate rewards, and larger, more delayed rewards. Other children were explicitly instructed to either try to obtain many rewards or obtain rewards sooner. Participants in the immediate prime condition were more likely to choose the smaller, more immediate rewards than those in the many prime condition, suggesting that nonconscious goals were activated in the children. However, children in the two explicit conditions did not differ in reward choices. Importantly, no child appeared aware of any association between the stories and task. The researchers concluded that in some circumstances it may be beneficial to attempt to alter children's behavior indirectly rather than directly. In the present study, we tested the prime as an honesty-promotion technique that may operate more indirectly than an explicit promise to tell the truth.

\section{Honesty-Promotion Techniques}

Several honesty-promotion techniques have been examined, and the effectiveness of these different techniques has varied. Researchers have generally found that a request for children to promise to tell the truth decreases lying behaviors. However, the effectiveness of other techniques on lying behaviors, such as having children engage in a conceptual discussion about truth and lies, providing children with reassurance about disclosing, telling children that the transgressor has already disclosed what happened and wants them to tell the truth, or appealing to children's internal and external standards, is less clear. Research on each of these techniques is reviewed below. 
Promise to tell the truth. Eliciting a promise to tell the truth, a request that is often made of children in the U.S. before testifying (Lyon, 2011), has increased children's true disclosures of their own and others' wrongdoing across a wide age range (i.e., 3- to 16-year-olds; Evans \& Lee, 2010; Lyon \& Dorado, 2008; Lyon et al., 2008; Talwar, Lee, Bala, \& Lindsay, 2002). For example, Talwar et al. (2002) examined whether a truth-lie discussion (TLD) or promise to tell the truth decreased lie-telling among 3- to 7-year-olds participating in a temptation resistance paradigm, a standardized experimental paradigm designed to induce transgressing in most children (e.g., peeking at a toy) so that researchers can observe whether they will lie about their transgression. Before the researchers asked whether the children had peeked at the toy, the children were either (1) asked questions about two presented situations to examine their understanding of truths and lies (TLD condition), or (2) asked to promise to tell the truth (oath condition). The researchers found that the majority of children in both conditions peeked at the toy, but children in the oath condition were less likely to lie about peeking (59\%) than children in the TLD condition $(75 \%)$. In three different experiments, the researchers concluded that asking children to promise to tell the truth promoted honesty; however, discussing truth and lies had little or no effect on children's subsequent truthtelling.

Lyon and Dorado (2008) found that promising to tell the truth encouraged truthtelling among 6- to 7-year-old maltreated children who passed a truth-lie competency task. Their experimental design was different from the paradigm used by Talwar et al. (2002). While an experimenter temporarily stepped out of a room, a confederate came in and led a child in play with a toy house, only warning the child that they could get into 
trouble for doing so right before exiting the room. Upon returning, the experimenter asked the child several questions regarding what happened when she left. Prior to being asked these questions, the child was (1) asked to promise to tell the truth (oath condition), (2) told that many children play with the toy house with no negative consequences and was reassured that it was okay to tell the truth (reassurance condition), or (3) given no additional instructions or information (control condition). The researchers found that children in both the oath and reassurance conditions responded more honestly than children in the control condition.

In a follow-up study, Lyon and Dorado (2008) examined the behaviors of 5- to 7year-old maltreated children using an almost identical paradigm; however, this time the confederate never engaged the child in play with the toy house. Although, the researchers replicated the beneficial effect of the oath, they found that children in the reassurance condition who did not pass a truth-lie competency task were more likely than children in the oath and control conditions to make false claims in response to the experimenter's questions, particularly suggestive questions.

A more recent study examined promises to tell the truth among 8-to 16-year-olds, a sample of children older than the previous studies (Evans \& Lee, 2010). Children participated in a variation of the temptation resistance paradigm in which they were motivated to answer all ten questions correctly on a trivia test in order to win a prize. However, two of the question answers were unknown, and thus the children were tempted to peek at the answers located on the inside of the test booklet. Upon completing the test, the experimenter inquired as to whether the child peeked at the test answers (Time 1 response). Children subsequently engaged in a TLD, were asked to promise to 
tell the truth, and once again were asked if they had peeked at the test answers (Time 2 response). Approximately half of the children peeked at the test answers, with $84 \%$ lying about having peeked at Time 1 , and $65 \%$ lying at Time 2.

Since it was difficult to discern which manipulation (a TLD or promise to tell the truth) resulted in the decrease in lying, Evans and Lee (2010) conducted a second experiment. The same protocol was used, although children were not requested to promise to tell the truth. Over half of the children peeked at the test answers (68\%), with $82 \%$ of these children lying about having peeked at Time 1 and $79 \%$ lying at Time 2. Since there was no significant decrease in lying when the children were not asked to promise to tell the truth, the researchers concluded that a promise to tell the truth had promoted honesty in children in the first experiment. Thus, the benefit of a promise to tell the truth appears to be a consistent finding across a number of studies using several different experimental paradigms and a wide age range of children.

Truth-lie discussion. Before being interviewed or appearing in court, children are often asked to demonstrate their conceptual understanding of the difference between truths and lies. In fact, in some states, children may be deemed incompetent to testify if they are not able to successfully make this distinction (Haugaard, Reppucci, Laird, \& Nauful, 1991; see Lyon, 2011, for a review). However, does children's participation in these competency tests or discussions about truths and lies imply that children will be more honest? Huffman, Warren, and Larson (1999), in fact, found that engaging children in a comprehensive discussion about truths and lies promoted honesty. They interviewed 4- to 6-year-old children twice (at 1-week and 1-week, 2-day delays) using a series of direct and suggestive questions about both true and false events following a classroom 
visit. Prior to the second interview, children either engaged in a standard TLD, an extended TLD, or no TLD. The standard TLD included a discussion of the meaning of truth and lies and examples of each. However, the extended TLD was much more indepth, also inquiring about the morality of lies, having the children come up with definitions and examples of lies, and asking that the children reflect upon the consequences of lie-telling. Although children in the three conditions did not differ significantly in accurate responses to the first set of interview questions about the classroom visit (prior to any TLD), children in the extended TLD condition provided more accurate responses during the second interview than both other conditions. However, the researchers recognized that differences in the amount of time that children spent with the experimenter across the three conditions may have been a potential confound.

London and Nunez (2002) further noted that the children in the Huffman et al. (1999) study did not engage in a task where they were motivated to lie. Therefore, in a follow-up study, London and Nunez (2002) had 3- to 6-year-old children participate in a temptation resistance paradigm task (where most children peeked at a toy when told not to), and subsequently engaged in a (1) short, standard TLD; (2) short, control discussion; (3) long, developmentally-appropriate TLD; or (4) long, control discussion. Both control discussions were matched in length to the respective short or long TLD discussion and followed a similar format; however, neither of these discussions mentioned truth and lies. The researchers found that children were significantly more likely to admit to peeking at a toy in both the short and long TLD discussions than either control condition. 
Despite the findings of these two studies, some studies have failed to consistently find the benefit of a standard TLD on children's lie-telling behaviors (Evans \& Lee, 2010; Talwar et al., 2002), and the findings of other studies are unclear. For example, Talwar, Lee, Bala, and Lindsay (2004) found that 3- to 11-year-old children's truthtelling about a parent's transgression increased from a first to second interview after both a TLD discussion and promise to tell the truth. There was no difference in children's truth-telling when they did not receive these techniques between the first and second interview. However, it is difficult to ascertain which honesty-promotion technique (TLD or promise to tell the truth) increased children's truth-telling. Thus, the mixed results on a TLD indicate that more research is warranted on the potential benefits of this technique, particularly different types of TLDs.

Reassurance. As aforementioned, Lyon and Dorado (2008) found that reassuring children about the lack of negative consequences for truth-telling led to increased true disclosures of self- and other wrongdoing, but also increased false allegations in some circumstances. Lyon et al. (2008) further examined the effects of providing reassurance to children who had been coached to lie, and compared reassurance to promising to tell the truth. In a study designed to examine true and false allegations and denials, 4- to 7year-old maltreated children completed a truth-lie competency task and were randomly assigned to one of four conditions. While the experimenter left the study room briefly, a confederate entered the room and either (1) engaged the child in play with a toy house, (2) engaged the child in play with a toy house but then coached the child to later deny playing with it, (3) did not engage the child in play with a toy house, or (4) did not engage the child in play with a toy house but coached the child to later claim having 
played with it. Upon returning, the experimenter inquired about what happened while she was gone using an open-ended question. Subsequently, the child was either asked (1) to promise to tell the truth (the oath condition), (2) reassured by the experimenter that she commonly talked with children who felt bad about something they had done and there would be no negative consequences for disclosing this information (the reassurance condition), or (3) was not given any further instructions or information (the control condition). Then, the child was again asked an open-ended question about what had happened while the experimenter was gone, followed by repeated yes-no questions and suppositional (i.e., highly suggestive) questions.

As with other studies, Lyon et al. (2008) found that asking children to promise to tell the truth, even when they had been coached to lie, led to more accurate and honest responses to the experimenter's open-ended and yes-no questions. The reassurance manipulation did not result in the same positive effects found in the Lyon and Dorado (2008) study, but it also did not have any detrimental effects on the honesty of children's reports (i.e., increasing false allegations). Notably, the reassurance manipulation used in the current study was less specific to the situation, however. In the Lyon and Dorado (2008) study, children had been specifically reassured that many children play with the toy house with no negative consequences, whereas Lyon et al. (2008) used more general reassurance that the experimenter commonly talked with children who felt bad about something they had done, and there would be no negative consequences for disclosing. Neither a promise to tell the truth nor general reassurance led to more accurate responding to suppositional questions. More research is needed to examine the effects of different types of reassurance on both false denials and allegations. 
Newer techniques. Recently, researchers have begun to explore some new techniques that may encourage children's honest responding about an act of wrongdoing. The burgeoning research on each of these techniques is outlined below.

Putative confession. Researchers have examined whether a putative confession or informing children that the transgressor already told them everything that happened and wants them to tell the truth, promotes honesty. Specifically, Lyon et al. (2014) examined both maltreated and non-maltreated children's willingness to disclose their own toy breakage (i.e., the toys seemed to break in the hands of the child) following a putative confession. In comparison with a control group who received no putative confession before being interviewed, 4- to 9-year-old children who received a putative confession were more likely to disclose and elaborate on toy breakage in response to free recall and cued recall questions (You said [names detail]. Tell me more about that.). They were also more likely to assent to a direct question asking whether anything bad had happened with the toys. Importantly, the putative confession did not increase false claims of toy breakage. Also, Rush, Stolzenberg, Quas, and Lyon (2017) found that 4- to 7-year-old children who received a putative confession were more likely to initially disclose their own toy breakage during free recall and yes-no questions relative to those who had not received a putative confession. Interestingly, hearing a putative confession even decreased false claims about playing with certain toys (that the children had not played with) relative to not hearing a putative confession.

Although a technique such as the putative confession seems promising, Lyon et al. (2014) acknowledge that its applied use may depend upon several factors: (1) whether the perpetrator has confessed and if the confession is admissible in court, (2) legal 
professionals' perceptions of the influence of a putative confession statement on the accuracy of children's reports, and (3) whether it is ethical to potentially falsely suggest to children that a perpetrator has confessed, particularly if the children find out otherwise later. Because of these concerns, researchers are now examining how a hypothetical putative confession may promote honest disclosures among children.

Appealing to children's standards. Talwar, Arruda, and Yachison (2015) found that appealing to 4- to 8-year-old children's external standards (e.g., "If you tell the truth, I will be really pleased with you") significantly decreased lie-telling about one's own transgression relative to not appealing to their external standards. Furthermore, appealing to children's internal standards (e.g., "Telling the truth is the right thing to do") while not suggesting punishment (e.g., "I will not be cross with you") decreased lie-telling relative to appealing to children's internal standards and suggesting punishment (e.g., "You will be in trouble"). The latter group did not significantly differ from the group where no appeal was made.

Two other studies have examined appealing to children's internal or moral standards. Lee at al. (2014) found that reading 3- to 7-year-olds a moral story that highlighted the benefits of truth-telling (George Washington and the Cherry Tree) decreased lying about their own transgressions (i.e., peeking at a toy). However, stories that highlighted the negative consequences of lie-telling (Pinocchio, Boy Who Cried Wolf, and even a modified version of George Washington and the Cherry Tree where punishment was a consequence of lying) did not significantly reduce children's lying behavior. In a similar study, Talwar, Yachison, and Leduc (2016) found that a positive 
moral story reduced lying about a stranger's transgression (i.e., breaking a toy) among 4to 7-year-olds.

\section{Limitations of Prior Research}

The prior research on honesty-promotion techniques is limited in several critical ways. First, several of the manipulations combined techniques, precluding definitive conclusions from being drawn about individual techniques. For example, Talwar et al. (2004) combined a TLD with a promise to tell the truth. Also, reassurance manipulations have appealed to how other children may feel or behave in combination with assuring the children that there would be no negative consequences of disclosing the truth (Lyon \& Dorado, 2008; Lyon et al., 2008). Second, it remains unknown whether the aforementioned techniques are effective when children are asked to keep a secret on behalf of a known and trusted adult. Several studies have examined the effects of honesty-promotion techniques on children's willingness to reveal their own transgressions (Evans \& Lee, 2010; Lee et al., 2014; Talwar et al., 2002) or a stranger's act of wrongdoing (Lyon \& Dorado, 2008; Lyon et al., 2008), but only one study (Talwar et al., 2004) has examined the effect of these techniques on children's willingness to reveal a parent's act of wrongdoing. However, the Talwar et al. (2004) study, which focused on whether a promise to tell the truth and a standard TLD promotes honesty, did not vary the identity of the transgressor to test children's willingness to disclose a parent's versus a stranger's act of wrongdoing. An examination of children's relationship to the "perpetrator" is particularly important given that the perpetrator in the majority of maltreatment cases is someone close to the child (U.S. Department of Health and Human Services, 2017). Experimental research indicates that children are less forthcoming about 
a caregiver's transgression (Lyon, Ahern, Malloy, \& Quas, 2010; Malloy et al., 2014;

Tye, Amato, Honts, Devitt, \& Peters, 1999), and field research indicates that children are less forthcoming about sexual abuse allegedly perpetrated by caregivers (London et al., 2005, 2008; Malloy et al., 2007). Thus, it is imperative to examine the effectiveness of honesty-promotion techniques while varying the transgressor's identity so that findings can generalize to situations where children are interviewed or asked to testify about the actions of a known and trusted adult.

Third, and perhaps most importantly, almost all techniques reviewed thus far have involved explicit requests to tell the truth or have engaged children in explicit discussions about honesty prior to questioning them about a transgression. However, the present study aimed to examine priming, a technique that indirectly or non-consciously may promote children's true disclosures of others' wrongdoing. Consciously deciding whether to tell the truth may be influenced by external pressures (e.g., from a transgressor) and a consideration of consequences to oneself and others, whereas nonconsciously activating the goal of truth-telling may be resistant to such socio-contextual factors. Furthermore, children's errors in, for example, explicit discussions about lies and truths can undermine their eyewitness credibility, even when extended discussions successfully suppress their lie-telling behaviors (Huffman et al., 1999).

The present study builds upon Lee et al. (2014) and Talwar et al. (2015) who appealed to children's internal or moral standards to promote honesty, with several key differences. Although hearing a moral story might, in some ways, resemble a prime, Lee et al. (2014) explicitly requested that children act/not act like the character in the moral story and tell the truth about their own transgression. Talwar et al. (2015) did not involve 
this explicit instruction before asking children about a stranger's transgression. However, the present study differs from their experiment in the following key ways: (1) we examined the effectiveness of several honesty-promotion techniques on children's disclosures of both a stranger's and parent's act of wrongdoing; (2) we examined the effectiveness of priming, an indirect honesty-promotion technique, on older children (6to 9-year-olds), an important age range given that more sophisticated lie-telling and secret-keeping appears to increase in the elementary school years (Gordon, Lyon, \& Lee, 2014; Talwar et al., 2015; Talwar \& Crossman, 2012); and (3) our prime manipulation did not discuss any punishment or benefit of lying or truth-telling, unlike in the moral stories. Furthermore, priming may circumvent some of the practical challenges associated with employing Lee et al. (2014) or Talwar et al. (2015)'s paradigms in the real world. For example, reading a child a moral story prior to an interview or courtroom testimony may not be possible within our criminal justice systen. That is, we cannot threaten children with consequences for lying or realistically promise benefits of truthtelling when they may, in fact, experience consequences for telling the truth (e.g., removal from home). Also, many children may be familiar with the "classic" moral stories discussed thus far, which raises the question as to whether simply reminding children of these stories will reliably promote honesty.

\section{CHAPTER III}

\section{THE PRESENT STUDY}

In the present study, two techniques designed to promote honesty were compared to a control condition: (1) priming children for the goal of honesty (prime condition) and (2) asking children to promise to tell the truth (oath condition). The oath condition was 
examined because of its effectiveness in previous research (Evans \& Lee, 2010; Lyon \& Dorado, 2008; Lyon et al., 2008; Talwar et al., 2002), and the control condition was included as a comparison group of children's typical disclosure patterns concerning an adult's act of wrongdoing without any honesty-promotion technique. Thus, we examined (1) whether priming honesty elicits more truthful disclosures from children regarding an adult's act of wrongdoing in comparison to requesting that children promise to tell the truth and a control condition, (2) whether children are more honest about a stranger's than parent's act of wrongdoing, (3) whether younger children (6- to 7-year-olds) are more honest about an adult's act of wrongdoing in comparison to older children (8- to 9year-olds), (4) whether priming honesty elicits more truthful disclosures for a parent's rather than a stranger's act of wrongdoing, and (5) whether priming honesty elicits more truthful disclosures about an adult's act of wrongdoing from older than younger children.

Six- to 9-year-old children and an adult (stranger or parent) engaged in play with forbidden puppets during which the adult broke the puppet and asked the child to keep it a secret. Prior to being questioned about the act of wrongdoing, children were either shown a story designed to prime for honesty (prime condition), asked to promise to tell the truth (oath condition), or given no further instructions or information (control condition). Then, children were asked a series of open-ended, direct, and suggestive questions about whether they or the adult touched, played with, or broke the puppets.

\section{Hypotheses}

Hypothesis 1: Children in the prime condition would be most honest about an adult's act of wrongdoing, followed by children in the oath and control conditions, respectively. 
Hypothesis 2: Children would be more honest about a stranger's than a parent's act of wrongdoing.

Hypothesis 3: Younger children (6- to 7-year-olds) would be more honest than older children (8- to 9-year-olds) about an adult's act of wrongdoing.

Hypothesis 4: Priming would be especially effective in the condition with a parent transgressor. That is, we hypothesized an Honesty-Promotion Technique x Transgressor Identity interaction such that those in the parent transgressor condition who received a prime would be as honest about the adult's act of wrongdoing as those in the stranger transgressor condition who received a prime. However, in the oath and control conditions, we expected the higher rates of disclosure in the stranger condition compared to the parent condition to remain.

Hypothesis 5: Priming would be especially effective with older children (i.e., 8- to 9-year-olds). That is, we hypothesized an Honesty-Promotion Technique x Age interaction such that older children who received a prime would be as honest about the adult's act of wrongdoing as younger children who received a prime. However, in the oath and control conditions, we expected the higher rates of disclosure among the younger children compared to the older children to remain.

\section{CHAPTER IV}

\section{METHOD}

\section{Participants}

One-hundred and twenty-two children and their mothers living in a southeastern state participated in the study. Families were recruited with the assistance of a recruitment firm, and from existing databases of families interested in research 
participation; local schools, community centers, and stores; children's groups (e.g., recreational sports teams); and email listservs. Seven children and their mothers were excluded from analyses for the following reasons: (1) there was no transgression because the children would not allow their mother to touch the puppets $(n=3),(2)$ the child broke the puppet instead of the transgressor $(n=1)$, (3) the transgressor was the grandmother instead of the mother $(n=1)$, (4) the video recording could not be retrieved and interviewer notes were not sufficient to conduct meaningful analyses $(n=1)$, and (5) the child was not willing to actively participate in the study $(n=1)$.

The final sample was thus comprised of 1156 - to 9-year-old children $\left(M_{\text {age }}=7.47\right.$ years, $S D=1.13$; 60 6- and 7-year-olds, 55 8- and 9-year-olds; 54\% male) and their mothers. The age range was examined for the following reasons: (1) it allows for appropriate comparisons with previous research, (2) lie-telling increases and becomes more sophisticated during the elementary school years (Talwar et al., 2015; Talwar \& Crossman, 2012), (3) there is evidence that secret-keeping may increase as children get older (Gordon, et al., 2014), and (4) most child witnesses who testify are within this age range or older (Goodman et al., 1992). The sample of children was ethnically and racially diverse with 61\% Hispanic/Latino (39\% not Hispanic/Latino), and 71\% White, $17 \%$ Black, and 12\% Multiracial.

Mothers were recruited to participate with their child because (1) children are often asked to keep maltreatment a secret by a parent figure (Malloy et al., 2011; Malloy et al., 2007), and (2) research shows that mothers have an impact on how, when, and to whom children disclose (Lawson \& Chaffin, 1992; Malloy et al., 2007; Malloy \& Mugno, 2016). During recruitment, all families indicated that the participating children 
and their mothers were fluent in English. Sixty-five percent of the families had one parent with at least a Bachelor's degree, and $28 \%$ of the families had an annual family income of $\$ 45,000$ or less. See Tables 1 through 3 for a specific breakdown of the sample by highest parental education and total annual family income.

$T$-test and chi-square analyses revealed no significant difference between the initial $(n=122)$ and analytic $(n=115)$ samples on any of the demographic variables. That is, there was no difference between the children who were included and excluded from the final sample on the child demographic variables [age: $t(120, N=122)=-.86, p$ $=.390$; sex: (Fisher's exact test, $N=122), p=.704)$; ethnicity: (Fisher's exact test, $N=$ $122), p=.253$; race: $\left.\chi^{2}(2, N=122)=1.06, p=.588\right]$ and family demographic variables [highest parental degree: (Fisher's exact test, $N=120$ ), $p=.700$ ), total annual family income: (Fisher's exact test, $N=121), p=1.000]$.

\section{Design and Procedural Overview}

The study conformed to a 3 (Honesty-Promotion Technique: prime, oath, control) x 2 (Adult Transgressor: mother, stranger) mixed factorial design with participants randomly assigned to each cell. See Figure 1 for an overview of the procedure. Six- to 9-year-old children and an adult (mother or research assistant) engaged in play with forbidden puppets during which the adult broke a puppet and asked the child to keep it a secret. Prior to being questioned about the act of wrongdoing, children were either shown a story designed to prime for honesty (prime condition), asked to promise to tell the truth (oath condition), or given no further instructions or information (control condition). Then, children were asked a series of open-ended, direct, and suggestive questions about whether they or the adult touched, played with, or broke the puppets. 
Undergraduate research assistants (RAs) were recruited to assist with data collection and processing following a thorough interview process. They were trained extensively on research ethics, recruitment and data collection protocols, data confidentiality, and data processing. The RAs were required to memorize most of the study protocol verbatim and demonstrate accurate administration of the entire protocol before collecting data. Once data collection began, the RAs received feedback on their performance for their first two study sessions to determine whether they could continue with data collection. Periodic reviews of study videos were conducted to ensure that all RAs maintained consistency in their administration of the study protocol for the duration of data collection. All RAs were re-certified on the data collection protocols following a three-week break during which data collection did not take place. Weekly lab meetings were held to discuss and resolve any study issues as they arose.

\section{Procedure}

Parents and children visited the university laboratory. The RAs obtained informed parental consent and child assent. All children participated in a modified version of an interactive first aid and safety event (Brown, Lewis, Lamb, \& Stephens, 2012; Malloy \& Mugno, 2016). Research assistant one (RA1) conducted three scripted "stations" with the children where they practiced caring for a small cut, identified unsafe situations on poster cards and discussed how to make them safer, and learned different ways to take their temperature. After the last station, RA1 excused him/herself from the room to retrieve a few papers for the next task.

Transgression. Depending upon the child's condition, RA1 escorted either another RA (research assistant two (RA2); stranger transgressor condition) or the child's 
mother (parent transgressor condition) into the room to wait with the child. Importantly, RA2 was always female and was never referred to as a "friend" or someone who had any association with RA1 or the research project. When escorting the adult transgressor into the room, RA1 noticed a box filled with puppets and labeled "DO NOT TOUCH" (with a circle and slash through it) sitting outside of the room. Research assistant one (RA1) brought the box of puppets into the room and said to the adult transgressor and child: $M y$ friend left this box outside of the room, and she told me she needs to take these toys to a school later. I'll leave them in here so they'll be safe. She told me that nobody should touch these toys since they're fragile, so I'll put them off to the side. I'll be back in just a few minutes.

When RA1 left the room, the adult transgressor questioned the child about what he/she had been doing and proceeded to look inside the different first aid and safety station boxes. The adult transgressor then peeked into the box of puppets and said: It seems like some of these characters could help you talk about first aid and safety. I know we are not supposed to touch them, but I think it will be okay as long as we are very careful. The adult transgressor engaged the child in play with the puppets (so the child was also mildly implicated in the act of wrongdoing). In cases of maltreatment, children often feel involved in the act of wrongdoing and experience self-blame (Anderson, et al., 1993; Hazzard, Celano, Gould, Lawry, \& Webb, 1995; Quas et al., 2003). While playing, the adult transgressor "broke the puppet" (which was designed to break), and exclaimed: Oh no! I broke it! We shouldn't have touched these puppets when we were told not to. I'll just put them away and maybe nobody will notice. Let's have this be our secret and not tell anybody that the puppet broke. We might get into trouble if anyone 
finds out! The adult transgressor put all of the puppets back into the box, burying the broken puppet in the bottom, and quickly left the room to see if RA1 was back. This broken puppet paradigm was also used in previous studies with a similar age group, and children rarely expressed any suspicion (Malloy \& Mugno, 2016).

While the child was experiencing the first aid and safety stations, mothers were trained on how to accidentally "break" the puppet and on brief, scripted language if they had been randomly assigned to the parent transgressor condition. Mothers first watched a training video with two RAs demonstrating the transgression, while following along with a document of the scripted language. Then, an RA broke down the transgression into two parts to facilitate learning the script, and demonstrated each part before asking the mother to practice that respective part. Before the mother conducted the transgression with the child, she then practiced the entire transgression twice more. The RA provided feedback as necessary. A hidden video camera in the study room allowed for fidelity checks.

Honesty-promotion techniques. Research assistant one (RA1) re-entered the room, thanked the child for waiting, and told the child they would get started on the next task. Then, RA1 proceeded to play a story for the child on a computer tablet and said to the child: Pay close attention because I will have some questions for you about it. The child listened to an audio recording of a story, while following along with pictures displayed on a computer tablet screen (Kesek et al., 2011). The sex of the child in the stories matched the sex of the participating child.

Children in the prime condition heard a story laden with words associated with honesty, whereas children in the oath and control conditions heard a neutral story so that children in all three conditions completed similar tasks and experienced the same delay 
before they were asked about what happened when RA1 was out of the room. Both stories were 215 words in length and were parallel in content. The story intended to prime honesty is written below, with the 15 words (Eaton, Visser, \& Burns, in press) associated with honesty in boldface. Notably, the honesty words were not associated with the moral character of any of the actors in the story.

Diane was a young girl who truly liked when her babysitter baked cookies. The truth is her younger brother liked sugar cookies, but Diane's favorite cookies were certainly chocolate chip. One afternoon, Diane came home from school to find chocolate chip cookies freshly baked and sitting on top of the kitchen counter. She thought they smelled really delicious! She sat in front of them, and was honestly tempted to eat just one. In fact, she began to reach for a cookie, but stopped herself. The truth is her babysitter would not want her to eat any sweets before dinner. A few minutes later, Diane's babysitter came downstairs and saw Diane sitting in front of the cookies. Her babysitter asked, "Do you want one of the cookies?" Diane replied, "Of course!" The honest truth is she could not wait another minute. With a smile on her face, Diane's babysitter said, "I honestly hoped you would be excited. Actually, guess what? It's your lucky day. If I counted correctly, I made exactly 12 cookies to take to work with me tomorrow, which means I have one extra cookie." She handed Diane the cookie. With a grin, Diane quickly bit into the cookie. It was truly yummy! She thought, "I honestly hope my babysitter can make some more!"

The neutral story is written below. The words replacing the honesty words in the prime condition are underlined. 
Diane was a young girl who always liked when her babysitter baked cookies. When it came to cookies, her younger brother liked sugar cookies, but Diane's favorite cookies were clearly chocolate chip. One afternoon, Diane came home from school to find chocolate chip cookies freshly baked and sitting on top of the kitchen counter. She thought they smelled so delicious! She sat in front of them, and was very tempted to eat just one. She even began to reach for a cookie, but stopped herself. The thing is her babysitter would not want her to eat any sweets before dinner. A few minutes later, Diane's babysitter came downstairs and saw Diane sitting in front of the cookies. Her babysitter asked, "Do you want one of the cookies?" Diane replied, "Of course!" She felt like she could not wait another minute. With a smile on her face, Diane's babysitter said, "I had hoped you would be excited. And guess what? It's your lucky day. I counted them, and think I made only 12 cookies to take to work with me tomorrow, which means I have one extra cookie." She handed Diane the cookie. With a grin, Diane quickly bit into the cookie. It was so yummy! She thought, "I wish my babysitter could make some more!"

Soon after the story finished, RA1 pretended to receive a text message from his/her friend and stated: My friend is about to come back for this box of puppets, so let me put it back outside for her. While walking out of the room to leave the box of puppets for the friend, RA1 peered into the box and hesitated as if to notice that something was different about the puppets. When RA1 walked back into the room, he/she stated: Before we go on to the next activity, I have some questions to ask you. I'm just going to make some notes so that I don't forget what you say. In the oath condition, the child was then 
asked: Can you promise that you will tell me the truth? Will you tell me any lies?

Asking both of these questions requires that children respond with a "yes" and "no," thus avoiding children simply responding "yes" to a question posed by an adult because of the relatively common "yay saying" biases of children (Lyon et al., 2008; Peterson, Dowden, \& Tobin, 1999). Children were asked these questions a second time if the correct responses were not elicited the first time. However, regardless of the child's responses to these questions the second time, RA1 still proceeded with the interview. In the prime and control conditions, no additional questions were asked before proceeding with the interview.

Interviews. A series of questions was asked to examine the effectiveness of the honesty-promotion techniques across different question types. We used a funnel approach for questioning children which is consistent with best-practice protocols for interviewing child witnesses and victims (e.g., National Institute of Child Health and Human Development (NICHD) Investigative Interview Protocol; Orbach et al., 2000). Following the appropriate instructions, the child was first asked an open-ended question: Tell me what happened while I was gone and you were waiting for me with [adult transgressor (mother or RA2)]. All responses were followed up with two Tell me more prompts (i.e., You said X. Tell me more about X.). If the child mentioned anything about the transgression or the puppets more broadly, RA1 followed up on these responses first. After the child provided free recall about what happened, RA1 stated: I'm going to ask you a few more questions. If you've already told me the answers to any of these questions, just tell me again. Then, RA1 proceeded to ask a series of direct questions (Lyon et al., 2008; Malloy \& Mugno, 2016). First, the child was asked: Did something 
bad happen while I was gone and you were waiting for me with [adult transgressor]? The word "something" was used instead of "anything" because previous research suggests that children are more likely to elaborate on a response when the question is framed in the form of the presence of an event (i.e., positive polarity term) rather than absence of an event (i.e., negative polarity term; Evans, Stolzenberg, Lee, \& Lyon, 2014). Research assistant one (RA1) paused after the child's response to allow the child time to elaborate on a potential "yes" or "no" response.

Next, three direct questions were asked that concerned the child's behaviors: While I was gone, did you (1) touch any of the puppets? (2) play with any of the puppets? (3) break any of the puppets? Also, three direct questions were asked that concerned the adult transgressor's behaviors: While I was gone, did [adult transgressor] (1) touch any of the puppets? (2) play with any of the puppets? (3) break any of the puppets? We counterbalanced whether children were first asked the direct questions about their own or the adult transgressor's behaviors. Finally, although not recommended as part of bestpractice protocols, suggestive or leading questions were asked given research evidence that these types of questions are still used frequently by interviewers and attorneys (Klemfuss, Quas, \& Lyon, 2014; Stolzenberg \& Lyon, 2014), and thus there was a need to determine whether and how priming affects children's responses to these question types. Specifically, children were asked a series of suppositional questions (Lyon et al., 2008). Research assistant one (RA1) stated: I could tell that someone used the puppets. I have a few more questions, so, once again, if you've already told me the answer to any of these questions, just tell me again. Then, RA1 asked: (1) When you touched the puppets, did you take them all out of the box?, (2) When you played with the puppets, which one 
were you holding?, (3) When you broke the puppet, were you happy or mad? Parallel questions were asked about the adult transgressor's behavior. Again, we counterbalanced whether children were first asked these suppositional questions about their own or the adult transgressor's behaviors.

Manipulation checks. After the suppositional interview questions, children were asked three questions to assess their memory for the content of the prime or neutral story (Kesek et al., 2011). Research assistant one (RA1) stated: Let's move on. I have some questions to ask you about the story you listened to on the computer about Diane/Derek: (1) Where did Diane/Derek find the cookies?, (2) Who made the cookies?, (3) What were the cookies for? Children were also asked three questions to assess their awareness of any association between the story and the puppet breaking: (1) Did you think that the story had anything to do with the puppets?, (2) Did you think about Diane/Derek when you answered my questions about the puppets?, (3) Did thinking about Diane/Derek have anything to do with the answers you gave me to the questions about the puppets? Finally, children were asked three questions to inquire about their feelings toward the prime and neutral stories using a scale of 1 (not at all) to 5 (very). These questions were asked to assess whether children's feelings about the two different stories were parallel. Research assistant one (RA1) asked: (1) How easy was the story to understand?, (2) How much did you like the story?, (3) How happy did the story make you feel?

Debriefing. Each child was debriefed by RA1 using procedures from similar studies (e.g., Malloy \& Mugno, 2016). The adult transgressor (mother or RA2) was always present for the debriefing session. First, RA1 said: I knew that you and [adult transgressor] would probably play with the puppets, and that's okay. [Adult 
transgressor] played with one of the puppets and it seemed to break, but that's because it was already broken since the puppets are fragile. [Adult transgressor] asked you to keep it a secret because she was helping us learn more about instances where children may be afraid to tell adults the truth. Nobody will get into trouble for playing with or breaking the puppets. Then, RA1 asked the child: Did you tell me the truth about the puppet? Depending upon the child's response, RA1 asked: Why did you [decide to/decide not to] tell me the truth about the puppet? Finally, RA1 stated: I know it can be hard to tell adults the truth sometimes, but you did a great job answering all of my questions. Just remember that it's always important to tell adults the truth about things. Do you have any questions? Following the debriefing, the child was allowed to choose a small prize from a prize box of toys, and the child and mother received a $\$ 50$ gift card for their participation.

Child questionnaires. During the study session, all children also completed the Early Childhood Generalized Trust Belief Scale (Betts, Rottenberg, \& Trueman, 2009) to assess their levels of interpersonal trust with mothers, fathers, teachers, and peers, and the Attachment Security Scale (Kerns, Klepac, \& Coles, 1996) to assess the quality of their relationship with their mother. One questionnaire was administered directly after the child assent, and the other questionnaire was administered before the child debriefing. The order of these child questionnaires were counterbalanced.

Early Childhood Generalized Trust Belief Scale (ECGTBS). The 24-item ECGTBS was designed for use with 5- to 8-year-olds and focuses on emotional trust (e.g., Emma scratches one of her new shoes. Emma asks her dad not to tell her mom about it. How sure are you that Emma's dad will not tell her mom about it?), reliability 
(e.g., Christina's mom promised that she would buy Christina some candy. How sure are you that Christina's mom will buy some candy for Christina?), and honesty (e.g., The teacher of Amy's class said that the class was going to watch a video instead of doing some work. The teacher said that the video was lost. How sure are you that the video was lost?), the bases of Rotenberg's (1994) framework for interpersonal trust. There were two items for each target person (i.e., mother, father, teacher, or peer) for each basis of interpersonal trust. Research assistant one (RA1) read each item aloud to the children, and the children responded on a 1 (very unsure) to 5 (very sure) Likert scale. To assist children in responding, they were shown a visual aid with stars representing each point on the Likert scale. Children were told that the more stars they chose, the more sure they were. Names and terms on the scale were slightly modified to increase its suitability for the study sample (e.g., "mom" instead of "mum"; "chips" instead of "crisps"). Also, all child names used on the scale corresponded to the sex of the child participant. In previous research (Betts et al., 2009), the ECGTBS has demonstrated good validity, acceptable test-retest reliability, and modest levels of internal consistency ( $\alpha=.72$ to .79 ). Four mean scores were created to represent children's trust in their mother, father, teacher, and peers, with higher scores indicating greater trust in that individual $(\alpha .=.82$ across all items).

Attachment Security Scale. The 15-item Attachment Security Scale was designed for use in middle childhood and early adolescence and requires the children to first decide which of two kids they are more like (e.g., Some kids find it easy to trust their mom. But other kids are not sure if they can trust their mom) and then decide whether that statement is "sort of true" for them or "very true" for them. Research assistant one 
(RA1) read each of the 15 items aloud to the children, including one final item that more broadly asked how the children felt about their mom. For this item, children were asked to choose one of three options that best described the way they felt about their mom: (1) I like to do things by myself rather than ask my mom for help. Sometimes it's hard for me to count on her or tell her what I am thinking or feeling; (2) I'm really close to my mom. I know my mom always listens when I tell her things. I know she'll be there if I need her; (3) Sometimes I wish my mom and I were closer. It also sometimes seems like my mom gets in the way when I'm trying to do things. In previous research (Kerns et al., 1996), the Attachment Security Scale has demonstrated adequate convergent validity, discriminant validity, test-retest reliability, and internal consistency ( $\alpha=.81$ to .93$)$. A mean score was created from the 15 items after six items were reverse scored, with higher scores representing that the children had a more secure attachment with their mother $(\alpha .=$ .55 across all items).

Parent questionnaires. While their children participated in the study session, mothers were asked to complete a brief demographic questionnaire, the Child-Parent Relationship Scale (Pianta, 1992) to assess the quality of their relationship with their child, and the Parenting Styles and Dimensions Questionnaire (Robinson, Mandleco, Olsen, \& Hart, 2001) to assess parenting behaviors. Mothers were also asked to note the contact information of families they thought might be interested in participating in the present study and whether they were interested in being contacted for future studies by the research team or other research teams at the university. Then, all mothers received a brochure on child development and lie-telling (see Appendix). Finally, when the children were choosing their prizes at the conclusion of the study session, mothers were asked to 
rate how satisfied they were with the study experience on a 1 (completely dissatisfied) to 5 (completely satisfied) Likert scale. They could also leave any comments for the research team. All ratings were anonymous, and parents dropped their ratings into a box before leaving.

Child-Parent Relationship Scale (CPRS). The 30-item CPRS was designed for 3- to 12-year-olds and focuses on conflicts in the relationship (e.g., My child and I always seem to be struggling with each other), positive aspects of the relationship (e.g., I share an affectionate, warm relationship with my child), and dependence within the relationship (e.g., My child is overly dependent on me). Mothers responded on a 1 (definitely does not apply) to 5 (definitely applies) Likert scale. In previous research (Driscoll \& Pianta, 2011; Pianta, 1992), the CPRS has demonstrated adequate validity, test-retest reliability, and internal consistency $(\alpha=.83, .72$, and .50 for the conflicts, positive aspects, and dependence subscales, respectively). For the present study, Cronbach's alphas for the conflicts, positive aspects, and dependence subscales were $.83, .72$, and .51 , respectively. First, a sum score was created for each subscale (i.e., conflicts in the relationship, positive aspects of the relationship, and dependence within the relationship). Next, a total raw score was calculated using the formula $(72$ - conflicts sum score $)+$ positive aspects sum score $+(24-$ dependence sum score $)$. The 72 represented the highest possible score on the conflicts subscale (60) added to the lowest possible score on the conflicts subscale (12), and the 24 represented the highest possible score on the dependence subscale (20) added to the lowest possible score on the dependence subscale (4). Higher total raw scores represented better mother-child relationship quality. 
Parenting Styles and Dimensions Questionnaire (PSDQ). The 32-item PSDQ-

Short Form was designed for use with toddlers through childhood and assesses

Baumrind's (1971) authoritative (e.g., I am responsive to my child's feelings and needs), authoritarian (e.g., I use physical punishment as a way of disciplining my child), and permissive (e.g., I find it difficult to discipline my child) parenting styles. Mothers responded using a 1 (never) to 5 (always) Likert scale. In previous research (Robinson et al., 2001), the PSDQ-Short Form has demonstrated good validity and adequate internal consistency ( $\alpha=.86, .82, .64$ for the authoritative, authoritarian, and permissive parenting styles, respectively). For the present study, Cronbach's alphas for the authoritative, authoritarian, and permissive parenting styles were $.74, .73$, and .69 , respectively. A sum score was created for each of the three parenting styles. Higher scores for each parenting style were more representative of that parenting style.

Study ethics. The broken puppet paradigm and debriefing protocol was used in this study and in many previous IRB-approved studies by the same research team with no adverse events (Malloy \& Mugno, 2016). Other researchers have used these paradigms and protocols without incident, as well (Talwar et al., 2004). During the child assent process, the child was informed that they could discontinue their participation or take a break at any point. The RAs were also prepared to modify and/or discontinue the study protocol if the child became upset or anxious. The breaking of the puppet (minor wrongdoing) and subsequent questions asked of the children were no different than what children may experience on a daily basis in school or at home. Additionally, children were never coerced to lie about the circumstances of the broken puppet. Rather, the adult transgressor simply requested that children keep the wrongdoing a secret, and children 
chose how to behave. All interactions with the children were positive, and children appeared to find participation enjoyable (e.g., Malloy \& Mugno, 2016). The study procedures were thoroughly explained to the parents during the informed consent process, and any questions were answered before the study began. On average, parents rated their satisfaction with the study experience as a 4.96 (with 5 being completely satisfied).

\section{Coding and Data Reduction}

The transgressor-child interactions and RA1 interviews with the child were transcribed verbatim to check for script adherence and to code the children's responses. Coding of the primary dependent variables was completed by two independent coders who first achieved a Cohen's kappa $\geq .75$ on $20 \%$ of the sample (see Table 4 ). The primary dependent variables included children's responses to the open-ended, direct, and suggestive questions about the puppets. See Table 5 for a complete description of the child interview questions and how they were coded.

First, in response to the open-ended question (Tell me what happened while I was gone and you were waiting for me with [adult transgressor]), coders recorded spontaneous mentions that the adult broke the puppet $(0=$ did not say the adult broke the puppet, 1 = said the adult broke the puppet). Children who only mentioned that the puppet broke but did not specify who broke the puppet or said that they broke the puppet received a score of 0 . Second, in response to the first direct question (Did something bad happen while I was gone and you were waiting for me with [adult transgressor]?), coders first recorded whether children told the truth and said "yes" (1) or did not tell the truth and said "no" or "I can't say" (0). Coders also recorded spontaneous mentions that the 
adult broke the puppet $(0=$ did not say the adult broke the puppet, $1=$ said the adult broke the puppet). Again, children who only mentioned that the puppet broke and did not specify who broke the puppet or said that they broke the puppet received a score of 0 . If children responded that both they and the adult broke the puppet, they also received a score of 0 since the response was not entirely truthful.

Third, for each direct and suggestive question (see Table 5), coders indicated whether the children did not tell the truth (0) or told the truth (1). Four sum scores were then created $(0=$ did not tell any truths, $3=$ told all truths $)$ for: $(1)$ direct questions about the child, (2) direct questions about the transgressor, (3) suggestive questions about the child, and (4) suggestive questions about the transgressor, thus providing a range of how willing children were to admit wrongdoing. For the direct questions, children who did not provide a response to the question, did not respond to the specific question asked, or responded with "don't know" received a score of "0" for that particular question since they did not tell the truth. For the suggestive (i.e., suppositional) questions, coders indicated that the children admitted that they or the transgressor touched, played with, or broke the puppet (and this was subsequently scored for whether it was the truth) unless the children explicitly said that they did not do so. For example, if children responded "no" to When you touched the puppets, did you take them all out of the box?, this would count as an admission that they still touched the puppets. If children responded "police officer" to When you played with the puppets, which one were you holding?, this would count as an admission that they played with the puppets. Finally, if children responded "mad" to When you broke the puppet, were you happy or mad?, this would count as an admission that they broke the puppet. If children did not provide a response to the 
question, did not answer the specific question asked, or responded with "don't know", this was scored as an admission of the presupposed action.

Sum scores were also created for the memory $(0=$ all incorrect, $3=$ all correct $)$ and awareness $(0=$ no awareness of an association, $3=$ complete awareness $)$ manipulation check questions. These questions assessed whether children remembered the content of the prime or neutral story and whether they were aware of any association between the story and puppet breaking. Finally, a sum score was created for each child for the manipulation check questions that inquired about the child's feelings about the story. Sum scores could range from 3 to 15 since each of the three questions was rated on a 1 to 5 scale.

Finally, as an exploratory analysis, we examined children's responses to the debriefing questions. Coding of the debriefing questions was completed by two independent coders who first achieved a Cohen's kappa $\geq .78$ on $20 \%$ of the sample (see Table 6). First, we coded the accuracy of children's responses to Did you tell me the truth about the puppet? $(0=$ not accurate, $1=$ accurate $)$. Children were considered to have told the truth if they said that the puppet broke at any point during the interview. They did not have to specify that the transgressor broke the puppet; however, if children said that they broke the puppet, this was considered a lie. Second, responses to Why did you decide to tell me the truth about the puppet? were coded into the following five categories: (1) moral reasoning (e.g., "It [puppet breaking] was bad”, It's important to tell the truth", "I told you I would", "I have trouble keeping secrets"), (2) desire to avoid trouble (e.g., "I didn't want to get into trouble"), (3) concern for others (e.g., "I didn’t want to not tell and her friend to find out it was broken", "You asked me"), (4) multiple 
reasons (e.g., "Because I tell the truth to grown-ups, and I don't want to get into trouble if I lie”), or (5) non-explanatory (e.g., "I wanted to", "I don’t know”, "I knew it was a trick", nonsensical, no response). Third, responses to Why did you decide not to tell me the truth about the puppet? were coded into the following five categories: (1) secretkeeping (e.g., "She told me to keep it a secret"), (2) desire to avoid trouble (e.g., "I didn't want to get into trouble"), (3) concern for others (e.g., "Because your friend would be mad"), (4) general worry (“I was scared"), or (5) non-explanatory (e.g., "I don’t know", no response).

\section{Data Analysis Plan}

Preliminary analyses. First, chi-square analyses were conducted to ensure the equivalence of child age, child sex, child ethnicity, child race, parental education, and family income across the randomly assigned honesty-promotion technique and transgressor identity conditions. Second, three 3 (Honesty-Promotion Technique) x 2 (Transgressor Identity) ANOVAs were conducted to test the equivalence of the sum scores concerning children's responses to the memory, awareness, and feelings about the story manipulation check questions across the randomly assigned conditions. Third, chisquare and ANOVA analyses examined the effects of child and family demographics (i.e., child sex, child ethnicity, child race, parental education, family income) on the primary dependent variables. If there were any significant demographic effects, we considered using these variables as covariates in the primary analyses. Fourth, ANOVA analyses were conducted to examine the effects of the child questionnaire counterbalancing (i.e., ECGTBS or Attachment Security Scale first) on responses to the ECGTBS and Attachment Security Scale questionnaires, and chi square and ANOVA 
analyses were conducted to examine the effects of the child questionnaire counterbalancing and the counterbalancing of the child and transgressor questions for both the direct and suggestive questions on the primary dependent variables. Fifth, the primary analyses were run excluding those children who did not correctly respond to the oath (i.e., appropriately answer "yes" and "no", respectively, to Can you promise that you will tell me the truth? and Will you tell me any lies?) after being asked up to two times. These analyses were compared to the full sample analyses to examine whether the same pattern of results emerged. Finally, the primary analyses were run excluding those children who disclosed that the adult broke the puppet before the honesty-promotion technique was administered, and again, these analyses were compared to the full sample analyses to examine whether the same pattern of results emerged.

Primary analyses. First, we conducted three binary logistic regression analyses with honesty-promotion technique (which was dummy coded), transgressor identity $(0=$ Mother , $1=\mathrm{RA})$, and age $(0=6$ to 7 years, $1=8$ to 9 years $)$ entered in the first step of the model and the Honesty-Promotion Technique $\mathrm{x}$ Transgressor Identity and HonestyPromotion Technique $\mathrm{x}$ Age interactions entered in the second step of the model predicting our three dichotomous dependent variables: (1) whether the child spontaneously mentioned that the adult broke the puppet to the open-ended question, (2) whether the child admitted (yes or no) that something bad had happened when asked, Did something bad happen while I was gone and you were waiting for me with [adult transgressor]?, and (3) whether the child spontaneously mentioned that the adult broke the puppet when asked this same question. Second, we conducted four ordinal logistic regressions with honesty-promotion technique (which was dummy coded), transgressor 
identity $(0=$ Mom, $1=$ RA), and age $(0=6$ to 7 years, $1=8$ to 9 years $)$ entered in the first step of the model and the Honesty-Promotion Technique x Transgressor Identity and Honesty-Promotion Technique x Age interactions entered in the second step of the model predicting the sum scores for the direct and suggestive questions.

\section{CHAPTER V}

\section{RESULTS}

\section{Preliminary Analyses}

Equivalence of study conditions in demographic characteristics. Chi-square analyses revealed no significant child demographic differences in the honesty-promotion technique or transgressor identity conditions (see Table 7). Specifically, the honestypromotion conditions did not significantly differ by age ( 6 to 7 v. 8 to $9 ; \chi^{2}(2, N=115)=$ $.11, p=.945), \operatorname{sex}\left(\chi^{2}(2, N=115)=.07, p=.968\right)$, ethnicity $\left(\chi^{2}(2, N=115)=1.71, p=\right.$ $.426)$, or race $\left(\chi^{2}(4, N=115)=4.15, p=.387\right)$. The transgressor identity conditions also did not significantly differ by age $\left(\chi^{2}(1, N=115)=.01, p=.935\right)$, sex $\left(\chi^{2}(1, N=115)=\right.$ $.01, p=.943)$, ethnicity $\left(\chi^{2}(1, N=115)=.18, p=.678\right)$, or race $\left(\chi^{2}(2, N=115)=1.12, p\right.$ $=.572)$.

Chi-square analyses only revealed one significant family demographic difference across the conditions. The transgressor identity conditions differed significantly by highest parental education, $\chi^{2}(1, N=113)=3.60, p=.058$. Seventy-three percent of children in the RA transgressor condition had at least one parent with a Bachelor's degree or higher, whereas only $56 \%$ of children in the mother transgressor condition had at least one parent with a Bachelor's degree or higher. However, the transgressor identity conditions did not significantly differ by total annual family income, $\chi^{2}(1, N=114)=$ 
$1.29, p=.297$. Also, the honesty-promotion conditions did not significantly differ by highest parental education $\left(\chi^{2}(2, N=113)=.52, p=.771\right)$ and total annual family income (below $\$ 45,000$ or above $\left.\$ 45,000, \chi^{2}(2, N=114)=.13, p=.136\right)$.

\section{Equivalence of study conditions in children's responses to manipulation}

check questions. Three 3 (Honesty-Promotion Technique) x 2 (Transgressor Identity)

ANOVAs revealed no significant difference between the conditions on the sum scores for the memory, awareness, and feelings about the story manipulation check questions. That is, there was no significant effect of honesty-promotion technique, $F(2,108)=2.17, p=$ .120 , transgressor identity, $F(1,108)=2.95, p=.089$, and no significant interaction of Honesty-Promotion Technique $\mathrm{x}$ Transgressor Identity, $F(2,108)=.76, p=.471$, on the story memory sum score. Generally, children answered most of the three story memory questions correctly $(M=2.69, S D=.60)$. There was also no significant effect of honestypromotion technique, $F(2,105)=.35, p=.702$, transgressor identity, $F(1,105)=3.09, p$ $=.082$, and no significant interaction of Honesty-Promotion Technique $\mathrm{x}$ Transgressor Identity, $F(2,105)=1.93, p=.150$, on the story awareness sum score. Generally, children were not aware of any association between the computer stories and interview questions $(M=.85, S D=.96)$. Finally, there was no significant effect of honestypromotion technique, $F(2,109)=.02, p=.980$, transgressor identity, $F(1,109)=3.35, p$ $=.070$, and no significant interaction of Honesty-Promotion Technique $\mathrm{x}$ Transgressor Identity, $F(2,109)=.51, p=.600$, on the story feelings sum score. Generally, children enjoyed the stories and thought they were easy to understand $(M=12.40, S D=.89)$. See Table 8 for a breakdown of the means and standard deviations for the story memory, story awareness, and story feelings sum scores across conditions. 
Effects of demographic characteristics on primary dependent variables. Chi square and ANOVA analyses revealed no significant effect of any of the child demographic variables on the primary dependent variables (see Tables 9 to 14). However, there was a significant effect of one family demographic variable: Children of families who had at least one parent with a Bachelor's degree or greater had higher sum scores for the suggestive questions about their own behavior $(M=2.51, S D=.67)$ than children who did not have at least one parent with a Bachelor's degree $(M=2.03, S D=$ $.86), F(1,110)=11.09, p=.001$. Family income did not significantly affect any of the primary dependent variables (see Tables 15 to 18 for the family demographic variables analyses). Because the transgressor identity conditions significantly differed by parental education, we ran all of our primary analyses with and without parental education as a covariate. The pattern of results remained the same, and thus, we report the primary analyses without this covariate.

\section{Effects of questionnaire counterbalancing on questionnaire scores and}

primary dependent variables. Two one-way ANOVAs revealed no significant effects of the counterbalancing of the child questionnaires (i.e., ECGTBS or Attachment Security Scale first) on children's responses to each scale. Three chi-square and four one-way ANOVAs also revealed no significant effects of the order that children received the ECGTBS and Attachment Security Scale on any of the primary dependent variables. Finally, six one-way ANOVAs revealed that the order in which the direct and suggestive questions were asked (i.e., child or transgressor questions first) did not significantly affect children's responses to any of the subsequent interview questions. Specifically, four one-way ANOVAs were conducted to examine the effects of the counterbalancing of 
the direct questions on the sum scores for each set (i.e., child and transgressor) of direct and suggestive questions. Two one-way ANOVAs were conducted to examine the effects of the counterbalancing of the suggestive questions on the sum scores for the child and transgressor suggestive questions.

\section{Effects of incorrect responses to the oath on primary dependent variables.}

There were four children who did not correctly respond to both questions of the oath. For example, some of these children responded "I don't know" or "I'm not sure" to one or both of the oath questions. The primary analyses were conducted with and without these children, and the same pattern of results emerged. Therefore, all primary analyses are reported with these children included.

Effects of early disclosure on primary dependent variables. There were four children who disclosed that the adult broke the puppet before the honesty-promotion technique was administered (i.e., disclosure before the prime story in the prime condition, disclosure before the oath in the oath condition). The primary analyses were conducted with and without these children, and the same pattern of results emerged. All primary analyses are reported with these children included, as well.

\section{Primary Analyses}

Almost all children $(94 \%, n=108)$ disclosed at some point during the interview that the transgressor had broken the puppet. However, the number of children disclosing their own and the adult's transgressions varied across question type.

Open-ended question. Overall, $45 \%(n=52)$ of children spontaneously said that the adult broke the puppet to the open-ended question, Tell me what happened while I was gone and you were waiting with [adult transgressor], and the associated follow-up 
prompts. A binary logistic regression was conducted with honesty-promotion technique (dummy coded with priming as the reference group first), transgressor identity $(0=$ Mom, $1=\mathrm{RA})$, and age ( $0=6$ to 7 years, $1=8$ to 9 years $)$ entered in the first step of the model and the Honesty-Promotion Technique $\mathrm{x}$ Transgressor Identity and Honesty-Promotion Technique $\mathrm{x}$ Age interactions entered in the second step of the model predicting whether children spontaneously disclosed that the adult broke the puppet $(0=$ did not say the adult broke the puppet, 1 = said the adult broke the puppet). Then, the binary logistic regression was run again using a dummy-coded system with the oath condition serving as the reference group. The model was not significant at the first step, $\chi^{2}(4, N=115)=$ $5.61, p=.234$, or at the second step when the interaction terms were added, $\chi^{2}(8, N=$ $115)=9.38, p=.311($ see Tables 19 and 20). That is, honesty-promotion technique (prime $=34 \%$, oath $=56 \%$, control $=47 \%)$, transgressor identity $($ Mom $=42 \%, \mathrm{RA}=$ $48 \%$ ), and age (6 to $7=40 \%, 8$ to $9=51 \%$ ) did not significantly predict whether children spontaneously disclosed that the adult broke the puppet to the open-ended question, nor did any of the interaction terms (see Figure 2).

Direct question about something bad happening. First, we examined the dichotomous variable of whether children admitted "yes" or "no" that something bad had happened when questioned directly about this. Overall, 59\% $(n=68)$ of children admitted that "yes" something bad had happened. A binary logistic regression was conducted with honesty-promotion technique (dummy coded with priming as the reference group first), transgressor identity $(0=\mathrm{Mom}, 1=\mathrm{RA})$, and age $(0=6$ to 7 years, $1=8$ to 9 years) entered in the first step of the model and the Honesty-Promotion Technique x Transgressor Identity and Honesty-Promotion Technique x Age interactions 
entered in the second step of the model predicting whether children admitted that something bad had happened $(0=$ did not tell the truth and said "no" or "I can't say, $1=$ told the truth and said "yes" something bad happened). Then, the binary logistic regression was run again using a dummy-coded system with the oath condition serving as the reference group. The overall model at the first step was significant, $\chi^{2}(4, N=115)=$ $10.15, p=.038$, and correctly classified $68 \%$ of the cases, Nagelkerke $R^{2}=.114$. Children in the RA transgressor condition were 2.56 times more likely to admit that "yes" something bad had happened (70\%) than children who were in the mother transgressor condition (49\%), Wald $=3.14, p=.019$. Also, there was a trend such that children in the oath condition (69\%) were 2.41 times more likely to admit that "yes" something bad had happened than children in the prime condition $(51 \%)$, Wald $=3.14, p=.076$. There were no significant differences between both of these honesty-promotion techniques and the control condition (58\%). Furthermore, age did not significantly predict whether children were more likely to admit that something bad had happened ( 6 to $7=53 \%, 8$ to $9=65 \%$ ). Adding the interaction terms at the second step did not contribute to a significant increase in explained variance. In fact, the model testing the interactions was not significant, $\Delta \mathrm{R}^{2}$ $=.032, \chi^{2}(8, N=115)=13.14, p=.107($ see Tables 21 and 22, Figure 3$)$.

Second, we examined children's spontaneous mentions that the adult broke the puppet when asked if something bad had happened. Overall, only $16 \%(n=18)$ of children spontaneously mentioned that the adult broke the puppet when asked if something bad had happened while RA1 was out of the room. A binary logistic regression was conducted with honesty-promotion technique (dummy coded with priming as the reference group first), transgressor identity $(0=$ Mom, $1=\mathrm{RA})$, and age $(0$ 
$=6$ to 7 years, $1=8$ to 9 years) predicting whether children spontaneously mentioned the adult broke the puppet when asked if something bad had happened $(0=$ did not say the adult broke the puppet, $1=$ said the adult broke the puppet). Because few children disclosed the adult wrongdoing to this question, the interaction terms were not added to the second step of the model. Then, the binary logistic regression was run again using a dummy-coded system with the oath condition serving as the reference group. The overall model was not significant, $\chi^{2}(4, N=115)=5.51, p=.239$. That is, honesty-promotion technique $($ prime $=15 \%$, oath $=17 \%$, control $=16 \%)$, transgressor identity $($ Mom $=8 \%$, $\mathrm{RA}=23 \%)$, and age ( 6 to $7=13 \%, 8$ to $9=18 \%)$ did not significantly predict whether children spontaneously mentioned that the adult broke the puppet when asked if something bad had happened (see Tables 23 and 24, Figure 4).

Direct questions about the child's behavior. Overall, the mean sum score for the direct questions about the child's behavior was $2.27(S D=.82)$. An ordinal logistic regression was conducted with honesty-promotion technique (dummy coded with priming as the reference group first $)$, transgressor identity $(0=$ Mom, $1=\mathrm{RA})$, and age $(0$ $=6$ to 7 years, $1=8$ to 9 years) entered in the first step of the model and the HonestyPromotion Technique x Transgressor Identity and Honesty-Promotion Technique x Age interactions entered in the second step of the model predicting children's sum scores on the direct questions about their own behavior. Then, the ordinal logistic regression was run again using a dummy-coded system with the oath condition serving as the reference group. The first step of the model was not significant, $\chi^{2}(4, N=114)=6.62, p=.158$. Honesty-promotion technique (prime: $M=2.10, S D=.90$; oath: $M=2.42, S D=.77$; control: $M=2.32, S D=.78$ ), transgressor identity (Mom: $M=2.19, S D=.81$; RA: $M=$ 
2.36, $S D=.84$ ), and age (6 to $7: M=2.17, S D=.85 ; 8$ to $9: M=2.38, S D=.78$ ) did not account for a significant amount of overall variance in the child direct sum scores. Similarly, the second step of the model was not significant, $\chi^{2}(8, N=114)=10.20, p=$ .251 (see Tables 25 and 26, Figure 5).

Direct questions about the transgressor's behavior. Overall, the mean sum score for the direct questions about the transgressor was $2.04(S D=1.28)$. An ordinal logistic regression was conducted with honesty-promotion technique (dummy coded with priming as the reference group first $)$, transgressor identity $(0=$ Mom, $1=\mathrm{RA})$, and age $(0$ $=6$ to 7 years, $1=8$ to 9 years) entered in the first step of the model and the HonestyPromotion Technique x Transgressor Identity and Honesty-Promotion Technique x Age interactions entered in the second step of the model predicting children's sum scores to the direct questions about the transgressor's behavior. Then, the ordinal logistic regression was run again using a dummy-coded system with the oath condition serving as the reference group. When entered in the first step, honesty-promotion technique, transgressor identity, and age accounted for a significant amount of overall variance in the transgressor direct sum scores, $\chi^{2}(4, N=114)=11.31, p=.023$. The ordered logit regression coefficient representing transgressor identity was statistically significant, $B=$ $1.10, p=.005$. That is, children in the RA transgressor condition were 2.99 times more likely to tell an additional truth to the direct questions about the transgressor than those in the mother transgressor condition. On average, the transgressor direct sum score was $2.37(S D=1.07)$ for children in the RA transgressor condition and $1.71(S D=1.38)$ for children in the mother transgressor condition. However, neither honesty-promotion technique (prime: $M=1.80, S D=1.34$; oath: $M=2.22, S D=1.20$; control: $M=2.11, S D$ 
$=1.27$ ) nor age (6 to $7: M=1.97, S D=1.29 ; 8$ to $9: M=2.11, S D=1.27$ ) significantly predicted the transgressor direct sum scores. When the interaction terms were entered in the second step, the model was not significant, $\chi^{2}(8, N=114)=13.91, p=.084$ (see Tables 27 and 28, Figure 6).

Suggestive questions about the child's behavior. Overall, the mean sum score for the child suggestive questions was $2.32(S D=.80)$. An ordinal logistic regression was conducted with honesty-promotion technique (dummy coded with priming as the reference group first), transgressor identity $(0=$ Mom, $1=$ RA), and age $(0=6$ to 7 years, $1=8$ to 9 years) entered in the first step of the model and the Honesty-Promotion Technique $\mathrm{x}$ Transgressor Identity and Honesty-Promotion Technique x Age interactions entered in the second step of the model predicting children's sum scores to the suggestive questions about the children's own behavior. Then, the ordinal logistic regression was run again using a dummy-coded system with the oath condition serving as the reference group. The first model was not significant, $\chi^{2}(4, N=114)=1.73, p=.786$. Honestypromotion technique (prime: $M=2.38, S D=.78$; oath: $M=2.33, S D=.86$; control: $M=$ $2.24, S D=.79)$ transgressor identity (Mom: $M=2.22, S D=.90 ;$ RA: $M=2.41, S D=.68)$ and age (6 to $7: M=2.32, S D=.80 ; 8$ to $9: M=2.31, S D=.81)$ did not account for a significant amount of overall variance in the child suggestive sum scores. When the interaction terms were entered in the second step, the model was still not significant, $\chi^{2}(8$, $N=114)=8.63 p=.374,($ see Tables 29 and 30, Figure 7$)$.

Suggestive questions about the transgressor's behavior. Overall, the mean sum score for the suggestive questions about the transgressor was $2.87(S D=.41)$. An ordinal logistic regression was conducted with honesty-promotion technique (dummy coded with 
priming as the reference group first $)$, transgressor identity $(0=$ Mom, $1=\mathrm{RA})$, and age $(0$ $=6$ to 7 years, $1=8$ to 9 years) predicting children's sum scores to the suggestive questions about the transgressor's behavior. Because there was little variability in children's responses to the suggestive questions about the transgressor (i.e., most children ( $n=103)$ told all truths), the interaction terms were not entered into the model. Then, the ordinal logistic regression was run again using a dummy-coded system with the oath condition serving as the reference group. The first model was not significant, $\chi^{2}(4, N=$ $113)=2.30, p=.680$. Honesty-promotion technique (prime: $M=2.82, S D=.50$; oath: $M$ $=2.86, S D=.42 ;$ control: $M=2.92, S D=.28$ ), transgressor identity (Mom: $M=2.81, S D$ $=.52 ; \mathrm{RA}=2.93, S D=.26$ ), and age (6 to $7: M=2.86, S D=.40 ; 8$ to $9: M=2.87, S D$ $=.43$ ) did not account for a significant amount of variance in the transgressor sum scores (see Tables 31 and 32, Figure 8).

\section{Exploratory Analyses}

Exploratory analyses were conducted to examine the effects of children's trust in others, children's attachment to their mother, mother-child relationship quality, and parenting style on each of the primary dependent variables. Binary and ordinal logistic regressions revealed that children's attachment to their mother (Tables 33 and 34), mother-child relationship quality (Tables 35 and 36), and parenting style (Tables 37 and 38) did not significantly predict any of the primary dependent variables. Also, there was little variability in children's responses to the final question on the Attachment Security Scale which asked children more broadly how they felt about their mother (option 1: $n=$ 13, option 2: $n=98$, option 3: $n=4$ ). Most children chose the second option, indicating that they felt close to their mother. Thus, subsequent analyses were not conducted with 
responses to this question. However, children's trust in others, particularly trust in their father, significantly predicted several of the primary dependent variables (see Tables 39 and 40). In the present study, we only focus on children's trust in their mother and father.

For each target of trust (i.e., mother, father), we conducted three logistic regressions and four ordinal logistic regressions with the mean trust score for the target person predicting the primary dependent variables (see Tables 39 and 40). First, we found that the mean trust score for the father significantly predicted whether children disclosed that the adult broke the puppet during the open-ended question, $\chi^{2}(1, N=115)$ $=7.06, p=.008$, and correctly classified $60.9 \%$ of the cases, Nagelkerke $R^{2}=.08$. That is, for every one unit increase in trust in the father, children were 1.79 times less likely to disclose that the adult broke the puppet to the open-ended question. The mean father trust score of children who did not disclose that the adult broke the puppet to the openended question was $3.63(S D=.81)$, whereas the mean father trust score of those who did disclose this was $3.20(S D=.95)$. Second, the mean father trust score significantly predicted whether children admitted (yes or no) that something bad had happened when directly asked, $\chi^{2}(1, N=115)=5.21, p=.023$, and correctly classified $62 \%$ of the cases, Nagelkerke $R^{2}=.06$. That is, for every one unit increase in trust in the father, children were 1.64 times less likely to admit (i.e., say "no") that something bad had happened. The mean father trust score of children who said "no" nothing bad happened was 3.66 $(S D=.88)$, and the mean father trust score of children who said "yes" something bad happened was $3.28(S D=.89)$. Third, the mean father trust score significantly predicted whether children disclosed that the adult broke the puppet when asked if something bad had happened, $\chi^{2}(1, N=115)=4.16, p=.041$, and correctly classified $84 \%$ of the cases, 
Nagelkerke $R^{2}=.06$. That is, for every one unit increase in trust in the father, children were 1.82 times less likely to disclose the transgression when asked if something bad had happened. The mean father trust score of children who did not disclose that the adult broke the puppet when asked if something bad had happened was $3.51(S D=.91)$, whereas the mean father trust score of children who did disclose this when asked the same question was $3.05(S D=.73)$. Fourth, the mean father trust score accounted for a significant amount of overall variance in sum scores for the direct questions about the transgressor, $\chi^{2}(1, N=114)=10.93 . p=.001$. For every one unit increase in trust in the father, children were 1.96 times less likely to tell an additional truth to the direct questions about the transgressor. Finally, the mean mother trust score accounted for a significant amount of overall variance in the sum scores for the direct questions about the transgressor, as well, $\chi^{2}(1, N=114)=5.43, p=.020$. For every one unit increase in trust in the mother, children were 1.67 times less likely to tell an additional truth to the direct questions about the transgressor.

We also conducted exploratory analyses to examine how children responded to the debriefing questions. First, children were asked if they told the truth about the puppet, and $90 \%(n=104)$ of children were accurate in their responses. Notably, eight children did not realize they had told the truth about the puppet when, in fact, they had. They all disclosed only to the suggestive questions. The other three children said "yes" they told the truth about the puppet, when they actually had not. Second, those children who said they told the truth about the puppet $(n=100)$ were subsequently asked why they told the truth, and these responses were coded into five categories. Forty-nine percent of children $(n=49)$ gave a moral reason for telling the truth, $16 \%(n=16)$ said they did not 
want to get into trouble, $8 \%(n=8)$ expressed concern for someone else (e.g., RA1 who was asking the questions, the friend who needed the puppets), $3 \%(n=3)$ gave multiple reasons that were always some combination of the first two categories, and $24 \%(n=24)$ did not give a clear explanation for why they told the truth (the majority simply said they wanted to). Finally, those children who said they did not tell the truth about the puppet ( $n$ =15) were subsequently asked why they did not tell the truth, and these responses were again coded into five categories. Twenty percent of children $(n=3)$ said the transgressor told them to keep it a secret, $27 \%(n=4)$ said they did not want to get into trouble, $13 \%$ $(n=2)$ said they did not want others to get into trouble, $7 \%(n=1)$ mentioned being scared, and $33 \%(n=5)$ did not give a clear explanation for why they decided not to tell the truth (the majority did not respond to the question). Explanations for why children decided to/decided not to tell the truth about the puppet did not differ by honestypromotion technique, transgressor identity, or age.

\section{CHAPTER VI}

\section{DISCUSSION}

The present study examined techniques for encouraging children's true disclosures of adult wrongdoing, particularly when the transgressor is a parent (as is often the case in instances of maltreatment; e.g., Hershkowitz, Horowitz, \& Lamb, 2005). In so doing, we advanced theoretical understanding of how children disclose negative events. Specifically, the present study was the first to examine the benefits of priming - a new technique for promoting honesty in children. By comparing the effectiveness of an indirect technique like priming honesty and an explicit technique (i.e., oath), we gained insight into the socio-contextual factors that influence children's honesty and dishonesty. 
First, we hypothesized that children in the prime condition would be the most honest about an adult's act of wrongdoing, followed by those in the oath and control conditions, respectively. We reasoned that priming the goal of honesty would circumvent some of the conscious reasoning why children may not want to disclose, thus encouraging more truthful disclosures. However, surprisingly, we did not find any significant differences between the prime, oath, and control conditions on children's truthful disclosures in response to the open-ended, direct, or suggestive questions. Second, we hypothesized that children in the stranger (RA) transgressor condition would be more honest about an adult's act of wrongdoing than children in the parent (mother) transgressor condition because children would be less concerned about protecting an adult who they did not know (London et al., 2005, 2008; Lyon et al., 2010; Malloy et al., 2007; Malloy et al., 2014; Tye et al., 1999). Consistent with this hypothesis and previous research, we did find that the RA transgressor condition elicited more truthful disclosures from children to several direct questions. Third, we hypothesized that younger children (6- to 7-year-olds) would be more honest about an adult's act of wrongdoing than older children (8- to 9-year-olds) because older children may be more cognizant about the negative consequences of disclosing (Malloy et al., 2011, 2014). However, contrary to our hypothesis, we did not find that older children were more honest to any of the openended, direct, or suggestive questions. Finally, we hypothesized that priming would be especially effective for those in the parent relative to stranger transgressor condition and for older children relative to younger children. We reasoned that in both of these conditions (i.e., parent transgressor, 8- to 9-year-olds), children may consider more reasons why they may not want to disclose, and priming for honesty would counter some 
of this conscious reasoning. However, contrary to our hypotheses, neither the HonestyPromotion Technique $\mathrm{x}$ Transgressor Identity or Honesty-Promotion Technique x Age interactions were significant.

\section{Honesty-Promotion Techniques}

We hypothesized that children in the prime condition would be the most honest about an adult's act of wrongdoing, followed by those in the oath and control conditions, respectively. However, we did not find any significant differences between the prime, oath, and control conditions on children's truthful disclosures in response to the openended, direct, or suggestive questions. The proportion of children who told the truth to the different question types was generally higher for children in the oath condition compared to the prime and control conditions, which is consistent with previous research that has compared the oath to other honesty-promotion techniques or a control condition (Evans \& Lee, 2010; Lyon \& Dorado, 2008; Lyon et al., 2008; Talwar et al., 2002). It is possible that with more power, we might find significant differences. In the present study, the oath condition had two fewer children $(n=36)$ than the control condition ( $n=$ $38)$ and five fewer children $(n=41)$ than the prime condition. Our targeted sample size was 120 children, however, several children had to be excluded from the final analyses for the various reasons described earlier. Subtle differences in the participants or methodology of the present study compared to previous studies could have also accounted for the null finding. For example, other studies that have found that the oath increased children's truthful disclosures of an adult's act of wrongdoing over a control condition examined a sample of maltreated children (Lyon \& Dorado, 2008; Lyon et al., 2008), only analyzed responses from those children who passed an oath-taking 
competency test (i.e., children were asked to differentiate between truths and lies and identify the consequences of lie-telling; Lyon \& Dorado, 2008), reminded children of the oath before different sets of question types (i.e., direct and suggestive questions; Lyon et al., 2008), and included less severe acts of adult wrongdoing (i.e., touching and playing with forbidden toys; Lyon \& Dorado, 2008; Lyon et al., 2008).

We can only speculate as to why the prime did not prove to be an effective honesty-promotion technique as we had predicted. There are several possible explanations. First, perhaps the prime needed to be more specific to the questions that children were later asked (i.e., telling the truth about their own and an adult's transgressions). The honesty words included in the prime may have gotten lost in the context of the story that contained 200 other words. For example, in Kesek et al. (2011), children were primed with the goal of obtaining many or immediate rewards. When priming for the goal of obtaining many rewards, the children listened to a story that talked about the child's desire to win a lot of prizes at the fair. When priming for the goal of obtaining immediate rewards, the story talked about winning prizes right away. Therefore, the use of the many and immediate connotations in these stories was highly similar to what children were asked to do in the delay of gratification task that they later completed (i.e., choose a smaller, more immediate reward or a larger, more delayed reward).

However, making the prime story more similar to the subsequent task at hand (i.e., telling the truth about their own and an adult's transgressions) presents several challenges. First, the child may become aware of an association between the story and the task, which would mean that the story is no longer a "prime," or an unknowing 
activation of a mental representation by mere exposure to a stimulus. In Kesek et al. (2011), the children were younger (4-year-olds) than the 6- to 9-year-olds in the present study, and thus may have been less aware of any similarities between the story that they heard and subsequent task that they performed. However, older children may be more suspicious, and thus act in accordance with how they believe the researchers want them to behave. Second, it may be difficult to construct two parallel stories (i.e., one for the prime condition and the other for the oath and control conditions) that are similar in valence when the prime story describes a very moral act like being honest (which would be specific to the subsequent task at hand). The oath and control story would need to evoke the same positive feelings without describing this act of honesty. The present study's prime story contained words associated with honesty, but they were carefully incorporated in such a way to avoid being associated with the moral character of those in the story. This allowed us to more readily construct parallel stories for the oath and control conditions that did not contain these honesty words, but still had the same general plot and characters. To avoid some of these challenges, future research could prime children in a different way. Perhaps children could complete age-appropriate word scramble or sentence completion tasks that have been used in much of the adult priming literature. In the present study, we used a prime story like Kesek et al (2011) because we thought it would be more engaging for children and appropriate for all children within our age range, but other priming tasks might be more effective by drawing more attention to the specific words (and therefore goals) that are being primed.

Another possible explanation for why the prime was not effective as an honestypromotion technique is that the goal of honesty may not have been congruent with one's 
natural dispositions or goals (Bargh et al., 2012). We chose to test 6- to 9-year-old children because lie-telling increases during this time. Perhaps, then, it is children's natural tendency or goal to lie in these types of circumstances instead of telling the truth. In fact, in other studies, upwards of $93 \%$ of 6- to 11-year-olds lied about their own transgression (i.e., peeking at a trivia answer) when directly asked (Talwar, Gordon, \& Lee, 2007), and upwards of 50\% of 3- to 11-year-olds lied about their parent's transgression (i.e., breaking a puppet) when asked what happened to the puppet (Talwar et al., 2004). Also, $75 \%$ of 6-year-olds and $34 \%$ of 10 -year-olds did not disclose a stranger's transgression in free recall (Pipe \& Wilson, 1994). In the present study, we found that less than half of the children $(45 \%)$ disclosed that the adult broke the puppet to the open-ended question, and only $16 \%$ spontaneously disclosed this transgression when asked if something bad had happened. It was only when more specific direct and suggestive questions were asked that most children told the truth. This is concerning because the information that children tend to provide in response to open-ended questions tends to be very accurate (Lamb, Orbach, Hershkowitz, Horowitz, \& Abbott, 2007), although they may sometimes omit crucial details (Malloy \& Mugno, 2016; Pipe \& Wilson, 1994). Therefore, the goal is to find a way to increase truthful disclosures particularly to these types of questions.

Finally, perhaps to prime for the goal of honesty it is important to demonstrate positive benefits of telling the truth, particularly if it is not children's natural inclination to tell the truth about minor transgressions during this developmental time period. In other studies (e.g., Lee et al., 2014; Talwar et al., 2015), researchers have found that popular moral stories for children emphasizing the positive benefits of telling the truth 
(e.g., George Washington and the Cherry Tree) increased truth-telling about children's own and adults' transgressions. These moral stories most closely approximate the prime used in the present study. However, we did not include any positive benefits of truthtelling in the prime story since these cannot always be promised to children when they disclose maltreatment or other negative events.

It is important to note that children in all three conditions listened to a story on the computer that had a moral component (i.e., Diane/Derek wanted to eat a cookie but did not because they knew they were not supposed to eat any sweets before dinner), and this may have concealed any effects of the different honesty-promotion techniques on truthtelling. That is, the moral component may have encouraged truth-telling across all three conditions, including the control condition, especially given that many children gave

moral reasons for why they told the truth about the adult transgression. Therefore, future research should clearly isolate the honesty-promotion technique across each experimental condition, and ensure that there is no honesty-promotion technique in the control condition.

\section{Transgressor Identity}

We hypothesized that those in the stranger (RA) transgressor condition would be more honest about an adult's act of wrongdoing than those in the parent (mother) transgressor condition. Several significant effects of transgressor identity on children's truthful disclosures emerged. When asked the direct question, Did something bad happen while I was gone and you were waiting for me with [adult transgressor]?, children in the RA transgressor condition were significantly more likely to admit that "yes" something bad had happened than children who were in the mother transgressor condition. To the 
same question, 23\% $(n=13)$ of children in the RA transgressor condition spontaneously disclosed that the adult broke the puppet, whereas $8 \%(n=5)$ of children in the mother transgressor condition did so. However, only 16\% $(n=18)$ of children disclosed that the adult broke the puppet to this question overall, so there was insufficient power to detect a significant difference in disclosures between the RA and mother conditions. Also, children in the RA transgressor condition were more honest (i.e., had higher sum scores to the direct questions about the transgressor) about the transgressor's wrongdoings (i.e., touching, playing with, breaking the puppet) than children in the mother transgressor condition. These findings are consistent with previous experimental (Lyon et al., 2010; Tye et al., 1999) and field research (London et al., 2005, 2008; Malloy et al., 2007) demonstrating that children are less forthcoming about a caregiver's transgressions. Investigators and other fact finders should be aware of this information when questioning children about maltreatment, for example, especially given that the perpetrator is often someone close to the child (U.S. Department of Health and Human Services, 2017). The present study is one of few experimental studies to directly compare the rates of children's disclosures regarding different "perpetrators" of wrongdoing (i.e., stranger, parent; also see Tye et al., 1999), and the first experimental study to do so while examining different honesty-promotion techniques.

We had also hypothesized that the prime would be especially effective when the transgressor was the parent as opposed to a stranger. We reasoned that when the transgressor was the parent, there may be more (and more severe) conscious reasons why children may not want to disclose the truth. For example, in real world situations, children may fear removal from the home, disbelief from other family members, 
punishment, and legal repercussions for the parent. In the present study, children may have feared getting themselves or others (i.e., mother, RA) in trouble if they disclosed the truth (which the transgressor directly stated as part of the script - We might get into trouble if anyone finds out!), upsetting RA1 because they disobeyed orders, or upsetting RA1's "friend" who needed the puppets for a school. Therefore, a prime could circumvent some of this conscious reasoning, thus resulting in an increase of truthful disclosures when the parent is the transgressor. However, contrary to our hypothesis, we did not find a significant Honest-Promotion Technique x Transgressor Identity interaction on children's truthful disclosures, and there may be several reasons for this null result. First, as aforementioned, we may need to work on strengthening the prime in general by using a different type of prime (e.g., word-scramble task) or by creating a prime story that depicts characters truthfully disclosing a transgression and thus making the story more similar to children's later task (i.e., responding to the interview questions about the transgression). Second, given that the transgression in the present study was relatively minor (i.e., breaking a puppet), children may not have anticipated more or more severe consequences of telling the truth in the mother transgressor condition compared to the RA condition. During the debriefing questions, only three children articulated multiple reasons that they told the truth about the puppet, and reasons for telling the truth did not differ by transgressor identity conditions. Also, in both transgressor identity conditions, children may have been concerned about getting themselves or others in trouble for disclosing the adult's act of wrongdoing, but reasoned that any punishment would be minimal because the transgression was minor and portrayed as an accident. Examining 
accidental versus intentional acts of wrongdoing in future research could be a way to increase the severity of the transgression.

\section{Age}

We hypothesized that younger children (6- to 7-year-olds) would be more likely to tell the truth about the adult transgression than older children (8- to 9-year-olds) because younger children may be less aware of the negative consequences of disclosing (Malloy et al., 2011, 2014), and secret-keeping and lie-telling increase as children grow older (Gordon et al., 2014; Talwar et al., 2015; Talwar \& Crossman, 2012). Contrary to our expectations, however, we did not find any significant age group differences on children's truthful disclosures in response to the different question types. We offer several possible explanations. First, our age range may have been too narrow to detect discernible age effects. Many of the lower age bounds for the aforementioned studies started at preschool (4- to 5-year-olds), and some of the upper age bounds continued into the teenage years (Gordon et al., 2014; Malloy et al., 2011, 2014; Talwar et al., 2015; Talwar \& Crossman, 2012). Malloy and Mugno (2016) also did not find significant age differences in their study on children's recantations using the same age range and type of event. Second, the younger children in the present study (6- to 7-year-olds) may have been as aware as the older children (8- to 9-year-olds) of negative consequences of disclosing a minor transgression, particularly a relatively common event in their everyday lives such as a toy breaking. This may explain why, contrary to our hypothesis, we also did not find a significant Honesty-Promotion Technique x Age interaction on children's truthful disclosures in response to any of the question types. We had expected that older children would consider more conscious reasons not to disclose any wrongdoing relative 
to younger children, and a prime may circumvent this, thus encouraging truth-telling. However, children's responses during the debriefing questions for why they decided to/decided not to tell the truth about the puppet did not differ by age. With more serious transgressions (e.g., child maltreatment), older children may consider consequences such as formal intervention from authorities or legal consequences for the perpetrator consequences that younger children may not have the life experience or sophistication to consider (Malloy et al., 2011, 2014). Therefore, we might expect to find age differences even with this narrow age range in these real world contexts (Malloy et al., 2007).

\section{Mother-Child Relationship Quality, Parenting Style, and Children's Trust}

Children's attachment to their mother, mother-child relationship quality, and parenting style did not significantly predict children's truthful disclosures to the different question types. It is important to note that the Cronbach's alpha for the Attachment Security Scale was fairly low (.50), and may not be considered an acceptable alpha value by some standards (Tavakol \& Dennick, 2011). This may have affected the predictive ability of this measure.

However, we found that those children with greater trust in their mothers were less truthful (or more likely to keep the transgressor's secret) than those with less trust in their mothers when answering the direct questions about the transgressor, a finding that is consistent with previous research (Gordon et al., 2014; Lyon et al., 2014). Interestingly, similar, but even more significant effects were found when we examined the predictive ability of children's trust in their fathers (who were not transgressors in the present study). Specifically, children with greater trust in their fathers were less likely than those with less trust in their fathers to spontaneously disclose that the adult broke the puppet to 
the open-ended question and when asked if something bad had happened. Children with greater trust in their fathers were also less likely to admit that "yes" something bad had happened and were less truthful when answering the direct questions about the transgressor. Children may be more likely to keep a secret for someone whom they trust because they reason that a trustworthy individual would not ask them to do something that they should not, and thus they would not get into trouble for keeping the secret. They may also assume that there must be a good reason that this individual is asking them to keep a secret. This relation between trust and secret-keeping (or lying) warrants further exploration and may be an important factor for interviewers to consider when questioning children about a known and trusted adult.

\section{Limitations and Future Directions}

There are a few limitations worth noting. First, for ethical purposes, we had mothers and RAs commit a minor act of wrongdoing (i.e., breaking a puppet), a transgression for which there may be few and not particularly severe consequences of disclosing, especially given that the majority of children in our sample came from families with high annual incomes. A prime may be less effective under these circumstances when the intended effect was to circumvent some of the conscious reasons not to disclose, thus encouraging more truthful disclosures. Although experimental studies need to abide by appropriate ethics, future studies should try utilizing a different transgression where the transgression itself may lead children to consider many reasons that they may not want to disclose the act of wrongdoing (e.g., children have greater involvement in the transgression; transgression is intentional; children do not realize that the transgression is wrong when it occurs, as might be the case in certain instances of 
child maltreatment). Second, the parent transgressor in the present study was always the child's mother. Although women are often the perpetrators of physical abuse (Straus, Hamby, Finkelhor, Moore, \& Runyan, 1998), in many cases of child sexual abuse, the mother is actually the nonoffending caregiver and male parent figures are the perpetrators (Malloy et al., 2007). Therefore, it is important to conduct experimental studies with father transgressors, to ascertain whether similar effects are obtained when a mother or father transgressor is used. Finally, the present study focused on the effects of honestypromotion techniques, transgressor identity, and age on children's truthful disclosures. However, it is also important to examine the effects of these variables on false allegations - those that could lead to the wrongful conviction of an innocent individual. For example, Lyon and Dorado (2008) found that specific reassurance increased both true and false allegations.

\section{Conclusions and Practical Applications}

Children's disclosures are crucial in maltreatment cases, since often children are the only witnesses to these types of crimes. However, for a number of reasons, children may delay disclosure of maltreatment or fail to disclose altogether (see London et al., 2005, 2008 for reviews). Thus, it is imperative to empirically test different techniques that may increase children's truthful disclosures of adults' transgressions.

Research on honesty-promotion techniques is still in its infancy, and thus far, techniques have primarily relied on explicit approaches. These techniques have presented several challenges. First, these explicit techniques focus on children's conscious decisions to tell the truth, decisions that may be influenced by external pressures and their expectations of disclosing. Second, in the U.S., many children have 
been disqualified from testifying after incorporating these techniques because, for example, they fail to promise to tell the truth or fail to demonstrate their conceptual understanding of truths and lies (Lyon, 2011; State v. Hooper, 2007; State v. Henderson, 2007). Because of these challenges, we decided to examine priming as a new and indirect approach to promoting honesty. This kind of indirect approach could provide a simple and cost-effective tool that legal professionals could use to circumvent some of the challenges posed by the explicit techniques. It could be easily, and with minimal training, be incorporated into best-practice protocols for interviewing child witnesses as a way of encouraging true disclosures. Although the present study did not find the honesty-promoting effects that we had expected with the prime, this was the first experimental study to examine this technique and thus warrants further research. Under the present study conditions, we also did not find the same beneficial effects of the oath that previous research has (Evans \& Lee, 2010; Lyon \& Dorado, 2008; Lyon et al.; Talwar et al., 2002). Therefore, it is necessary to continue to examine the benefits of both explicit and indirect honesty-promotion techniques under different study conditions. Any technique recommended for use in the criminal justice system should be based on strong empirical research. 
Table 1

Sample Breakdown of Parent 1 's (Mother's) Highest Education $(N=113)$

\begin{tabular}{lcc}
\hline Highest degree & $n$ & $\begin{array}{c}\text { Percent of } \\
\text { participants }\end{array}$ \\
\hline High school/GED & 17 & $15 \%$ \\
Associate & 14 & $12.4 \%$ \\
Technical & 15 & $13.3 \%$ \\
Bachelor's & 27 & $23.9 \%$ \\
MA/MS & 29 & $25.7 \%$ \\
MSW & 5 & $4.4 \%$ \\
PhD & 4 & $3.5 \%$ \\
JD & 2 & $1.8 \%$ \\
\hline
\end{tabular}


Table 2

Sample Breakdown of Parent 2's Highest Education $(N=99)$

\begin{tabular}{lcc}
\hline Highest degree & $n$ & $\begin{array}{c}\text { Percent of } \\
\text { participants }\end{array}$ \\
\hline High school/GED & 30 & $30.3 \%$ \\
Associate & 11 & $11.1 \%$ \\
Technical & 13 & $13.1 \%$ \\
Bachelor's & 23 & $23.2 \%$ \\
MA/MS & 12 & $12.1 \%$ \\
MSW & 0 & $0 \%$ \\
PhD & 5 & $5.1 \%$ \\
JD & 5 & $5.1 \%$ \\
\hline
\end{tabular}


Table 3

Sample Breakdown of Total Annual Family Income $(N=114)$

\begin{tabular}{lcc}
\hline Income breakdown & $n$ & $\begin{array}{c}\text { Percent of } \\
\text { participants }\end{array}$ \\
\hline Less than $\$ 15 \mathrm{k}$ & 6 & $5.3 \%$ \\
$15 \mathrm{k}$ to $25 \mathrm{k}$ & 12 & $10.5 \%$ \\
$25 \mathrm{k}$ to $35 \mathrm{k}$ & 7 & $6.1 \%$ \\
$35 \mathrm{k}$ to $45 \mathrm{k}$ & 7 & $6.1 \%$ \\
$45 \mathrm{k}$ to $55 \mathrm{k}$ & 7 & $6.1 \%$ \\
$55 \mathrm{k}$ to $75 \mathrm{k}$ & 19 & $16.7 \%$ \\
$75 \mathrm{k}$ to $100 \mathrm{k}$ & 22 & $19.4 \%$ \\
Over $100 \mathrm{k}$ & 34 & $29.8 \%$ \\
\hline
\end{tabular}


Table 4

Kappa and Percent Agreement Scores for Coding of Primary Dependent Variables and Manipulation Check Questions

Variables

Open-ended question: Spontaneous mention adult broke puppet

Did child mention that the puppet broke?

Did child mention who broke the puppet?

Direct question: Did something bad happen?

Did child tell the truth?

Did child mention that the puppet broke?

Did the child mention who broke the puppet?

Child direct questions

Did you touch any of the puppets?

Did you play with any of the puppets?

Did you break any of the puppets?

Transgressor direct questions

Did [adult] touch any of the puppets?

Did [adult] play with any of the puppets?

Did [adult] break any of the puppets?

Child suggestive questions

When you touched the puppets, did you take them all out of the box? When you played with the puppets, which one were you holding?

When you broke the puppet, were you happy or mad?

Transgressor suggestive questions

When [adult] touched the puppets, did she take them all out?

When [adult] played with the puppets, which one was she holding?

When [adult] broke the puppet, was she happy or mad?

Memory check questions

Where did Diane/Derek find the cookies?

Who made the cookies?

What were the cookies for?

Awareness check questions

Did you think the story had anything to do with the puppets?

Did you think about Diane/Derek when you answered my questions

about the puppets?

Did thinking about Diane/Derek have anything to do with the answers you gave me to the questions about the puppets?
Kappa \% agreement

$\begin{array}{ll}.92 & 96 \% \\ .86 & 92 \%\end{array}$

$1.00 \quad 100 \%$

$1.00 \quad 100 \%$

$1.00 \quad 100 \%$

$1.00 \quad 100 \%$

$.84 \quad 92 \%$

$.84 \quad 96 \%$

$1.00 \quad 100 \%$

$1.00 \quad 100 \%$

$1.00 \quad 100 \%$

$.92 \quad 96 \%$

$.88 \quad 96 \%$

$.88 \quad 92 \%$

$.87 \quad 92 \%$

$1.00 \quad 100 \%$

$.82 \quad 88 \%$

$1.00 \quad 100 \%$

$1.00 \quad 100 \%$

$.83 \quad 96 \%$

$1.00 \quad 100 \%$

$.90 \quad 96 \%$

$.75 \quad 92 \%$ 
Table 5

Primary Dependent Variables

\begin{tabular}{ll}
\hline Interview questions & Dependent variable \\
\hline $\begin{array}{l}\text { Open-ended question } \\
\text { Tell me what happened while I was gone. }\end{array}$ & $\begin{array}{l}\text { Spontaneous mention that adult broke puppet: } \\
0=\text { did not disclose, } 1=\text { disclosed }\end{array}$ \\
$\begin{array}{l}\text { Direct questions } \\
\text { Did something bad happen while I was gone? }\end{array}$ & $\begin{array}{l}\text { (a) } 0=\text { did not tell the truth, } 1=\text { told the truth } \\
\text { (b) } 0=\text { did not disclose adult broke puppet, } \\
1=\text { disclosed adult broke puppet }\end{array}$ \\
$\begin{array}{l}\text { Child's behavior } \\
\text { While I was gone, did you touch any of the puppets? }\end{array}$ & Sum score: $0=$ told no truths, $3=$ told all truths \\
$\begin{array}{l}\text { While I was gone, did you play with any of the puppets? } \\
\text { While I was gone, did you break any of the puppets? }\end{array}$ & \\
$\begin{array}{l}\text { Transgressor's behavior } \\
\text { While I was gone, did [adult] touch any of the puppets? }\end{array}$ & Sum score: $0=$ told no truths, $3=$ told all truths \\
While I was gone, did [adult] play with any of the puppets? & \\
While I was gone, did [adult] break any of the puppets? & \\
$\begin{array}{l}\text { Suppositional questions } \\
\text { Child's behavior }\end{array}$ & \\
When you touched the puppets, did you take them all out of the box? & Sum score: $0=$ told no truths, $3=$ told all truths \\
When you played with the puppets, which one were you holding? & \\
When you broke the puppet, were you happy or mad? & \\
$\begin{array}{l}\text { Transgressor's behavior } \\
\text { When [adult] touched the puppets, did she take them all out of the box? } \\
\text { When [adult] played with the puppets, which one was she holding? } \\
\text { When [adult] broke the puppet, was she happy or mad? }\end{array}$ & Sum score: $0=$ told no truths, $3=$ told all truths \\
\hline
\end{tabular}


Table 6

Kappa and Percent Agreement Scores for Coding of Exploratory Debriefing Questions

\begin{tabular}{lcc}
\hline Variables & Kappa $\%$ agreement \\
\hline Accuracy of response to: Did you tell me the truth about the puppet? & - & $92 \%$ \\
Why did you decide to tell me the truth about the puppet? & .78 & $83 \%$ \\
Why did you decide not to tell me the truth about the puppet? & .84 & $96 \%$ \\
\hline
\end{tabular}


Table 7

Sample Breakdown of Child Demographic Characteristics Across Honesty-Promotion Technique x Transgressor Identity Conditions

\begin{tabular}{|c|c|c|c|c|c|c|}
\hline & $\begin{array}{c}\text { Prime, } \\
\text { Mom } \\
(n)\end{array}$ & $\begin{array}{c}\text { Prime, } \\
\text { RA } \\
(n)\end{array}$ & $\begin{array}{l}\text { Oath, } \\
\text { Mom } \\
(n)\end{array}$ & $\begin{array}{l}\text { Oath, } \\
\text { RA } \\
(n)\end{array}$ & $\begin{array}{l}\text { Control, } \\
\text { Mom } \\
(n)\end{array}$ & $\begin{array}{c}\text { Control, } \\
\text { RA } \\
(n)\end{array}$ \\
\hline \multicolumn{7}{|l|}{ Age } \\
\hline 6 and 7 & 11 & 11 & 10 & 9 & 10 & 9 \\
\hline 8 and 9 & 9 & 10 & 10 & 7 & 9 & 10 \\
\hline \multicolumn{7}{|l|}{ Sex } \\
\hline Male & 11 & 11 & 11 & 9 & 10 & 10 \\
\hline Female & 9 & 10 & 9 & 7 & 9 & 9 \\
\hline \multicolumn{7}{|l|}{ Ethnicity } \\
\hline Hispanic/Latino & 12 & 12 & 13 & 12 & 12 & 9 \\
\hline Not Hispanic/Latino & 8 & 9 & 7 & 4 & 7 & 10 \\
\hline \multicolumn{7}{|l|}{ Race } \\
\hline White & 14 & 18 & 14 & 13 & 13 & 10 \\
\hline Black & 4 & 2 & 3 & 1 & 2 & 7 \\
\hline Multiracial & 2 & 1 & 3 & 2 & 4 & 2 \\
\hline
\end{tabular}


Table 8

Means and Standard Deviations of Manipulation Check Sum Scores Across Honesty-

Promotion Technique and Transgressor Identity Conditions

Story memory Story awareness Story feelings

Honesty-promotion technique

Prime

Oath

Control
$2.59(.71)$

$2.86(.36)$

$2.68(.62)$
$.76(.92)$

$.88(.95)$

$.92(1.03)$
$12.44(2.21)$

$12.31(1.75)$

12.45 (1.66)

Transgressor identity

Mother

RA
$2.62(.62)$

$2.79(.56)$
$.68(.92)$

$1.02(.97)$
$12.08(2.04)$

12.73 (1.67) 
Table 9

Chi-Square Analyses for Effect of Child Sex on Dichotomous Primary Dependent

Variables

\begin{tabular}{llllll}
\hline Variables & $\chi^{2}$ & df & $N$ & $p$ \\
\hline $\begin{array}{l}\text { Open-ended question } \\
\quad \text { Did child mention the adult broke the puppet? }\end{array}$ & .00 & 1 & 115 & .990 \\
& & & & \\
Direct question: Did something bad happen? & & & & & \\
$\quad$ Did child tell the truth? & .79 & 1 & 115 & .373 \\
$\quad$ Did child mention the adult broke the puppet? & .13 & 1 & 115 & .717 \\
\hline
\end{tabular}


Table 10

ANOVA Analyses for Effect of Child Sex on Primary Dependent Sum Score Variables

\begin{tabular}{lllll}
\hline Variables & $F$ & df & $p$ \\
\hline $\begin{array}{l}\text { Child direct questions sum score } \\
\quad \text { How many truths did the child tell? }\end{array}$ & 3.54 & 1,112 & .063 \\
$\quad \begin{array}{l}\text { Transgressor direct questions sum score } \\
\quad \text { How many truths did the child tell? }\end{array}$ & .07 & 1,112 & .789 \\
$\quad \begin{array}{l}\text { Child suggestive questions sum score } \\
\quad \text { How many truths did the child tell? }\end{array}$ & .64 & 1,112 & .425 \\
$\quad \begin{array}{l}\text { Transgressor suggestive questions sum score } \\
\quad \text { How many truths did the child tell? }\end{array}$ & & & \\
\end{tabular}


Table 11

Chi-Square Analyses for Effect of Child Ethnicity on Dichotomous Primary Dependent

Variables

\begin{tabular}{llllll}
\hline Variables & $\chi^{2}$ & df & $N$ & $p$ \\
\hline $\begin{array}{l}\text { Open-ended question } \\
\quad \text { Did child mention the adult broke the puppet? }\end{array}$ & 1.04 & 1 & 115 & .309 \\
& & & & \\
$\quad$ Direct question: Did something bad happen? & & & & & \\
$\quad$ Did child tell the truth? & .02 & 1 & 115 & .879 \\
$\quad$ Did child mention the adult broke the puppet? & .25 & 1 & 115 & .615 \\
\hline
\end{tabular}


Table 12

ANOVA Analyses for Effect of Child Ethnicity on Primary Dependent Sum Score

Variables

\begin{tabular}{llll}
\hline Variables & $F$ & df & $p$ \\
\hline $\begin{array}{l}\text { Child direct questions sum score } \\
\quad \text { How many truths did the child tell? }\end{array}$ & .27 & 1,112 & .605 \\
$\begin{array}{l}\text { Transgressor direct questions sum score } \\
\quad \text { How many truths did the child tell? }\end{array}$ & .44 & 1,112 & .509 \\
$\begin{array}{l}\text { Child suggestive questions sum score } \\
\quad \text { How many truths did the child tell? }\end{array}$ & 3.54 & 1,112 & .062 \\
$\begin{array}{l}\text { Transgressor suggestive questions sum score } \\
\quad \text { How many truths did the child tell? }\end{array}$ & & & \\
\end{tabular}


Table 13

Chi-Square Analyses for Effect of Child Race on Dichotomous Primary Dependent

Variables

\begin{tabular}{|c|c|c|c|c|}
\hline Variables & $\chi^{2}$ & $\mathrm{df}$ & $N$ & $p$ \\
\hline \multicolumn{5}{|l|}{ Open-ended question } \\
\hline Did child mention the adult broke the puppet? & 1.05 & 2 & 115 & .591 \\
\hline \multicolumn{5}{|l|}{ Direct question: Did something bad happen? } \\
\hline Did child tell the truth? & 1.15 & 2 & 115 & .564 \\
\hline Did child mention the adult broke the puppet? & .52 & 2 & 115 & .770 \\
\hline
\end{tabular}


Table 14

ANOVA Analyses for Effect of Child Race on Primary Dependent Sum Score Variables

\begin{tabular}{lcccc}
\hline Variables & $F$ & df & $p$ \\
\hline $\begin{array}{l}\text { Child direct questions sum score } \\
\quad \text { How many truths did the child tell? }\end{array}$ & .83 & 2,111 & .440 \\
$\quad \begin{array}{l}\text { Transgressor direct questions sum score } \\
\quad \text { How many truths did the child tell? }\end{array}$ & .84 & 2,111 & .435 \\
$\quad \begin{array}{l}\text { Child suggestive questions sum score } \\
\quad \text { How many truths did the child tell? }\end{array}$ & .95 & 2,111 & .389 \\
$\quad \begin{array}{l}\text { Transgressor suggestive questions sum score } \\
\quad \text { How many truths did the child tell? }\end{array}$ & 1.81 & 2,110 & .168 \\
\hline
\end{tabular}


Table 15

Chi-Square Analyses for the Effect of Highest Parental Education on Dichotomous

Primary Dependent Variables

\begin{tabular}{|c|c|c|c|c|}
\hline Variables & $\chi^{2}$ & $\mathrm{df}$ & $N$ & $p$ \\
\hline \multicolumn{5}{|l|}{ Open-ended question } \\
\hline Did child mention the adult broke the puppet? & .90 & 1 & 113 & .342 \\
\hline \multicolumn{5}{|l|}{ Direct question: Did something bad happen? } \\
\hline Did child tell the truth? & .001 & 1 & 113 & .977 \\
\hline Did child mention the adult broke the puppet? & 1.63 & 1 & 113 & .202 \\
\hline
\end{tabular}


Table 16

ANOVA Analyses for Effect of Highest Parental Education on Primary Dependent Sum

Score Variables

\begin{tabular}{lcccc}
\hline Variables & $F$ & df & $p$ \\
\hline $\begin{array}{l}\text { Child direct questions sum score } \\
\quad \text { How many truths did the child tell? }\end{array}$ & .09 & 1,110 & .770 \\
$\quad$ Transgressor direct questions sum score & & & \\
$\quad$ How many truths did the child tell? & .58 & 1,110 & .449 \\
$\quad \begin{array}{l}\text { Child suggestive questions sum score } \\
\quad \text { How many truths did the child tell? }\end{array}$ & 11.09 & 1,110 & $.001^{*}$ \\
$\quad \begin{array}{l}\text { Transgressor suggestive questions sum score } \\
\quad \text { How many truths did the child tell? }\end{array}$ & & & \\
\end{tabular}

Note. ${ }^{*}=$ significant. 


\section{Table 17}

Chi-Square Analyses for Effect of Total Annual Family Income on Dichotomous Primary Dependent Variables

\begin{tabular}{|c|c|c|c|c|}
\hline Variables & $\chi^{2}$ & $\mathrm{df}$ & $N$ & $p$ \\
\hline \multicolumn{5}{|l|}{ Open-ended question } \\
\hline Did child mention the adult broke the puppet? & .45 & 1 & 114 & .504 \\
\hline \multicolumn{5}{|l|}{ Direct question: Did something bad happen? } \\
\hline Did child tell the truth? & .21 & 1 & 114 & .644 \\
\hline Did child mention the adult broke the puppet? & 3.05 & 1 & 114 & .081 \\
\hline
\end{tabular}


Table 18

ANOVA Analyses for Effect of Total Annual Family Income on Primary Dependent Sum

Score Variables

\begin{tabular}{lllll}
\hline Variables & $F$ & df & $p$ \\
\hline $\begin{array}{l}\text { Child direct questions sum score } \\
\quad \text { How many truths did the child tell? }\end{array}$ & .21 & 1,111 & .649 \\
$\quad \begin{array}{l}\text { Transgressor direct questions sum score } \\
\quad \text { How many truths did the child tell? }\end{array}$ & .19 & 1,111 & .662 \\
$\quad \begin{array}{l}\text { Child suggestive questions sum score } \\
\quad \text { How many truths did the child tell? }\end{array}$ & .05 & 1,111 & .820 \\
$\quad \begin{array}{l}\text { Transgressor suggestive questions sum score } \\
\quad \text { How many truths did the child tell? }\end{array}$ & .27 & 1,110 & .602 \\
\hline
\end{tabular}


Table 19

Open-Ended Question: Binary Logistic Regression Analyses Examining Effects of Predictor Variables on Children's Disclosure of the Adult Transgression

\begin{tabular}{llllll}
\hline Variables & $B$ & $S E$ & $p$ & $\operatorname{Exp}(B)$ & $\begin{array}{c}95 \% \text { CI for } \\
\operatorname{Exp}(B)\end{array}$ \\
\hline
\end{tabular}

Step 1

Oath v. prime ${ }^{\mathrm{r}}$

Control v. prime ${ }^{\mathrm{r}}$

Control v. oath ${ }^{\mathrm{r}}$

Transgressor identity

Child age
$.91 \quad .48 \quad .056 \quad 2.49 \quad .98-6.31$

$\begin{array}{llll}.55 & .47 \quad .241 \quad 1.73 \quad .69-4.32\end{array}$

$\begin{array}{lllll}-.36 \quad .47 \quad .443 \quad .70 & .28-1.76\end{array}$

$\begin{array}{lllll}.28 & .39 & .462 & 1.33 & .62-2.83\end{array}$

$\begin{array}{lllll}.45 & .38 & .244 & 1.57 \quad .74-3.32\end{array}$

Step 2

$\begin{array}{llllll}\text { Oath v. prime }^{\mathrm{r}} \mathrm{x} \text { transgressor identity } & .12 & .95 & .900 & 1.13 & .18-7.19\end{array}$

$\begin{array}{llllll}\text { Control v. } \text { prime }^{\mathrm{r}} \mathrm{x} \text { transgressor identity } & .96 & .96 & .320 & 2.61 & .39-17.25\end{array}$

$\begin{array}{lllllll}\text { Control v. } \text { oath }^{\mathrm{r}} \mathrm{x} \text { transgressor identity } & .84 & .98 & .389 & 2.32 & .34-15.69\end{array}$

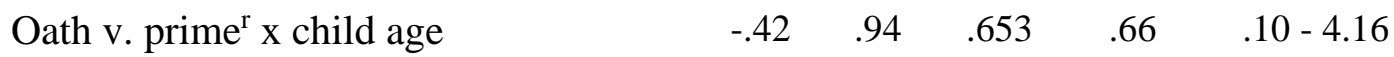

$\begin{array}{llllllll}\text { Control v. prime } & \mathrm{r} x \text { child age } & & 1.10 & .96 & .254 & 3.01 & .45-19.91\end{array}$

$\begin{array}{lllllll}\text { Control v. oath } & \mathrm{r} \text { x child age } & 1.53 & .97 & .117 & 4.59 & .68-30.96\end{array}$

Note. Neither model was significant.

${ }^{r}=$ reference group. 
Table 20

Open-Ended Question: Percent of Children Disclosing Adult Transgression Across

Honesty-Promotion Technique, Transgressor Identity, and Age Conditions $(N=115)$

\begin{tabular}{lcc}
\hline Conditions & $\%$ & $n$ \\
\hline Total & $45 \%$ & 52 \\
\hline Honesty-promotion technique & & \\
Prime & $34 \%$ & 14 \\
Oath & $56 \%$ & 20 \\
Control & $47 \%$ & 18 \\
\hline Transgressor identity & & 28 \\
Mother & & 24 \\
RA & $42 \%$ & 28 \\
\hline Age & & \\
\hline
\end{tabular}


Table 21

Did Something Bad Happen: Binary Logistic Regression Analyses Examining Effects of

Predictor Variables on Children's Admissions (Yes or No) that Something Bad Happened

\begin{tabular}{|c|c|c|c|c|c|}
\hline Variables & $B$ & $S E$ & $p$ & $\operatorname{Exp}(B)$ & $\begin{array}{c}95 \% \text { CI for } \\
\operatorname{Exp}(B)\end{array}$ \\
\hline \multicolumn{6}{|l|}{ Step $1 *$} \\
\hline Oath v. prime ${ }^{r}$ & .88 & .50 & .076 & 2.41 & $.91-6.39$ \\
\hline Control v. prime ${ }^{r}$ & .28 & .47 & .549 & 1.33 & $.53-3.33$ \\
\hline Control v. oath ${ }^{\mathrm{r}}$ & -.60 & .51 & .237 & .55 & $.20-1.48$ \\
\hline Transgressor identity & .94 & .40 & $.019 *$ & 2.56 & $1.16-5.63$ \\
\hline Child age & .53 & .40 & .183 & 1.70 & $.78-3.72$ \\
\hline
\end{tabular}

Step 2

$\begin{array}{lllllll}\text { Oath v. prime }{ }^{\mathrm{r}} \mathrm{x} \text { transgressor identity } & -1.37 & .99 & .164 & .25 & .04-1.75\end{array}$

$\begin{array}{lllllll}\text { Control v. prime }{ }^{\mathrm{r}} \mathrm{x} \text { transgressor identity } & .04 & .98 & .964 & 1.05 & .15-7.10\end{array}$

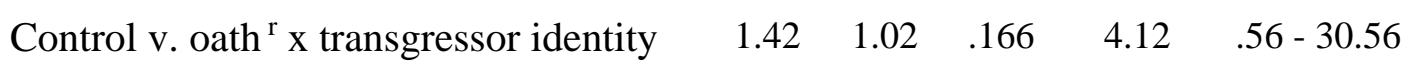

$\begin{array}{lllllll}\text { Oath v. prime }{ }^{\mathrm{r}} \mathrm{x} \text { child age } & -.42 & .99 & .670 & .66 & .10-4.54\end{array}$

$\begin{array}{lllllll}\text { Control v. prime }{ }^{\mathrm{r}} \mathrm{x} \text { child age } & .38 & .98 & .695 & 1.47 & .22-9.94\end{array}$

$\begin{array}{llllll}\text { Control v. oath }{ }^{\mathrm{r}} \mathrm{x} \text { child age } & .80 & 1.02 & .430 & 2.23 & .30-16.45\end{array}$

Note. The first model was significant.

${ }^{\mathrm{r}}=$ reference group.

* = significant. 
Table 22

Did Something Bad Happen: Percent of Children Admitting (Yes or No) that Something Bad Happened Across Honesty-Promotion Technique, Transgressor Identity, and Age

Conditions $(N=115)$

\begin{tabular}{lcc}
\hline Conditions & $\%$ & $n$ \\
\hline Total & $59 \%$ & 68 \\
\hline Honesty-promotion technique & & \\
Prime & $51 \%$ & 21 \\
Oath & $69 \%$ & 25 \\
Control & $58 \%$ & 22 \\
\hline Transgressor identity & & 32 \\
Mother & & 36 \\
RA to 9 years & $49 \%$ & 39 \\
\hline Age & & \\
\hline
\end{tabular}


Table 23

Did Something Bad Happen: Binary Logistic Regression Analyses Examining Effects of Predictor Variables on Children's Disclosure of Adult Transgression

\begin{tabular}{lccccc}
\hline Variables & $B$ & $S E$ & $p$ & $\operatorname{Exp}(B)$ & $\begin{array}{c}95 \% \text { CI for } \\
\operatorname{Exp}(B)\end{array}$ \\
\hline Oath v. prime $^{\mathrm{r}}$ & .25 & .65 & .703 & 1.28 & $.36-4.53$ \\
Control v. prime $^{\mathrm{r}}$ & .09 & .64 & .886 & 1.10 & $.31-3.86$ \\
Control v. oath $^{\mathrm{r}}$ & -.15 & .65 & .813 & .86 & $.24-3.06$ \\
Transgressor identity & 1.20 & .57 & .035 & 3.32 & $1.09-10.10$ \\
Child age & .38 & .53 & .475 & 1.46 & $.52-4.11$ \\
\hline
\end{tabular}

Note. The model was not significant.

${ }^{\mathrm{r}}=$ reference group. 
Table 24

Did Something Bad Happen: Percent of Children Disclosing Adult Transgression Across Honesty-Promotion Technique, Transgressor Identity, and Age Conditions $(N=115)$

\begin{tabular}{lcc}
\hline Conditions & $\%$ & $n$ \\
\hline Total & $16 \%$ & 18 \\
\hline Honesty-promotion technique & & \\
Prime & $15 \%$ & 6 \\
Oath & $17 \%$ & 6 \\
Control & $16 \%$ & 6 \\
\hline Transgressor identity & & 10 \\
Mother & & 5 \\
\hline RA to 9 years & $18 \%$ & 13 \\
\hline
\end{tabular}


Table 25

Ordinal Logistic Regression Analyses Examining Effects of Predictor Variables on Child Direct Sum Scores

\begin{tabular}{|c|c|c|c|c|c|}
\hline Model & $B$ & $S E$ & $p$ & $\operatorname{Exp}(B)$ & $\begin{array}{c}95 \% \mathrm{CI} \text { for } \\
\operatorname{Exp}(B)\end{array}$ \\
\hline \multicolumn{6}{|l|}{ Step 1} \\
\hline Oath v. prime ${ }^{r}$ & .77 & .45 & .089 & 2.16 & $.89-5.22$ \\
\hline Control v. prime ${ }^{\mathrm{r}}$ & .47 & .43 & .279 & 1.59 & $.69-3.70$ \\
\hline Control v. oath ${ }^{\mathrm{r}}$ & -.30 & .45 & .500 & .74 & $.31-1.78$ \\
\hline Transgressor identity & .51 & .36 & .161 & 1.67 & $.82-3.40$ \\
\hline Child age & .53 & .36 & .145 & 1.69 & $.83-3.45$ \\
\hline
\end{tabular}

Step 2

$\begin{array}{lllllll}\text { Oath v. prime }{ }^{\mathrm{r}} \mathrm{x} \text { transgressor identity } & -1.38 & .91 & .128 & .25 & .04-1.49\end{array}$

$\begin{array}{llllllll}\text { Control v. } \text { prime }^{\mathrm{r}} \mathrm{x} \text { transgressor identity } & -.78 & .88 & .377 & .46 & .08 & -2.58\end{array}$

$\begin{array}{llllll}\text { Control v. oath }{ }^{\mathrm{r}} \mathrm{x} \text { transgressor identity } & .60 & .90 & .504 & 1.83 & .31-10.78\end{array}$

$\begin{array}{lllllll}\text { Oath v. prime }{ }^{\mathrm{r}} \mathrm{x} \text { child age } & -.45 & .90 & .617 & .64 & .11-3.73\end{array}$

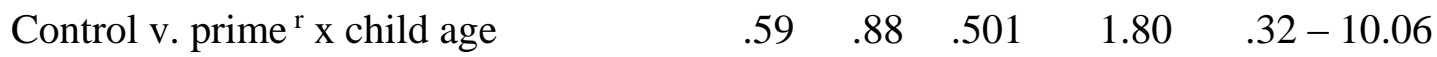

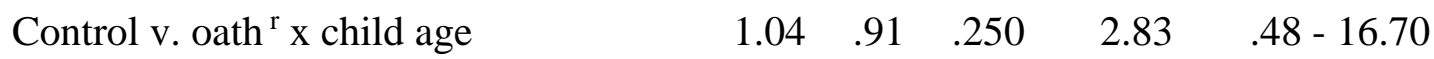

Note. Neither model was significant.

${ }^{r}=$ reference group. 
Table 26

Means and Standard Deviations for Child Direct Sum Scores Across Honesty-Promotion Technique, Transgressor Identity, and Age Conditions

\begin{tabular}{|c|c|c|c|}
\hline Conditions & $M$ & $S D$ & $N$ or $n$ \\
\hline Total & 2.27 & .82 & 114 \\
\hline \multicolumn{4}{|c|}{ Honesty-promotion technique } \\
\hline Prime & 2.10 & .90 & 40 \\
\hline Oath & 2.42 & .77 & 36 \\
\hline Control & 2.32 & .78 & 38 \\
\hline \multicolumn{4}{|c|}{ Transgressor identity } \\
\hline Mother & 2.19 & .81 & 58 \\
\hline RA & 2.36 & .84 & 56 \\
\hline \multicolumn{4}{|l|}{ Age } \\
\hline 6 to 7 years & 2.17 & .85 & 59 \\
\hline 8 to 9 years & 2.38 & .78 & 55 \\
\hline
\end{tabular}


Table 27

Ordinal Logistic Regression Analyses Examining Effects of Predictor Variables on

Transgressor Direct Sum Scores

\begin{tabular}{|c|c|c|c|c|c|}
\hline Model & $B$ & $S E$ & $p$ & $\operatorname{Exp}(B)$ & $\begin{array}{c}95 \% \text { CI for } \\
\operatorname{Exp}(B)\end{array}$ \\
\hline \multicolumn{6}{|l|}{ Step $1 *$} \\
\hline Oath v. prime ${ }^{\mathrm{r}}$ & .81 & .47 & .085 & 2.24 & $.89-5.61$ \\
\hline Control v. prime ${ }^{r}$ & .52 & .45 & .247 & 1.69 & $.70-4.08$ \\
\hline Control v. oath ${ }^{\mathrm{r}}$ & -.28 & .48 & .555 & .75 & $.29-1.93$ \\
\hline Transgressor identity & 1.10 & .39 & $.005 *$ & 2.99 & $1.40-6.38$ \\
\hline Child age & .31 & .38 & .412 & 1.37 & $.65-2.87$ \\
\hline
\end{tabular}

Step 2

$\begin{array}{llllllll}\text { Oath v. prime } & \mathrm{r} x \text { transgressor identity } & -1.16 & .93 & .215 & .31 & .05 & -1.96\end{array}$

$\begin{array}{lllllll}\text { Control v. } \text { prime }^{\mathrm{r}} \mathrm{x} \text { transgressor identity } & -.15 & .92 & .874 & .86 & .14-5.28\end{array}$

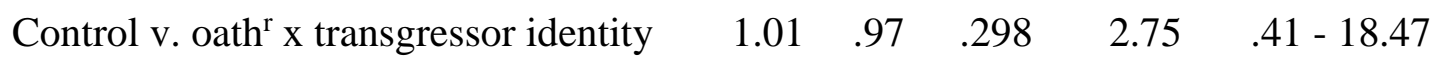

$\begin{array}{llllll}\text { Oath v. prime }^{\mathrm{r}} \mathrm{x} \text { child age } & -93 & .94 & .324 & .40 & .06-2.49\end{array}$

$\begin{array}{llllllll}\text { Control v. } \text { prime }^{\mathrm{r}} \mathrm{x} \text { child age } & & -.18 & .93 & .848 & .84 & .14-5.18\end{array}$

$\begin{array}{lllllll}\text { Control v. oath }{ }^{\mathrm{r}} \mathrm{x} \text { child age } & \text { 75 } & .96 & .435 & 2.11 & .32-13.76\end{array}$

Note. Model 1 was significant.

${ }^{\mathrm{r}}=$ reference group.

$*$ = significant. 
Table 28

Means and Standard Deviations for Transgressor Direct Sum Scores Across Honesty-

Promotion Technique, Transgressor Identity, and Age Conditions

\begin{tabular}{lccc}
\hline Conditions & $M$ & $S D$ & N or $n$ \\
\hline Total & 2.04 & 1.28 & 114 \\
\hline
\end{tabular}

Honesty-promotion technique

Prime

1.80

1.34

40

Oath

2.22

1.20

36

Control

2.11

1.27

48

Transgressor identity

Mother

1.71

1.38

58

RA

2.37

1.07

56

Age

6 to 7 years

1.97

1.29

59

8 to 9 years

2.11

1.27

55 
Table 29

Ordinal Logistic Regression Analyses Examining Effects of Predictor Variables on Child Suggestive Sum Scores

\begin{tabular}{lccccc}
\hline Model & $B$ & $S E$ & $p$ & $\operatorname{Exp}(B)$ & $\begin{array}{c}95 \% \text { CI for } \\
\operatorname{Exp}(B)\end{array}$ \\
\hline Step 1 & & & & & \\
Oath v. prime ${ }^{\mathrm{r}}$ & & & & & \\
Control v. prime ${ }^{\mathrm{r}}$ & -.01 & .44 & .983 & .99 & $.41-2.38$ \\
Control v. oath & & & & & \\
& -.37 & .43 & .384 & .69 & $.30-1.60$ \\
Transgressor identity & -.36 & .44 & .414 & .70 & $.29-1.66$ \\
Child age & .32 & .36 & .373 & 1.38 & $.68-2.78$ \\
& -.02 & .36 & .949 & .98 & $.49-1.97$
\end{tabular}

Step 2

\begin{tabular}{|c|c|c|c|c|c|}
\hline Oath v. prime ${ }^{r} \mathrm{x}$ transgressor identity & -1.85 & .92 & .043 & .16 & $.03-.95$ \\
\hline Control v. prime $^{\mathrm{r}} \mathrm{x}$ transgressor identity & .19 & .87 & .827 & 1.21 & $.22-6.73$ \\
\hline Control v. oath ${ }^{r} \mathrm{x}$ transgressor identity & 2.04 & .92 & .026 & 7.71 & $1.28-46.39$ \\
\hline Oath v. prime ${ }^{\mathrm{r}} \mathrm{x}$ child age & .47 & .91 & .602 & 1.61 & $.27-9.57$ \\
\hline Control v. prime ${ }^{r} x$ child age & .73 & .87 & .403 & 2.08 & $.37-11.54$ \\
\hline Control v. oath ${ }^{\mathrm{r}} \mathrm{x}$ child age & .26 & .90 & .776 & 1.29 & $.22-7.60$ \\
\hline
\end{tabular}

Note. Neither model was significant.

${ }^{r}=$ reference group. 
Table 30

Means and Standard Deviations for Child Suggestive Sum Scores Across Honesty-

Promotion Technique, Transgressor Identity, and Age Conditions

\begin{tabular}{|c|c|c|c|}
\hline Conditions & $M$ & $S D$ & $n$ \\
\hline Total & 2.32 & .80 & 114 \\
\hline \multicolumn{4}{|c|}{ Honesty-promotion technique } \\
\hline Prime & 2.38 & .774 & 40 \\
\hline Oath & 2.33 & .862 & 36 \\
\hline Control & 2.24 & .786 & 38 \\
\hline \multicolumn{4}{|c|}{ Transgressor identity } \\
\hline Mother & 2.22 & .899 & 58 \\
\hline RA & 2.41 & .682 & 56 \\
\hline \multicolumn{4}{|l|}{ Age } \\
\hline 6 to 7 years & 2.32 & .797 & 59 \\
\hline 8 to 9 years & 2.31 & .814 & 55 \\
\hline
\end{tabular}


Table 31

Ordinal Logistic Regression Analyses Examining Effects of Predictor Variables on Transgressor Suggestive Sum Scores

\begin{tabular}{lccccc}
\hline Model & $B$ & $S E$ & $p$ & $\operatorname{Exp}(B)$ & $\begin{array}{c}95 \% \text { CI for } \\
\operatorname{Exp}(B)\end{array}$ \\
\hline Oath v. prime ${ }^{\mathrm{r}}$ & .21 & .72 & .768 & 1.24 & $.30-5.09$ \\
Control v. prime ${ }^{\mathrm{r}}$ & .53 & .78 & .494 & 1.70 & $.37-7.78$ \\
Control v. oath ${ }^{\mathrm{r}}$ & .32 & .81 & .694 & 1.37 & $.28-6.69$ \\
Transgressor identity & .80 & .65 & .214 & 2.23 & $.63-7.93$ \\
Child age & .27 & .62 & .667 & 1.31 & $.39-4.44$ \\
\hline
\end{tabular}

Note. The model was not significant.

${ }^{\mathrm{r}}=$ reference group. 
Table 32

Means and Standard Deviations for Transgressor Suggestive Sum Scores Across Honesty-Promotion Technique, Transgressor Identity, and Age Conditions

\begin{tabular}{|c|c|c|c|}
\hline Conditions & $M$ & $S D$ & Nor $n$ \\
\hline Total & 2.87 & .41 & 113 \\
\hline \multicolumn{4}{|c|}{ Honesty-promotion technique } \\
\hline Prime & 2.82 & .50 & 40 \\
\hline Oath & 2.86 & .42 & 36 \\
\hline Control & 2.92 & .28 & 37 \\
\hline \multicolumn{4}{|c|}{ Transgressor identity } \\
\hline Mother & 2.81 & .52 & 57 \\
\hline RA & 2.93 & .26 & 56 \\
\hline \multicolumn{4}{|l|}{ Age } \\
\hline 6 to 7 years & 2.86 & .40 & 58 \\
\hline 8 to 9 years & 2.87 & .43 & 55 \\
\hline
\end{tabular}


Table 33

Binary Logistic Regression Analyses for Effect of Children's Attachment to their Mother on Dichotomous Primary Dependent Variables $(N=113)$

\begin{tabular}{llllll}
\hline Variables & $B$ & $S E$ & $p$ & $\operatorname{Exp}(B) \begin{array}{l}95 \% \mathrm{CI} \\
\text { for } \operatorname{Exp}(B)\end{array}$ \\
\hline
\end{tabular}

Open-ended: Did the child mention the adult broke the puppet?
Average attachment score

$\begin{array}{lllll}-.16 & .53 & .763 \quad .85 & .30-2.41\end{array}$

Direct question: Did the child tell the truth to "Did something bad happen?"

Average attachment score

$\begin{array}{lllll}-.32 & .55 & .559 & .73 \quad .25-2.12\end{array}$

Direct question: Did the child mention the adult broke the puppet to "Did something bad happen?"

Average attachment score

$\begin{array}{lllll}.12 & .73 & .867 & 1.13 & .27-4.74\end{array}$


Table 34

Ordinal Logistic Regression Analyses for Effect of Children's Attachment to their Mother on Primary Dependent Sum Score Variables

\begin{tabular}{lcccccc}
\hline Variables & $B$ & $S E$ & $p$ & $\operatorname{Exp}(B) \begin{array}{c}95 \% \mathrm{CI} \\
\text { for } \operatorname{Exp}(B)\end{array}$ \\
\hline Child direct sum score $(N=112)$ & -.18 & .50 & .725 & .84 & $.31-2.25$ \\
Transgressor direct sum score $(N=112)$ & -.38 & .51 & .452 & .68 & $.25-1.85$ \\
Child suggestive sum score $(N=112)$ & -.74 & .51 & .146 & .48 & $.18-1.29$ \\
Transgressor suggestive sum score $(N=111)$ & .12 & .84 & .888 & 1.13 & $.22-5.82$ \\
\hline
\end{tabular}


Table 35

Binary Logistic Regression Analyses for Effect of Mother-Child Relationship Quality on Dichotomous Primary Dependent

Variables $(N=114)$

\begin{tabular}{lllllcc}
\hline Variables & $B$ & $S E$ & $p$ & $\operatorname{Exp}(B)$ & $\begin{array}{c}95 \% \mathrm{CI} \\
\text { for } \operatorname{Exp}(B)\end{array}$ \\
\hline
\end{tabular}

Open-ended: Did the child mention the adult broke the puppet?

$\begin{array}{lllllll}\text { Total relationship-quality score } & -.02 & .02 & .189 & .98 & .95-1.01\end{array}$

Direct question: Did the child tell the truth to "Did something bad happen?"

$\begin{array}{lllllll}\text { Total relationship-quality score } & .01 & .02 & .527 & 1.01 & .98-1.05\end{array}$

Direct question: Did the child mention the adult broke the puppet to "Did something bad happen?"

Total relationship-quality score

$\begin{array}{lllll}.04 & .03 & .163 & 1.04 & .99-1.10\end{array}$


Table 36

Ordinal Logistic Regression Analyses for Effect of Mother-Child Relationship Quality on Primary Dependent Sum Score Variables

\begin{tabular}{lcccccc}
\hline Variables & $B$ & $S E$ & $p$ & $\operatorname{Exp}(B)$ & $\begin{array}{c}95 \% \text { CI } \\
\text { for } \operatorname{Exp}(B)\end{array}$ \\
\hline Child direct sum score $(N=113)$ & .01 & .02 & .463 & 1.01 & $.98-1.04$ \\
Transgressor direct sum score $(N=113)$ & -.02 & .02 & .397 & .99 & $.95-1.02$ \\
Child suggestive sum score $(N=113)$ & .01 & .02 & .499 & 1.01 & $.98-1.04$ \\
Transgressor suggestive sum score $(N=112)$ & -.03 & .03 & .377 & .97 & $.92-1.03$ \\
\hline
\end{tabular}


Table 37

Binary Logistic Regression Analyses for Effects of Parenting Styles on Dichotomous

Primary Dependent Variables

\begin{tabular}{lllllll}
\hline Variables & $B$ & $S E$ & $p$ & $\operatorname{Exp}(B)$ & $\begin{array}{c}95 \% \mathrm{CI} \\
\text { for } \operatorname{Exp}(B)\end{array}$ \\
\hline
\end{tabular}

Open-ended: Did the child mention the adult broke the puppet?

$\begin{array}{lccccc}\text { Authoritative sum }(N=111) & .00 & .04 & .974 & 1.00 & .93-1.07 \\ \text { Authoritarian sum }(N=112) & .00 & .04 & .996 & 1.00 & .92-1.08 \\ \text { Permissive sum }(N=113) & -.07 & .06 & .271 & .94 & .83-1.05\end{array}$

Direct question: Did the child tell the truth to "Did something bad happen?"

$\begin{array}{lccccc}\text { Authoritative sum }(N=111) & .07 & .04 & .083 & 1.07 & .99-1.15 \\ \text { Authoritarian sum }(N=112) & -.01 & .04 & .847 & .99 & .92-1.08 \\ \text { Permissive sum }(N=113) & -.10 & .06 & .112 & .91 & .80-1.02\end{array}$

Direct question: Did the child mention the adult broke the puppet to "Did something bad happen?"

Authoritative sum $(N=111)$

Authoritarian sum $(N=112)$

$\begin{array}{lllll}.04 & .05 & .377 & 1.05 & .95-1.15 \\ -.07 & .06 & .212 & .93 & .83-1.04 \\ -.14 & .09 & .136 & .87 & .73-1.04\end{array}$

Permissive sum $(N=113)$

$\begin{array}{llll}-.14 & .09 & .136 & .87\end{array}$ 
Table 38

Ordinal Logistic Regression Analyses for Effects of Parenting Styles on Primary

Dependent Sum Score Variables

\begin{tabular}{|c|c|c|c|c|c|}
\hline Variables & $B$ & $S E$ & $p$ & $\operatorname{Exp}(B)$ & $\begin{array}{c}95 \% \text { CI for } \\
\operatorname{Exp}(B)\end{array}$ \\
\hline \multicolumn{6}{|l|}{ Child direct sum score } \\
\hline Authoritative sum $(N=110)$ & .01 & .03 & .820 & 1.01 & $.94-1.08$ \\
\hline Authoritarian sum $(N=111)$ & -.06 & .04 & .117 & .94 & $.87-1.02$ \\
\hline Permissive $\operatorname{sum}(N=112)$ & -.07 & .06 & .231 & .94 & $.84-1.04$ \\
\hline \multicolumn{6}{|l|}{ Transgressor direct sum score } \\
\hline Authoritative sum $(N=110)$ & -.00 & .04 & .986 & 1.00 & $.93-1.07$ \\
\hline Authoritarian sum $(N=111)$ & -.03 & .04 & .504 & .97 & $.90-1.05$ \\
\hline Permissive sum $(N=112)$ & -.04 & .06 & .478 & .96 & $.86-1.08$ \\
\hline \multicolumn{6}{|l|}{ Child suggestive sum score } \\
\hline Authoritative sum $(N=110)$ & .01 & .03 & .869 & 1.01 & $.94-1.07$ \\
\hline Authoritarian sum $(N=111)$ & -.04 & .04 & .371 & .97 & $.90-1.04$ \\
\hline Permissive sum $(N=112)$ & -.04 & .06 & .473 & .96 & $.86-1.07$ \\
\hline \multicolumn{6}{|l|}{ Transgressor suggestive sum score } \\
\hline Authoritative sum $(N=109)$ & -.05 & .06 & .420 & .95 & $.84-1.08$ \\
\hline Authoritarian sum $(N=110)$ & -.06 & .06 & .330 & .94 & $.84-1.06$ \\
\hline Permissive sum $(N=111)$ & .03 & .10 & .787 & 1.03 & $.85-1.24$ \\
\hline
\end{tabular}


Table 39

Binary Logistic Regression Analyses for Effects of Children's Average Total Trust in Mothers and Fathers on the Dichotomous Primary Dependent Variables $(N=115)$

\begin{tabular}{llllll}
\hline Variables & $B$ & $S E$ & $p$ & $\operatorname{Exp}(B) \begin{array}{c}95 \% \mathrm{CI} \\
\text { for } \operatorname{Exp}(B)\end{array}$ \\
\hline
\end{tabular}

Open-ended: Did the child mention the adult broke the puppet?
Mother
$-.23 \quad .23$
Father*
$.23 \quad .315$
$.315 \quad .80$
$.51-1.24$
$\begin{array}{lllll}-.58 & .23 & .011 * & .56 & .36-.87\end{array}$

Direct question: Did the child tell the truth to "Did something bad happen?"
Mother
$-.34 \quad .23$
$23 \quad .147$
.71
$.45-1.13$
Father*

$\begin{array}{llll}-.50 & .22 & .026^{*} \quad .61\end{array}$
$.39-.94$

Direct question: Did the child mention the adult broke the puppet to "Did something bad happen?"

$\begin{array}{llllll}\text { Mother } & -.04 & .31 & .893 & .96 & .53-1.76 \\ \text { Father* } & -.61 & .31 & .049 * & .55 & .30-1.00\end{array}$

Note. ${ }^{*}=$ significant. 
Table 40

Ordinal Logistic Regression Analyses for Effects of Children's Average Total Trust in Mothers and Fathers on Primary Dependent Sum Score Variables

\begin{tabular}{|c|c|c|c|c|c|}
\hline Variables & B & $S E$ & $p$ & $\operatorname{Exp}(B)$ & $\begin{array}{c}95 \% \mathrm{CI} \text { for } \\
\operatorname{Exp}(\mathrm{B})\end{array}$ \\
\hline \multicolumn{6}{|c|}{ Child direct sum score $(N=114)$} \\
\hline Mother & -.20 & .21 & .346 & .82 & $.54-1.24$ \\
\hline Father & -.30 & .20 & .137 & .74 & $.50-1.10$ \\
\hline \multicolumn{6}{|c|}{ Transgressor direct sum score $(N=114)$} \\
\hline Mother* & -.51 & .22 & $.022 *$ & .60 & $.39-.93$ \\
\hline Father* & -.67 & .21 & $.001 *$ & .51 & $.34-.77$ \\
\hline \multicolumn{6}{|c|}{ Child suggestive sum score $(N=114)$} \\
\hline Mother & -.12 & .22 & .566 & .88 & $.58-1.35$ \\
\hline Father & .05 & .20 & .803 & 1.05 & $.72-1.54$ \\
\hline \multicolumn{6}{|c|}{ Transgressor suggestive sum score $(N=113)$} \\
\hline Mother & -.06 & .37 & .871 & .94 & $.46-1.93$ \\
\hline Father & .53 & .35 & .132 & 1.70 & $.85-3.38$ \\
\hline
\end{tabular}

Note. ${ }^{*}=$ significant. 
Figure 1

Flow Chart for Child Study Protocol

Child Assent,

Questionnaire 1:

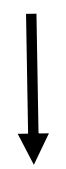

First Aid/Safety

Event:

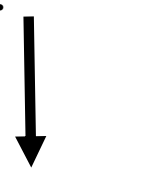

Transgression:

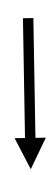

RA1 assented child and

administered the Early

Childhood Generalized Trust

Belief Scale (1/2 of sample).
RA1 assented child and

administered the Attachment

Security Scale (1/2 of sample).
Child and RA1 participated in first aid/safety event. Then,

RA1 left the room.

Stranger Transgressor
Condition (1/2 of sample):
$R A 2$ and child played with
"forbidden" puppets, and $R A 2$
"broke" a puppet and requested
that child keep it a secret.

Mother and child played with

"forbidden" puppets, and mother

"broke" a puppet and requested

that child keep it a secret. 


\begin{tabular}{|c|c|}
\hline $\begin{array}{l}\text { Honesty- } \\
\text { Promotion } \\
\text { Technique: }\end{array}$ & $\begin{array}{l}\quad \begin{array}{l}\text { Prime Condition } \\
\text { (1/3 of sample): }\end{array} \\
\text { RA1 played the prime story } \\
\text { for child. Later, RA1 put box } \\
\text { of puppets outside of study } \\
\text { room and hesitated as if to } \\
\text { notice something was } \\
\text { different about puppets. RA1 } \\
\text { stated: Before we go on to our } \\
\text { next activity, I have some } \\
\text { questions to ask you. }\end{array}$ \\
\hline
\end{tabular}

notice something was different
about puppets. RA1 stated:
Before we go on to our next
activity, I have some questions
to ask you. Can you promise
that you will tell me the truth?
Will you tell me any lies?
Will you tell me any lies?

\section{Oath Condition}

(1/3 of sample):

RA1 played the neutral story for child. Later, RA1 put box of puppets outside of study room and hesitated as if to

Interview:

Child was asked a series of questions about what happened when adult transgressor was in study room: one open-ended question, seven total direct questions about both the child's and adult's behaviors, and six total suppositional questions about both the child's and adult's behaviors. 


\begin{tabular}{l|l|}
$\begin{array}{l}\text { Manipulation } \\
\text { checks: }\end{array}$ & $\begin{array}{l}\text { Child was asked three questions } \\
\text { about the content of the prime or } \\
\text { neutral story, three questions } \\
\text { about his/her awareness of } \\
\text { any association between the } \\
\text { story and puppet breaking, } \\
\text { and three questions about } \\
\text { his/her feelings about story. }\end{array}$ \\
\hline
\end{tabular}

Questionnaire 2:

$\begin{aligned} & \text { RA1 administered the Early } \\
& \text { Childhood Generalized Trust } \\
& \text { Belief Scale (1/2 of sample). }\end{aligned}$ OR \begin{tabular}{l}
$\begin{array}{l}\text { RA1 administered the } \\
\text { Attachment Security Scale (1/2 } \\
\text { of sample). }\end{array}$ \\
\hline
\end{tabular}

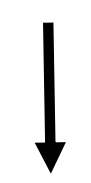

Belief Scale (1/2 of sample).

Debriefing:

Child was debriefed by RA1 with

the adult transgressor present.

The child received a small prize. 


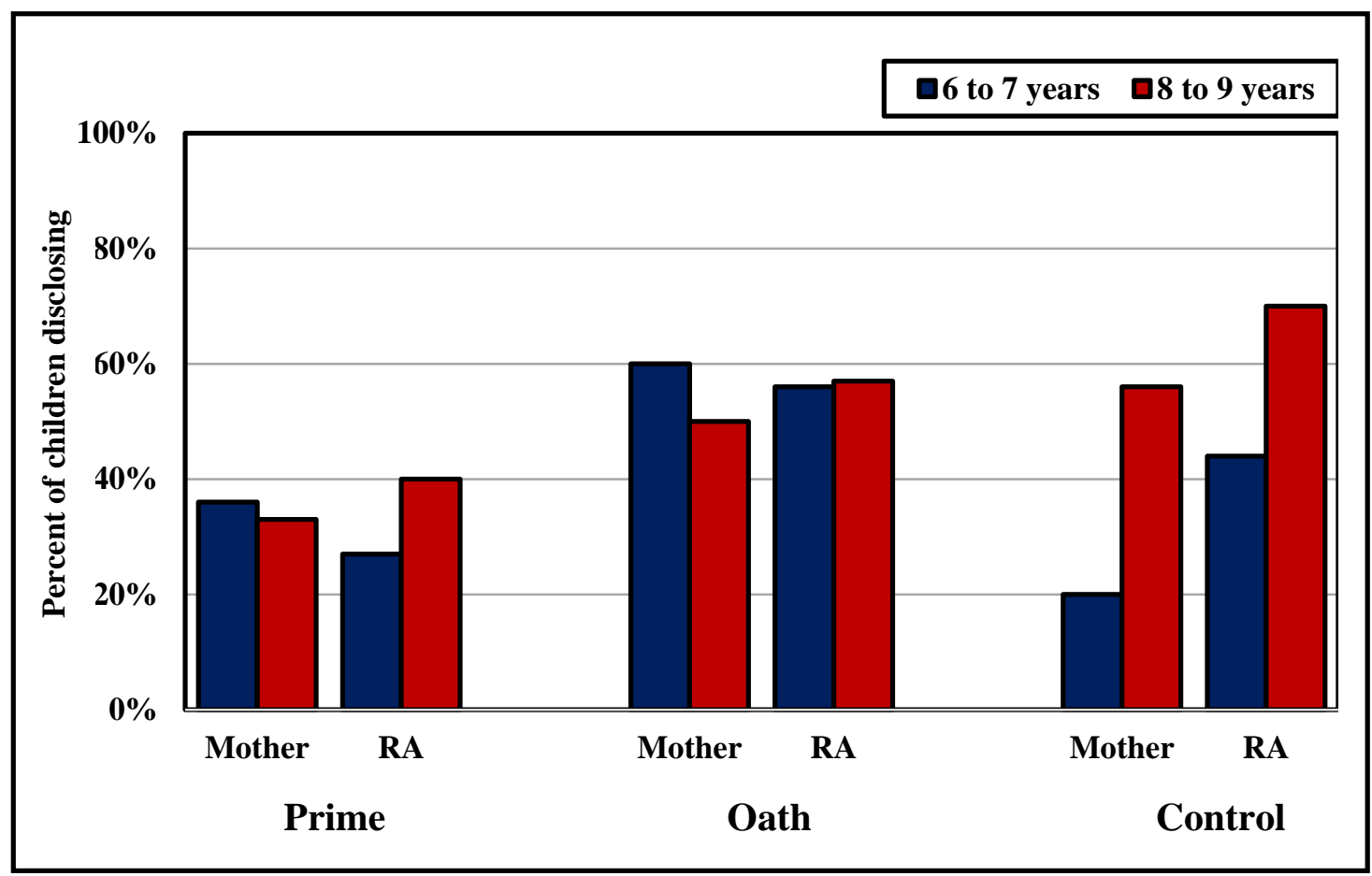

Figure 2. Percent of children disclosing adult transgression to open-ended question. This figure illustrates the percent of children spontaneously disclosing that the adult broke the puppet to Tell me what happened while I was gone and you were waiting for me with [adult transgressor] across the honesty-promotion technique, transgressor identity, and age group conditions. 


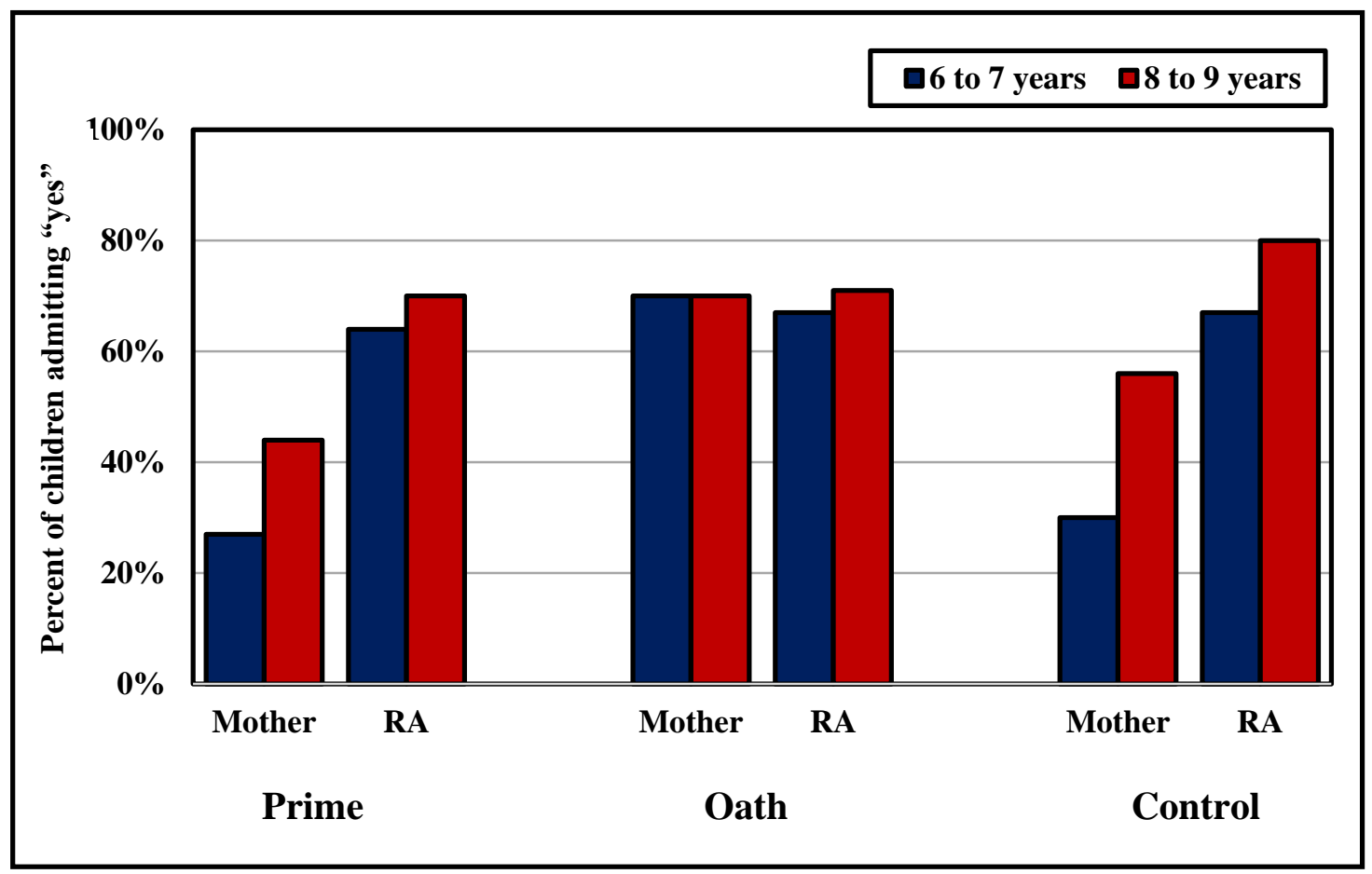

Figure 3. Percent of children admitting something bad happened to direct question. This figure illustrates the percent of children admitting that "yes" something bad had happened to Did something bad happen while I was gone and you were waiting for me with [adult transgressor] across the honesty-promotion technique, transgressor identity, and age group conditions. 


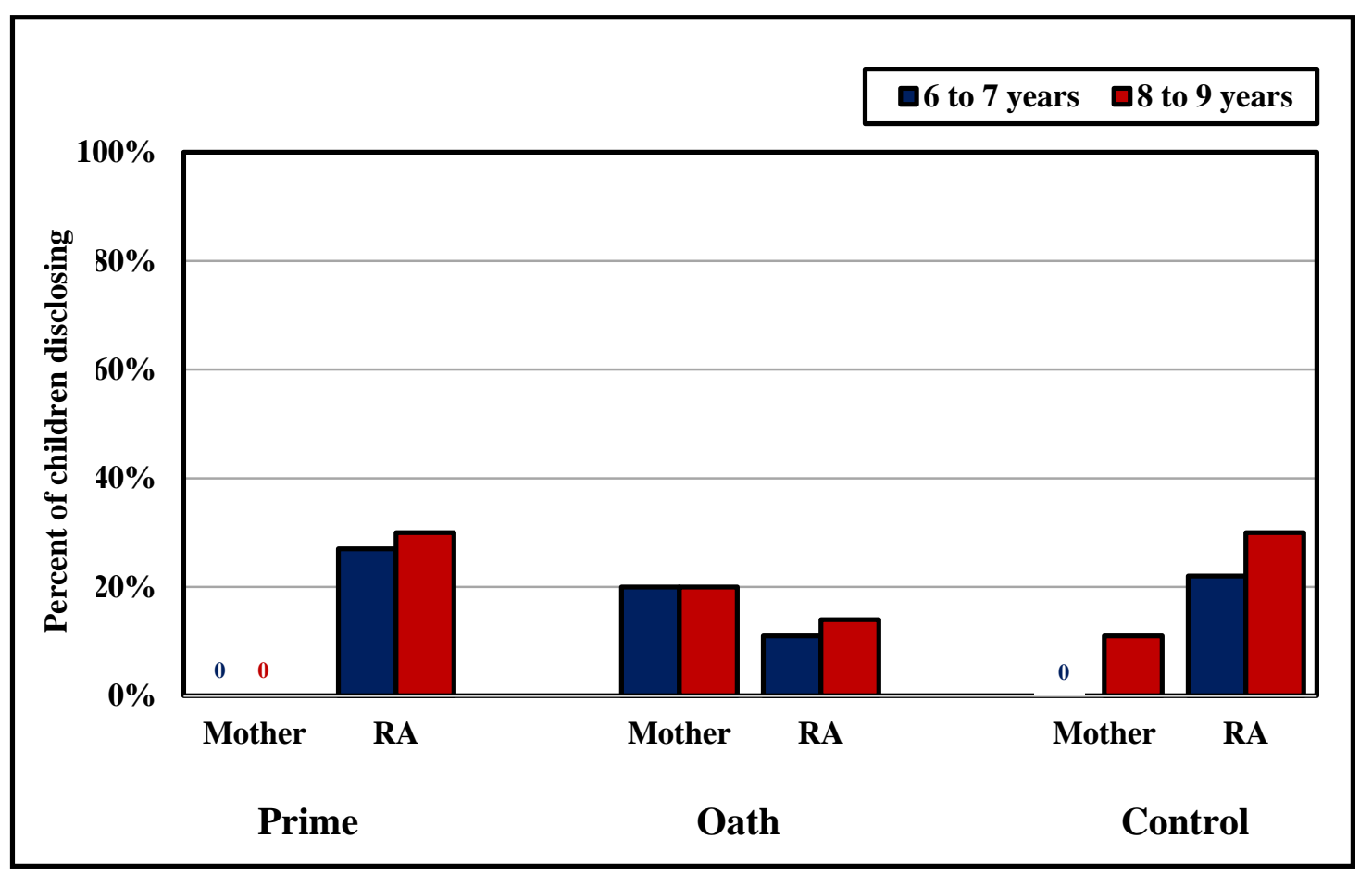

Figure 4. Percent of children disclosing adult transgression when directly asked if something bad happened. This figure illustrates the percent of children spontaneously disclosing that the adult broke the puppet to Did something bad happen while I was gone and you were waiting for me with [adult transgressor] across the honesty-promotion technique, transgressor identity, and age group conditions. In three of the conditions, none of the children disclosed. This is noted with a " 0 ". 


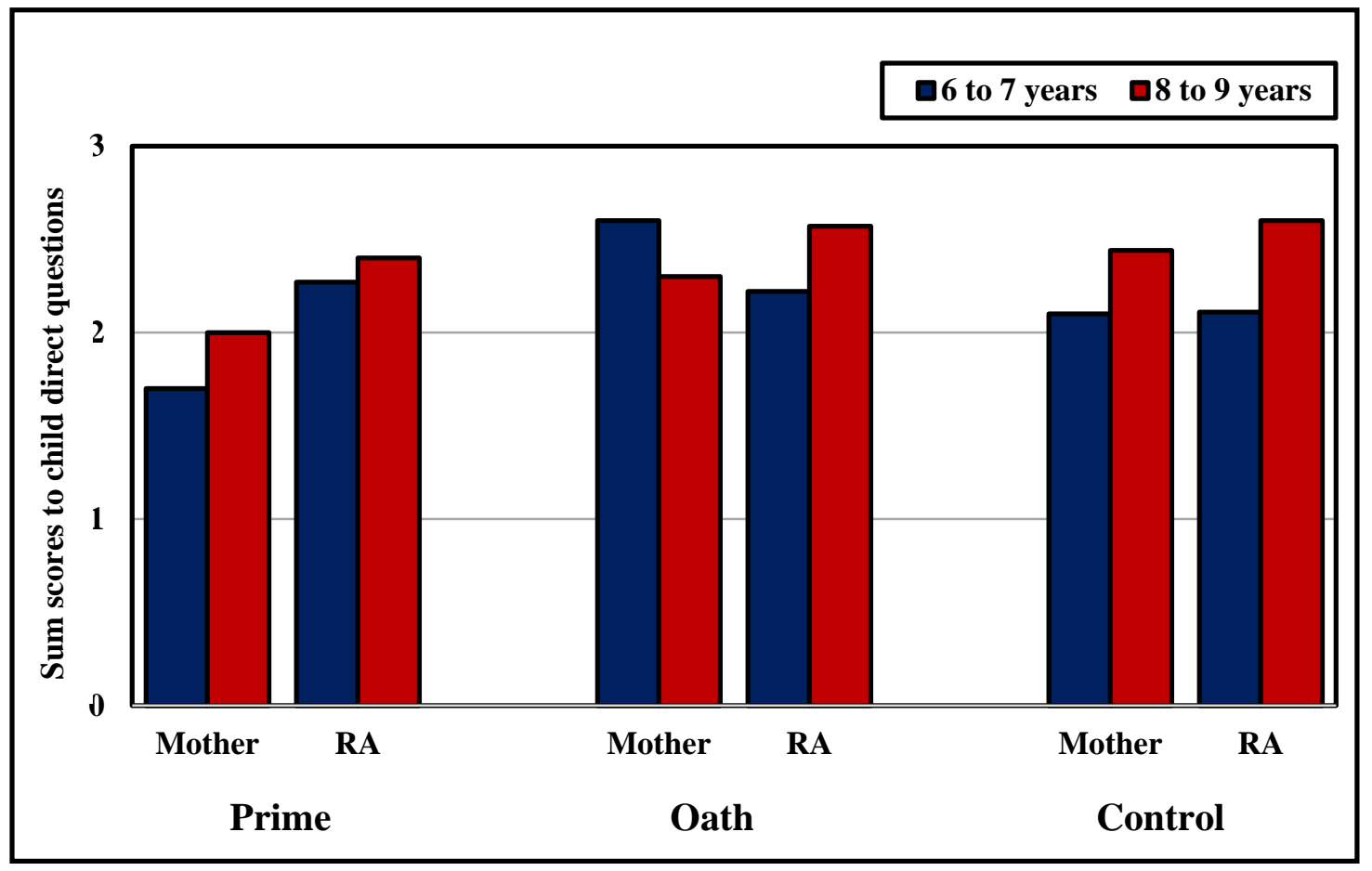

Figure 5. Children's average sum scores to direct questions about child. This figure illustrates children's average sum scores when asked three direct questions about the child touching, playing with, and breaking the puppet. Larger sum scores indicate that children were more truthful to these direct questions. 


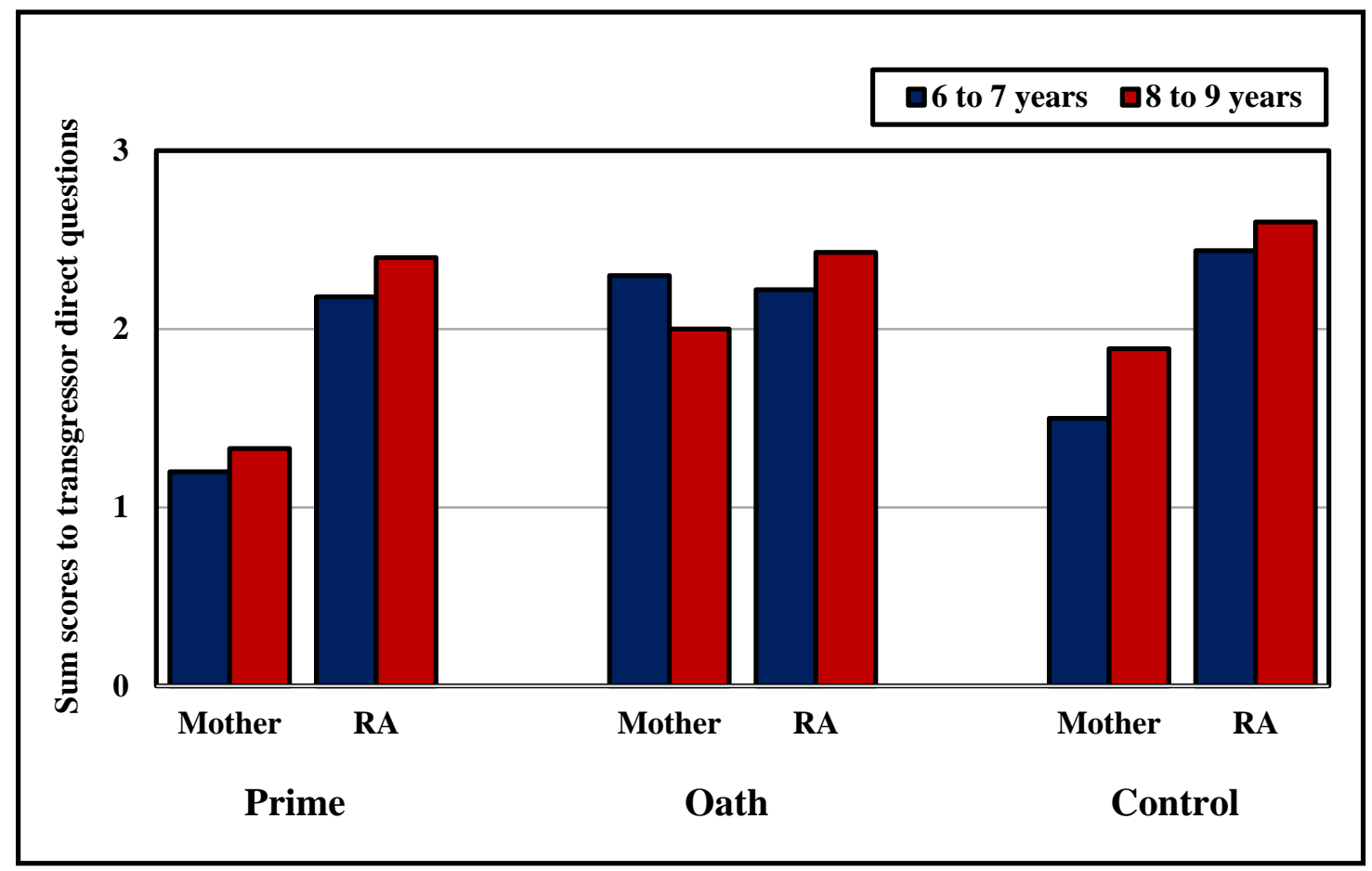

Figure 6. Children's average sum scores to direct questions about transgressor. This figure illustrates children's average sum scores when asked three direct questions about the adult transgressor touching, playing with, and breaking the puppet. Larger sum scores indicate that children were more truthful to these direct questions. 


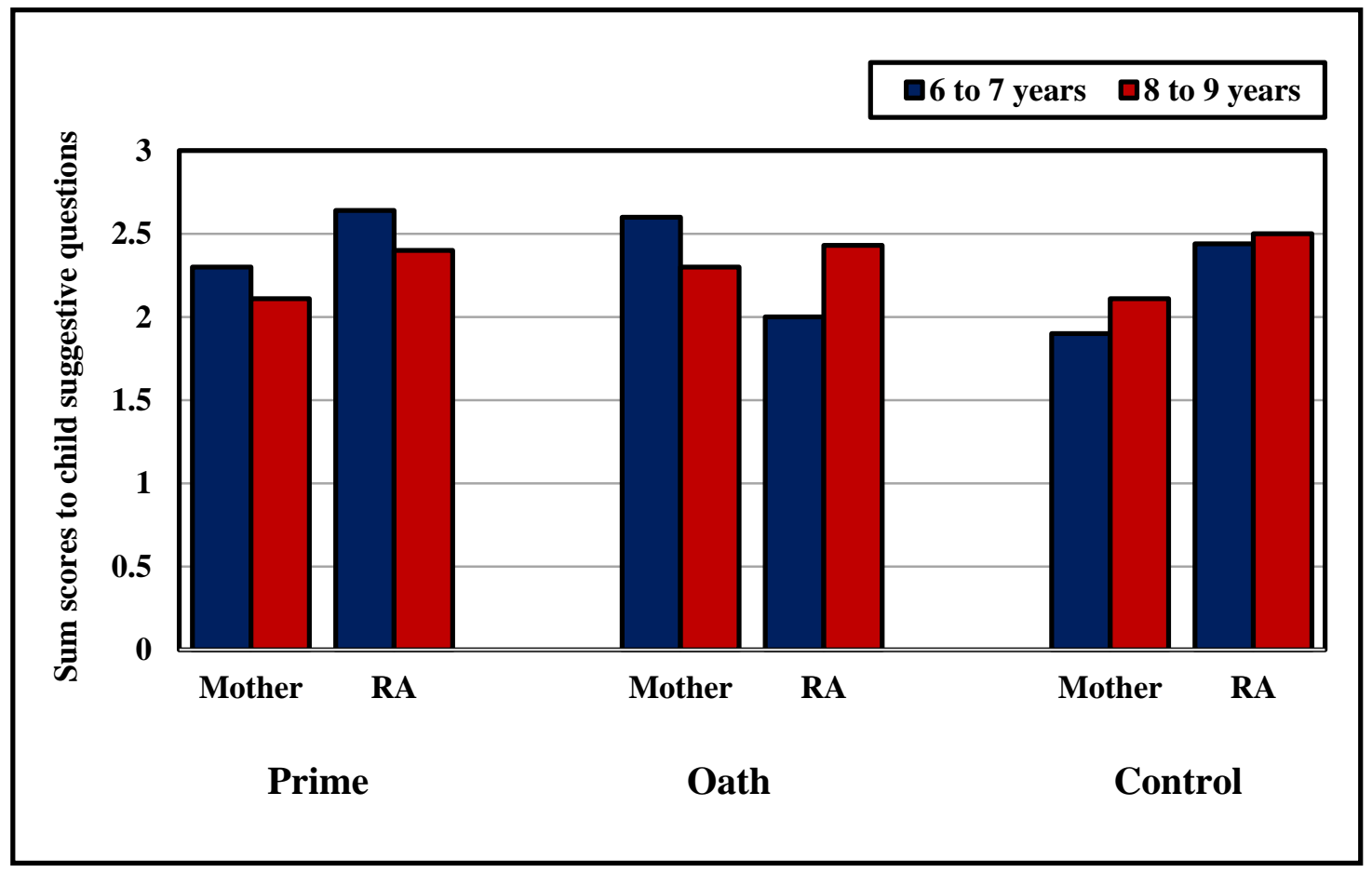

Figure 7. Children's average sum scores to suggestive questions about child. This figure illustrates children's average sum scores when asked three suggestive (i.e., suppositional) questions about the child touching, playing with, and breaking the puppet. Larger sum scores indicate that children were more truthful to these suggestive questions. 


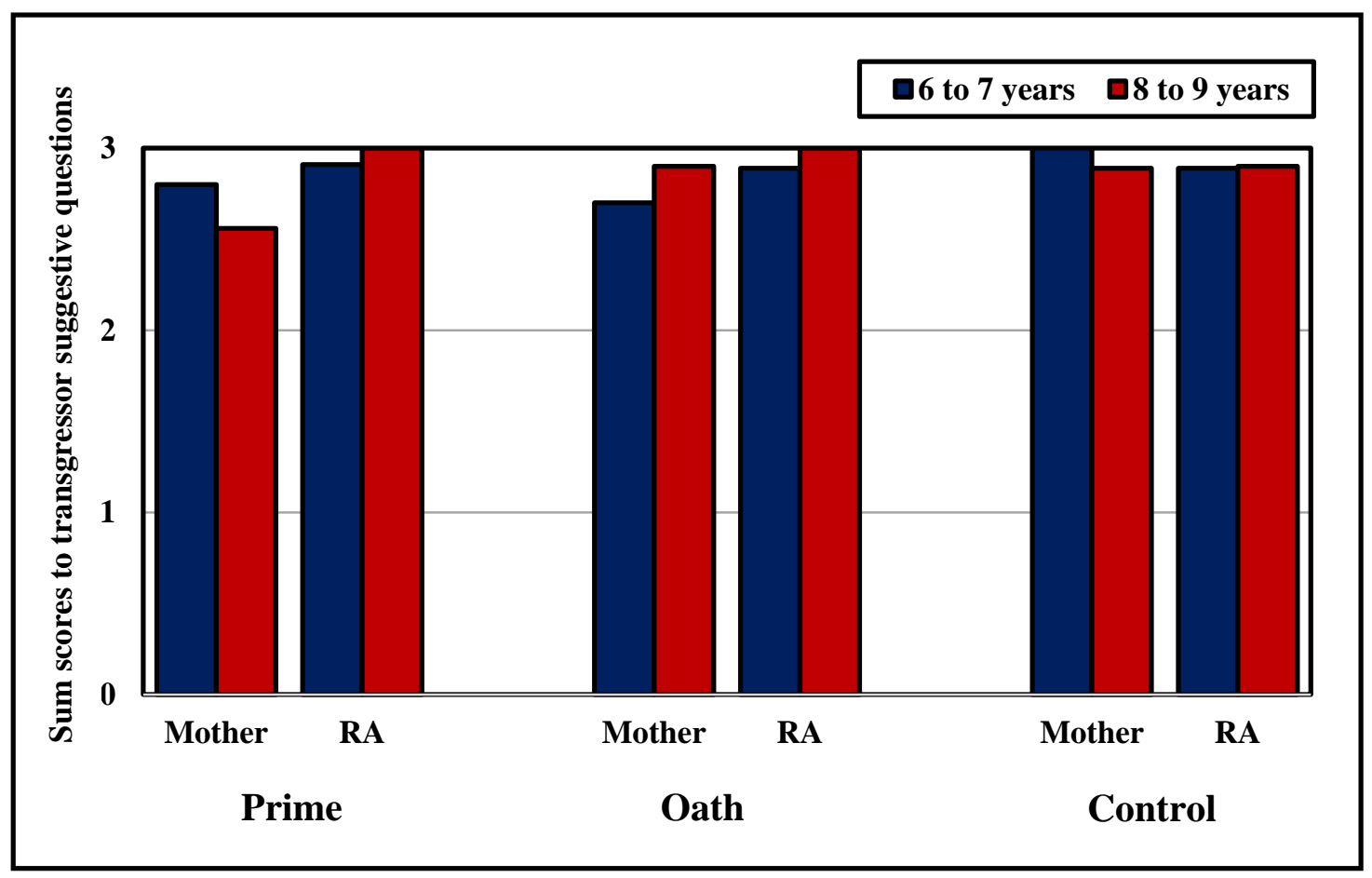

Figure 8. Children's average sum scores to suggestive questions about the transgressor. This figure illustrates children's average sum scores when asked three suggestive (i.e., suppositional) questions about the transgressor touching, playing with, and breaking the puppet. Larger sum scores indicate that children were more truthful to these suggestive questions. 


\section{REFERENCES}

Anderson, J., Martin, J., Mullen, P., Romans, S., \& Herbison, P. (1993). Prevalence of childhood sexual abuse experiences in a community sample of women. Journal of the American Academy of Child \& Adolescent Psychiatry, 32, 911-919. doi: 10.1097/00004583-199309000-00004

Ahern, E. C., Stolzenberg, S. N., McWilliams, K., \& Lyon, T. D. (2016). The effects of secret instructions and yes/no questions on maltreated and non-maltreated children's reports of a minor transgression. Behavioral Sciences \& the Law, 34, 784-802. doi: 10.1002/bsl.2277

Bargh, J. A., Chen, M., \& Burrows, L. (1996). Automaticity of social behavior: Direct effects of trait construct and stereotype activation on action. Journal of Personality and Social Psychology, 71, 230-244. doi: 10.1037/00223514.71.2.230

Bargh, J. A., Gollwitzer, P. M., Lee-Chai, A., Barndollar, K., \& Trotschel, R. (2001). The automated will: Nonconscious activation and pursuit of behavioral goals. Journal of Personality and Social Psychology, 81, 1014-1027. doi: 10.1037/00223514.81.6.1014

Bargh, J. A., Schwader, K. L., Hailey, S. E., Dyer, R. L., \& Boothby, E. J. (2012). Automaticity in social-cognitive processes. Trends in Cognitive Sciences, 16, 593605. doi:10.1016/j.tics.2012.10.002

Baumrind, D. (1971). Current patterns of parental authority. Developmental Psychology, 4, 1-103. doi: 10.1037/h0030372

Betts, L. R., Rotenberg, K. J., \& Trueman, M. (2009). The early childhood generalized trust belief scale. Early Childhood Research Quarterly, 24, 175-185. doi: 10.1016/j.ecresq.2008.10.002

Brown, D. A., Lewis, C. N., Lamb, M. E., \& Stephens, E. (2012). The influences of delay and severity of intellectual disability on event memory in children. Journal of Consulting and Clinical Psychology, 80, 829-841. doi: 10.1037/a0029388

Driscoll, K., \& Pianta, R. C. (2011). Mothers' and fathers' perceptions of conflict and closeness in parent-child relationships during early childhood. Journal of Early Childhood and Infant Psychology, 7, 1-24.

Eaton, A. A., Visser, P. S., \& Burns, V. (in press). Prescriptions for persuasion: How gender role salience influences attitude strength and persuasive message processing. Psychology of Women Quarterly. 
Evans, A. D., \& Lee, K. (2010). Promising to tell the truth makes 8- to 16-year-olds more honest. Behavioral Sciences and the Law, 28, 801-811. doi: 10.1111/j.14677687.2011.01043.x

Evans, A. D., Stolzenberg, S. N., Lee, K., \& Lyon, T. D. (2014). Young children's difficulty with indirect speech acts: Implications for questioning child witnesses. Behavioral Sciences \& the Law, 32, 775-788. doi: 10.1002/bsl.2142

Goodman, G. S., Taub, E. P., Jones, D. P., England, P., Port, L. K., Rudy, L., . . Melton, G. B. (1992). Testifying in criminal court: Emotional effects on child sexual assault victims. Monographs of the Society for Research in Child Development, 57, v-142. doi: 10.2307/1166127

Gordon, H. M., Lyon, T. D., \& Lee, K. (2014). Social and cognitive factors associated with children's secret-keeping for a parent. Child Development, 85, 2374-2388. doi: 10.1111/cdev.12301

Haugaard, J. J., Reppucci, N. D., Laird, J., \& Nauful, T. (1991). Children's definitions of the truth and their competency as witnesses in legal proceedings. Law and Human Behavior, 15, 253-271. doi: 10.1007/BF01061712

Hazzard, A., Celano, M., Gould, J., Lawry, S., \& Webb, C. (1995). Predicting symptomatology and self-blame among child sex abuse victims. Child Abuse \& Neglect, 19, 707-714. doi: 10.1016/0145-2134(95)00028-7

Hershkowitz, I., Horowitz, D., \& Lamb, M. E. (2005). Trends in children's disclosure of abuse in Israel: A national study. Child Abuse \& Neglect, 29, 1203-1214. doi: 10.1016/j.chiabu.2005.04.008

Huffman, M. L., Warren, A. R., \& Larson, S. M. (1999). Discussing truth and lies in interviews with children: Whether, why, and how? Applied Developmental Science, 3, 6-15. doi: 10.1207/s1532480xads0301_2

Kerns, K. A., Klepac, L., \& Cole, A. (1996). Peer relationships and preadolescents' perceptions of security in the child-mother relationship. Developmental Psychology, 32, 457-466. doi: 10.1037/0012-1649.32.3.457

Kesek, A., Cunningham, W. A., Packer, D. J., \& Zelazo, P. D. (2011). Indirect goal priming is more powerful than explicit instruction in children. Developmental Science, 14, 944-948. doi: 10.1111/j.1467-7687.2011.01043.x

Klemfuss, J. Z., Quas, J. A., \& Lyon, T. D. (2014). Attorneys' questions and children's productivity in child sexual abuse criminal trials. Applied Cognitive Psychology, 28, 780-788. doi: 10.1002/acp.3048 
Lamb, M. E., Orbach, Y., Hershkowitz, I., Horowitz, D., \& Abbott, C. B. (2007). Does the type of prompt affect the accuracy of information provided by alleged victims of abuse in forensic interviews? Applied Cognitive Psychology, 21, 1117-1130. doi: $10.1002 /$ acp. 1318

Lawson, L., \& Chaffin, M. (1992). False negatives in sexual abuse disclosure interviews: Incidence and influence of caretaker's belief in abuse in cases of accidental abuse discovery by diagnosis of STD. Journal of Interpersonal Violence, 7, 532-542. doi: $10.1177 / 088626092007004008$

Lee, K., Talwar, V., McCarthy, A., Ross, I., Evans, A., \& Arruda, C. (2014). Can classic moral stories promote honesty in children? Psychological Science, 25, 1630-1636. doi: 10.1177/0956797614536401

London, K., Bruck, M., Ceci, S. J., \& Shuman, D. W. (2005). Disclosure of child sexual abuse: What does the research tell us about the ways that children tell? Psychology, Public Policy, and Law, 11, 194-226. doi: 10.1037/10768971.11.1.194

London, K., Bruck, M., Wright, D. B., \& Ceci, S. J. (2008). Review of the contemporary literature on how children report sexual abuse to others: Findings, methodological issues, and implications for forensic interviewers. Memory, 16, 29-47. doi: $10.1080 / 09658210701725732$

London, K., \& Nunez, N. (2002). Examining the efficacy of truth/lie discussions in predicting and increasing the veracity of children's reports. Journal of Experimental Child Psychology, 83, 131-147. doi: 10.1016/S00220965(02)00119-4

Lyon, T. D. (2011). Assessing the competency of child witnesses: Best practice informed by psychology and law. In M. E. Lamb, D. La Rooy, C. Katz, \& L. C. Malloy (Eds.), Children's testimony: A handbook of psychological research and forensic practice (pp. 69-85). Sussex, UK: Wiley-Blackwell.

Lyon, T. D., Ahern, E. C., Malloy, L. C., \& Quas, J. A. (2010). Children's reasoning about disclosing adult transgressions: Effects of maltreatment, child age, and adult identity. Child Development, 81, 1714-1728. doi: 10.1111/j.14678624.2010.01505.x

Lyon, T. D., \& Dorado, J. S. (2008). Truth induction in young maltreated children: The effects of oath-taking and reassurance on true and false disclosures. Child Abuse \& Neglect, 32, 738-748. doi: 10.1016/j.chiabu.2007.08.008 
Lyon, T. D., Malloy, L. C., Quas, J. A., \& Talwar, V. A. (2008). Coaching, truth induction, and young maltreated children's false allegations and false denials. Child Development, 79, 914-929. doi: 10.1111/j.1467-8624.2008.01167.x

Lyon, T. D., Wandrey, L., Ahern, E., Licht, R., Sim, M. P. Y., \& Quas, J. A. (2014). Eliciting maltreated and nonmaltreated children's transgression disclosures: Narrative practice rapport building and a putative confession. Child Development, 85, 1756-1769. doi: 10.1111/cdev.12223

Malloy, L. C., Brubacher, S. P., \& Lamb, M. E. (2011). Expected consequences of disclosure revealed in investigative interviews with suspected victims of child sexual abuse. Applied Developmental Science, 15, 8-19. doi: 10.1080/10888691.2011.538616

Malloy, L. C., Lyon, T. D., \& Quas, J. A. (2007). Filial dependency and recantation of child sexual abuse allegations. Journal of the American Academy of Child \& Adolescent Psychiatry, 46, 162-170. doi: 10.1097/01.chi.0000246067.77953.f7

Malloy, L. C., \& Mugno, A. P. (2016). Children's recantation of adult wrongdoing: An experimental investigation. Journal of Experimental Child Psychology, 145, 1121. doi: 10.1016/j.jecp.2015.12.003

Malloy, L. C., Quas, J. A., Lyon, T. D., \& Ahern, E. C. (2014). Disclosing adult wrongdoing: Maltreated and non-maltreated children's expectations and preferences. Journal of Experimental Child Psychology, 124, 78-96. doi: 10.1016/j.jecp.2014.01.018

Mullen, P. E., Martin, J. L., Anderson, J. C., Romans, S. E., \& Herbison, G. P. (1993). Childhood sexual abuse and mental health in adult life. The British Journal of Psychiatry, 163, 721-732. doi: 10.1192/bjp.163.6.721

Orbach, Y., Hershkowitz, I., Lamb, M. E., Sternberg, K. J., Esplin, P. W., \& Horowitz, D. (2000). Assessing the value of structured protocols for forensic interviews of alleged child abuse victims. Child Abuse \& Neglect, 24, 733-752. doi: 10.1016/S0145-2134(00)00137-X

Over, H., \& Carpenter, M. (2009). Eighteen-month-old infants show increased helping following priming with affiliation. Psychological Science, 20, 1189-1193. doi: 10.1111/j.1467-9280.2009.02419.x

Pashler, H., Rohrer, D. \& Harris, C. R. (2013). Can the goal of honesty be primed? Journal of Experimental Social Psychology, 49, 959-964. doi: 10.1016/j.jesp.2013.05.011 
Peterson, C., Dowden, C., \& Tobin, J. (1999). Interviewing preschoolers: Comparisons of yes/no and wh- questions. Law and Human Behavior, 23, 539-555. doi: 10.1023/A:1022396112719

Pianta, R. C. (1992). Child-Parent Relationship Scale. Unpublished measure, University of Virginia.

Pipe, M., \& Wilson, J. C. (1994). Cues and secrets: Influences on children's event reports. Developmental Psychology, 30, 515-525. doi: 10.1037/0012-1649.30.4.515

Quas, J. A., Goodman, G. S., \& Jones, D. (2003). Predictors of attributions of self-blame and internalizing behavior problems in sexually abused children. Journal of Child Psychology and Psychiatry, 44, 723-736. doi: 10.1111/1469-7610.00158

Randolph-Seng, B., \& Nielsen, M. E. (2007). Honesty: One effect of primed religious representations. International Journal for the Psychology of Religion, 17, 303315. doi: 10.1080/10508610701572812

Rasinski, K. A., Visser, P. S., Zagatsky, M., \& Rickett, E. M. (2005). Using implicit goal priming to improve the quality of self-report data. Journal of Experimental Social Psychology, 41, 321-327. doi: 10.1016/j.jesp.2004.07.001

Robinson, C. C., Mandleco, B., Olsen, S. F., \& Hart, C. H. (2001). The Parenting Styles and Dimensions Questionnaire (PSDQ). In B. F. Perlmutter, J. Touliatos, \& G. W. Holden (Eds.), Handbook of family measurement techniques: Vol 3 (pp. 319-321). Thousand Oaks: Sage.

Rotenberg, K. J. (1994). Loneliness and interpersonal trust. Journal of Social and Clinical Psychology, 13, 152-173. doi: 10.1521/jscp.1994.13.2.152

Rush, E. B., Stolzenberg, S. N., Quas, J. A., \& Lyon, T. D. (2017). The effects of the putative confession and parent suggestion on children's disclosure of a minor transgression. Legal and Criminological Psychology, 22, 60-73. doi: 10.1111/lcrp. 1208

Smith, D. W., Letourneau, E. J., Saunders, B. E., Kilpatrick, D. G., Resnick, H. S., \& Best, C. L. (2000). Delay in disclosure of childhood rape: Results from a national survey. Child Abuse \& Neglect, 24, 273-287. doi: 10.1016/S0145-2134(99)001301

State v. Henderson, 160 P.3d 776 (Kan. 2007).

State v. Hooper, 176 P.3d 911 (Idaho 2007). 
Stolzenberg, S. N., \& Lyon, T. D. (2014). How attorneys question children about the dynamics of sexual abuse and disclosure in criminal trials. Psychology, Public Policy, and Law, 20, 19-30. doi: 10.1037/a0035000

Straus, M. A., Hamby, S. L., Finkelhor, D., Moore, D. W., \& Runyan, D. (1998). Identification of child maltreatment with the Parent-Child Conflict Tactics scales: Development and psychometric data for a national sample of American parents. Child Abuse \& Neglect, 22, 249-270. doi: 10.1016/S0145-2134(97)00174-9

Talwar, V., Arruda, C., \& Yachison, S. (2015). The effects of punishment and appeals for honesty on children's truth-telling behavior. Journal of Experimental Child Psychology, 130, 209-217. doi: 10.1016/j.jecp.2014.09.011

Talwar, V., \& Crossman, A. M. (2012). Children's lies and their detection: Implications for child witness testimony. Developmental Review, 32, 337-359. doi: 10.1016/j.dr.2012.06.004

Talwar, V., Gordon, H. M., \& Lee, K. (2007). Lying in the elementary school years: Verbal deception and its relation to second-order belief understanding. Developmental Psychology, 43, 804-810. doi: 10.1037/0012-1649.43.3.804

Talwar, V., Lee, K., Bala, N., \& Lindsay, R. C. L. (2002). Children's conceptual knowledge of lying and its relation to their actual behaviors: Implications for court competence examinations. Law and Human Behavior, 26, 395-415. doi: 10.1023/A:1016379104959

Talwar, V., Lee, K., Bala, N., \& Lindsay, R. C. L. (2004). Children's lie-telling to conceal a parent's transgression: Legal implications. Law and Human Behavior, 28, 411435. doi: 10.1023/B:LAHU.0000039333.51399.f6

Talwar, V., Yachison, S., \& Leduc, K. (2016). Promoting honesty: The influence of stories on children's lie-telling behaviours and moral understanding. Infant and Child Development, 25, 484-501. doi: 10.1002/icd.1949

Tavakol, M., \& Dennick, R. (2011). Making sense of Cronbach's alpha. International Journal of Medical Education, 2, 53 - 55. doi: 10.5116/ijme.4dfb.8dfd

Tye, M. C., Amato, S. L., Honts, C. R., Devitt, M. K., \& Peters, D. (1999). The willingness of children to lie and the assessment of credibility in an ecologically relevant laboratory setting. Applied Developmental Science, 3, 92-109. doi: 10.1207/s1532480xads0302_4

U.S. Department of Health and Human Services, Administration for Children and Families, Administration on Children, Youth and Families, Children's Bureau. (2017). Child Maltreatment 2015. Retrieved from 
http://www.acf.hhs.gov/programs/cb/research-data-technology/statisticsresearch/child-maltreatment.

Vinski, M. T., \& Watter, S. (2012). Priming honesty reduces subjective bias in self-report measures of mind wandering. Consciousness and Cognition, 21, 451-455. doi: 10.1016/j.concog.2011.11.00 
APPENDIX 
APPENDIX

Debriefing Brochure for Parents

\section{Development, Context, and Communication (DCC) Lab \\ Phone: (305) 348-3057 \\ Email: dcclab@fiu.edu}

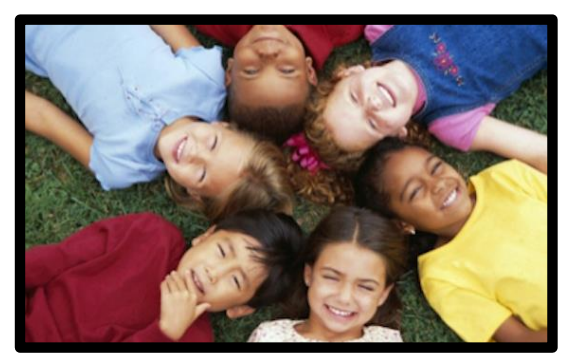

\section{Dear Parent/Legal Guardian,}

Thank you for the support of your child's participation in our study! We sincerely appreciate your interest in our research and hope that both you and your child had a wonderful experience in our lab.

The following are common questions that parents have about children and their lie-telling behavior.

\section{Q: If my child lied today, does it mean anything?}

A: No, if your child lied today, it does not mean that your child always tells lies. The situation in this study was designed to elicit lie-telling behavior, so our research team can study lie-telling and ways to promote honesty.

\section{Q: Why do children tell lies?}

A: Children tell lies for the same reason adults tell lies: to gain something, protect themselves, or protect others and be polite. A child may tell a lie to avoid getting in trouble or to prevent another person's feelings from being hurt. There are different reasons and intentions behind various lies.

Lie-telling is a part of normal development and associated with increasing mental and social skill. During the preschool years, the majority of children will attempt to lie (albeit not always convincingly!). It is around this time that children become aware of a mental world, beyond the physical or real world. They learn that peoples' beliefs and knowledge can be different from their own and from reality. By the end of middle childhood, the frequency of lie-telling drops to the same level as adults. Children learn that in most situations lie-telling is not appropriate behavior and often has the potential to be more harmful than helpful. 


\section{Q: How should I react when my child lies and how do I curb their lie-telling?}

A: There are two things to keep in mind when dealing with lies:

1) What is the child's stage of development?

2) What is the context and motivation for the lie?

Under six years of age, children's lies are often confused with their imagination and fantasy world. Furthermore, children are also learning to experiment and get what they want. For young children, pleasing their parents is very important to them. Thus, they may sometimes tell a fib which they think will satisfy their parents more than the truth would.

Since lying is a part of normal development, parents should not overreact when children lie. However, the behavior should not be ignored either. Rather, it is an opportunity to start discussing honesty and the positive outcomes of telling the truth. Also it is important to stress that lying to avoid punishment for a prior misdeed can lead to "double trouble."

When a child lies, it is important not to put all the emphasis on the lie but also to explore what caused the child to lie. Not all lies are to cover up a transgression. It is important to investigate the context and motivation behind the lie (e.g., a child may lie about what happened at school to avoid talking about being bullied). Talk about ways that the child can avoid being dishonest in different situations. For instance, a child may be given a toy that they do not like. Give them suggestions on how they can thank the person for the toy without lying.

With age, children become more effective lie-tellers. They begin to grasp the subtleties of lying and its consequences. They also start to assess the situations in which lies are told. They develop an understanding that in some circumstances, people tell "white lies" with an intention of being polite or preventing harm. This is a good time to teach them to weigh the consequences of a lie.

As children reach adolescent years, they resemble adults in their lie-telling tendencies. It is important to keep the lines of communication open so that there is mutual trust between parent and child. This way your child will feel more comfortable telling you what has happened (good or bad) and will not fear your reaction. They will understand that your support is unconditional and telling the truth, although it may disappoint at first, is always the best option.

\section{Q: If my child tells lies, is she/he going to become a chronic liar?}

A: Probably not! All children tell lies at some time or another, while very few become chronic liars. Chronic lie-telling is usually a difficulty in adolescence and is often symptomatic of other social-emotional or behavioral problems. It may be that the child is

trying to get attention or is trying to cope with an adverse school/home environment. If 
there appears to be a problem, you may wish to seek (or continue receiving) professional advice.

Thank you once again for your participation!

If there are any further questions, please feel free to contact us at (305) $348-3057$. 
VITA

\section{ALLISON P. MUGNO}

Spring 2004

Spring 2012

Spring 2015

Spring 2015

Spring 2016

\author{
B.A., Psychology \\ Wake Forest University \\ Winston, Salem, NC
}

National Science Foundation Graduate Research Fellowship Honorable Mention

M.S., Psychology

Florida International University

Miami, FL

College of Arts and Sciences' Best Master's Thesis in Psychology Florida International University

Miami, FL

National Science Foundation Doctoral Dissertation Improvement Grant Award

\section{PUBLICATIONS AND PRESENTATIONS}

Malloy, L. C., Mugno, A. P., Waschbusch, D. A., Pelham, W. E., \& Talwar, V. (under revision). Parents' attitudes about and socialization of honesty and dishonesty in typically-developing children and children with disruptive behavior disorders. Journal of Abnormal Child Psychology.

Malloy, L. C., Mugno, A. P., \& Arndorfer, A. (in press). Interviewing children with Autistic Spectrum Disorder: The NICHD Protocol and Ten Step Investigative Interview. In G. S. Goodman, J. L. Johnson, \& P. C. Mundy (Eds.), Wiley handbook of autobiographical memory, Autism Spectrum Disorder, and the law. West Sussex: John Wiley \& Sons.

Mugno, A. P., Malloy, L. C., \& La Rooy, D. J. (in press). Interviewing witnesses. In G. Davies \& A. Beech (Eds.), Forensic psychology: Crime, justice, law, interventions, third edition. West Sussex: John Wiley \& Sons.

Mugno, A. P., Malloy, L. C., Waschbusch, D. A., Pelham, W. E., \& Talwar, V. (in press). An experimental investigation of antisocial lie-telling among children with disruptive behavior disorders and typically-developing children. Child Development. 
Olaguez, A. P., Klemfuss, J. Z., \& Mugno, A. P. (March, 2017). Jury-eligible adults' opinions on children's abilities as witnesses and reasons behind their verdict decision. Paper presented at the annual meeting for the American Psychology-Law Society, Seattle, WA.

Malloy, L. C., \& Mugno, A. P. (2016). Children's recantation of adult wrongdoing: An experimental investigation. Journal of Experimental Child Psychology, 145, 11-21.

Malloy, L. C., Mugno, A. P., Rivard, J. R., Lyon, T. D., \& Quas, J. A. (2016). Familial influences on recantation in substantiated child sexual abuse cases. Child Maltreatment, $21,256-261$.

Mugno, A. P., Klemfuss, J. Z., \& Lyon, T. D. (2016). Attorney questions predict juryeligible adult assessments of attorneys, child witnesses, and defendant guilt. Behavioral Sciences \& the Law, 34, 178-199.

Mugno, A. P., Klemfuss, J. Z., \& Lyon, T. D. (2016, March). Attorney questions predict credibility assessments of attorneys and child witnesses. Paper presented at the annual meeting for the American Psychology-Law Society, Atlanta, GA.

Mugno, A. P., \& Malloy, L. C. (2016, March). Caregiver supportiveness and children's willingness to disclose wrongdoing: An experimental study. Paper presented at the annual meeting for the American Psychology-Law Society, Atlanta, GA.

Perez, C., Mugno, A. P., Alvarez, F., \& Malloy, L. C. (2016, March). The effects of age and maternal supportiveness on children's (non)-disclosure strategies. Paper presented at the annual meeting for the American Psychology-Law Society, Atlanta, GA.

Malloy, L. C., \& Mugno, A. P. (2015, August). Maternal supportiveness and children's recantation of adult wrongdoing. Paper presented at the American Psychological Association Annual Convention, Toronto, Canada.

Malloy, L. C., \& Mugno, A. P., Pelham, W., Hawk, L., \& Lamb, M. (2015, June). Memory and suggestibility among children with attention deficit hyperactivity disorder. Paper presented at the International Congress on Children and the Law, Porto, Portugal.

Mugno, A. P., Malloy, L. C., Talwar, V., \& Waschbusch, D. (2015, March). Lying for concealment or gain: Antisocial lie-telling among children with disruptive behavior disorders. Paper presented at the biennial meeting for the Society for Research in Child Development, Philadelphia, PA.

Rivard, J., Mugno, A. P., Malloy, L. C., Lyon T., \& Quas, J. (2015, March). In the field: Predictors of children's recantation in substantiated child sexual abuse cases. Paper presented at the annual meeting for the American Psychology-Law Society, San Francisco, CA. 